\title{
Beliefs, learning, and personality in the indefinitely repeated prisoner's dilemma
}

CAGE working paper no. 489

July 2020

David Gill

Yaroslav Rosokha 


\title{
Beliefs, learning, and personality in the indefinitely repeated prisoner's dilemma *
}

\author{
David Gill ${ }^{\dagger}$ \\ Yaroslav Rosokha $\ddagger$
}

This version: July 15, 2020

\begin{abstract}
The indefinitely repeated prisoner's dilemma (IRPD) captures the trade-off between the short-term payoff from exploiting economic partners and the long-term gain from building successful relationships. We aim to understand more about how people form and use beliefs about others in the IRPD. To do so, we elicit beliefs about the supergame strategies chosen by others. We find that initial beliefs match behavior quite well and that most subjects choose strategies that perform well given their beliefs. Motivated by belief clustering, we use beliefs to estimate a level- $k$ model of boundedly rational thinking. We analyze how beliefs and behavior evolve with experience: beliefs become more accurate over time, and we use beliefs to provide new evidence about the mechanism that underlies learning from experience. Finally, we find that a survey measure of trust predicts cooperative behavior and optimism about others' cooperation, which helps to explain how trust underpins successful economic exchanges.
\end{abstract}

Keywords: Indefinitely repeated prisoner's dilemma; infinitely repeated prisoner's dilemma; cooperation; optimism; beliefs; belief elicitation; supergame strategies; level-k; bounded rationality; clustering; learning; best response; experimentation; strategy revision; personality; agreeableness; anxiety; cautiousness; kindness; manipulativeness; trust; factor analysis; Raven test; Quadratic Scoring Rule; game theory; experiment.

JEL Classification: $C 72 ; C 73 ; C 91 ; D 91$

${ }^{*}$ We are grateful for helpful comments from seminar participants and in private conversations. We thank: the Blake Family Fund for Ethics, Leadership and Governance (administered by the Krannert School of Management) for funding; the Vernon Smith Experimental Economics Laboratory for hosting our experiment; and Benjamin Raymond, Peter Wagner, Lu Wang, Chen Wei and Junya Zhou for excellent research assistance.

${ }^{\dagger}$ Purdue University, Department of Economics; dgill.econ@gmail.com

${ }^{\ddagger}$ Purdue University, Department of Economics; yrosokha@purdue.edu 


\section{Introduction}

Repeated interactions that persist for an uncertain length of time underpin many economic transactions and relationships. ${ }^{1}$ In such environments, the indefinitely repeated prisoner's dilemma captures well the trade-off between the short-term payoff from exploiting economic partners and the long-term gain from building successful enduring relationships. Recent experimental work has advanced our understanding of behavior in the indefinitely repeated prisoner's dilemma (e.g., Dal Bó, 2005, Blonski et al., 2011, Dal Bó and Fréchette, 2011, Fudenberg et al., 2012, Bigoni et al., 2015, Aoyagi et al., 2019, Proto et al., 2019). However, we know little about how people form and use beliefs about others when they play indefinitely repeated prisoner's dilemma games.

In this paper we want to understand the role of beliefs in the indefinitely repeated prisoner's dilemma (following the literature, we call one indefinitely repeated prisoner's dilemma game a 'supergame'). In particular, we aim to: (i) elicit initial supergame strategies and initial beliefs about the supergame strategies chosen by others; (ii) analyze how beliefs and behavior change with experience; and (iii) understand whether personality predicts behavior and beliefs. To achieve these aims, we build on recent work that: (i) directly elicits supergame strategies in the indefinitely repeated prisoner's dilemma after some experience of playing the game (Romero and Rosokha, 2018; Cason and Mui, 2019; Dal Bó and Fréchette, 2019); ${ }^{2}$ and (ii) studies the role of personal traits in the indefinitely repeated prisoner's dilemma without eliciting strategies or beliefs about strategies (e.g., Dreber et al., 2014, Proto et al., 2019, 2020).

Our 394 subjects played 25 supergames with random rematching and between-subject treatment variation in the the return to joint cooperation (cooperation is an equilibrium in all treatments). Since we wanted to elicit both supergame strategies and beliefs about the supergame strategies chosen by others, we restricted attention to ten strategies (see Table 1 in Section 2.4). In each supergame the subject's chosen strategy and that of her opponent were played out roundby-round on the subject's screen. We elicited beliefs twice, in the first supergame and again in the final (25th) supergame. Building on Costa-Gomes and Weizsäcker (2008), we elicited incentivized beliefs about the distribution of the ten supergame strategies using the Quadratic Scoring Rule (QSR). ${ }^{3}$ Web Appendix I provides screenshots from the experiment.

In order to elicit initial strategies and beliefs, we did not allow subjects to interact in any way with each other before eliciting strategies and beliefs in the first supergame. Nonetheless, we wanted subjects to understand the structure of the game and the nature of repeated game strategies before eliciting initial strategies and beliefs. To achieve this, we designed two forms of training. First, subjects played 'practice' supergames against themselves using the directresponse method. Second, subjects tested pairs of supergame strategies against each other in training supergames that were played out round-by-round on the subject's screen.

\footnotetext{
${ }^{1}$ For example: (i) firms compete in an industry until their products becomes obsolete; (ii) a labor union bargains with a firm for so long as the firm continues to exist; and (iii) countries sign free trade agreements that last until a protectionist government is elected.

${ }^{2}$ In their setting, Dal Bó and Fréchette (2019) find no evidence that eliciting supergame strategies systematically changes behavior.

${ }^{3}$ Costa-Gomes and Weizsäcker (2008) find that when using the QSR to elicit beliefs about a distribution over strategies, the belief elicitation has a mostly insignificant effect on behavior. Nonetheless, to avoid contamination of behavior, we elicited beliefs after subjects had chosen their strategy.
} 
We also selected short directed measures of personality that we judged most likely to help explain behavior and beliefs in the indefinitely repeated prisoner's dilemma. At the beginning of the experiment we used short surveys to measure: anxiety; cautiousness; forgiveness; kindness; manipulativeness; and trust (we also measured cognitive ability and basic demographics).

In Section 3 we analyze initial beliefs and behavior in the first supergame. We find that average beliefs in the first supergame match the distribution of chosen strategies quite well, although initial beliefs respond less strongly to the return to joint cooperation than does behavior. Furthermore, most subjects choose strategies that perform well given their beliefs. We also find that expected earnings increase with the accuracy of beliefs and with the ability of subjects to choose strategies that perform well given beliefs. To better understand initial beliefs, we group subjects into clusters according to the similarity of their beliefs: subjects in the largest cluster hold initial beliefs that are close to uniform over the ten supergame strategies; and a number of other belief clusters gravitate toward simple memory-0 strategies. The belief clustering analysis motivates allocating subjects to behavioral types using their elicited strategies and beliefs; as a proof-of-concept, we develop a model of level- $k$ boundedly rational thinking in our setting, which allows us to estimate the proportion of level- 1 and level-2 types in the first supergame. ${ }^{4}$

In Section 4 we analyze how beliefs and behavior evolve in response to experience (of opponent cooperation and realized supergame length), and we use beliefs to provide new evidence about the mechanism that underlies learning from experience. The previous literature focuses on behavior in the first round of each supergame (Dal Bó and Fréchette, 2011, 2018), and we replicate these findings in our dataset. We then go beyond this analysis of first-round behavior in three ways. First, because we elicited strategies in consecutive supergames, we are able to show that experience affects cooperation at the level of the whole supergame strategy; and we also study the factors that predict experimentation and use transitions between strategies to help understand how experience changes cooperation. Second, because we elicited beliefs in the first supergame, we can show that cooperation depends on both experience and initial beliefs; thus we find that beliefs elicited in the first supergame predict cooperation throughout the experiment. Third, because we also elicited beliefs in the final supergame, we can show that beliefs themselves respond to experience and that beliefs in the final supergame predict cooperation at the end of the experiment. We also find that beliefs become more accurate over time as subjects gain experience.

In Section 5 we find that subjects who reveal themselves to be more trusting in our personality survey cooperate more on average. When we elicit beliefs in the final supergame, we also find that trust predicts optimism about others' cooperation, which suggests that beliefs mediate the relationship between trust and cooperation. Interestingly, we find no evidence that trust predicts behavior or beliefs in the first supergame. To understand how trusting subjects learn to cooperate, we study how trust interacts with experience. We find that subjects high in trust respond more strongly when they experience cooperative behavior; by contrast, subjects low in trust respond more strongly when they experience uncooperative behavior. The tendency of high trust subjects to amplify good news and discount bad news drives their cooperation up.

\footnotetext{
${ }^{4}$ See Nagel (1995) and Stahl and Wilson (1995) for early applications of the level- $k$ model, and see Gill and Prowse (2016) for a recent application in a repeated $p$-beauty contest.
} 
The main contribution of our paper is to elicit beliefs over supergame strategies in the indefinitely repeated prisoner's dilemma. To the best of our knowledge, we are the first to elicit such beliefs. Davis et al. (2016) elicit round-by-round beliefs about the opponent's behavior in the indefinitely repeated prisoner's dilemma; like us, they find that beliefs correlate with behavior. ${ }^{5,6}$ We complement the literature that measures beliefs in the one-shot or finitely repeated prisoner's dilemma, which consistently finds that beliefs correlate with cooperation. ${ }^{7,8}$ We also extend the level- $k$ literature by showing how elicited beliefs over supergame strategies can be used to identify level- $k$ types in the repeated prisoner's dilemma; our methodology can easily be extended to other repeated games. ${ }^{9}$

In contemporaneous work, Aoyagi et al. (2020) elicit round-by-round beliefs in definitely and indefinitely repeated prisoner's dilemmas, and develop a novel identification strategy to estimate beliefs over supergame strategies from the round-by-round beliefs. ${ }^{10}$ Aoyagi et al. (2020)'s focus is different to ours: because they estimate beliefs using data from later supergames, they do not study initial beliefs over supergame strategies or the evolution of these beliefs in response to experience. Aoyagi et al. (2020) find that estimated beliefs over supergame strategies depend on whether the game is finitely or indefinitely repeated, that different behavioral types hold different beliefs, and that most subjects choose strategies that perform well given their beliefs. ${ }^{11}$

\footnotetext{
${ }^{5}$ Davis et al. (2016)'s main focus is on the relationship between personal characteristics and behavior, and so their analysis of beliefs appears only in the appendix (where they also find little correlation between beliefs and personal characteristics).

${ }^{6} \mathrm{Li}$ and $\mathrm{Liu}$ (2017) find a weak relationship between group identity and beliefs in the first round of their first indefinitely repeated prisoner's dilemma game. Dreber et al. (2014) find that cooperation in indefinitely repeated prisoner's dilemma games with mistakes in implementation is correlated with beliefs (measured after the games) about the likelihood that defections were due to mistakes. When subjects play a sequence of indefinitely repeated prisoner's dilemma games where they are randomly rematched after every round within a supergame: (i) Duffy and Ochs (2009) find that cooperation is low and can be predicted well using threshold strategies elicited in an earlier one-shot prisoner's dilemma together with subjects' round-by-round forecasts of how many others in the matching group of fourteen will cooperate in that round; and (ii) Duffy and Fehr (2018) elicit beliefs about how many others in the matching group of ten will cooperate in the first round of each supergame, finding that beliefs and behavior are correlated and that beliefs respond to experience in an earlier stag hunt game.

${ }^{7}$ In one-shot prisoner's dilemmas, see: Messé and Sivacek (1979); Croson (2000); Miettinen and Suetens (2008); Charness et al. (2016); Engel and Zhurakhovska (2016); Ridinger and McBride (2017); Peeters and Vorsatz (2018); Heuer and Orland (2019); and Sutter and Untertrifaller (2020). Croson (2000) also finds that eliciting beliefs lowers cooperation (but see footnote 11 below), while Charness et al. (2016) also find that beliefs change with the payoff from joint cooperation. In Miettinen and Suetens (2008), beliefs are more cooperative when both players send a message expressing a desire for mutual cooperation.

${ }^{8}$ In finitely repeated prisoner's dilemmas: (i) Zhang et al. (2019) elicit round-by-round beliefs, finding that beliefs and behavior correlate within rounds, and that beliefs in one round vary with behavior in the previous round; and (ii) Kagel and McGee (2016) find that over time teams form beliefs that the opposing team will defect toward the end of each supergame (where these beliefs are inferred from team chat).

${ }^{9}$ To the best of our knowledge, no existing paper has used beliefs together with behavior to estimate the proportion of level- $k$ types in the prisoner's dilemma (whether one-shot or repeated). Polonio et al. (2015), Stewart et al. (2016) and Castagnetti and Proto (2020) use data on behavior from the prisoner's dilemma to estimate level- $k$ or cognitive hierarchy models.

${ }^{10}$ Aoyagi et al. (2020) estimate beliefs under the identifying assumption that subjects correctly Bayes update from observed within-supergame histories. Because their approach is data intensive, they estimate beliefs at the level of behavioral types rather than at the individual level.

${ }^{11}$ Aoyagi et al. (2020) also study the round-by-round beliefs themselves in later supergames, finding that average beliefs track cooperation rates closely, that beliefs correlate with within-supergame experience, and that beliefs correlate with behavior. Unlike Croson (2000) in the one-shot prisoner's dilemma, they find no indication of important changes in behavior caused by the belief elicitation.
} 
Turning now to personality, to the best of our knowledge we are the first to study the relationship between a survey measure of trust and behavior or beliefs in the indefinitely repeated prisoner's dilemma; the positive effect of trust on cooperation that we find is broadly consistent with evidence from related one-shot or finitely repeated games. ${ }^{12,13}$ Nor are we aware of any previous studies that consider how trust interacts with experience in the prisoner's dilemma. ${ }^{14}$ Outside of the lab, trust matters for economic outcomes: for example, Algan and Cahuc (2010) find that trust fosters growth; Lopez-de Silanes et al. (1997) find that trust promotes performance in large organizations; and Aghion et al. (2010) find that trust lowers the demand for government regulation. Our finding that, in indefinitely repeated interactions, trust predicts cooperative behavior and beliefs about how much others cooperate provides one mechanism for the broader role of trust in underpinning successful economic exchanges. In the lab, Proto et al. (2019) find a transitory effect of agreeableness on cooperation in the indefinitely repeated prisoner's dilemma (they also find that the cautiousness facet of conscientiousness lowers cooperation, but only when subjects are matched by their level of conscientiousness). ${ }^{15}$ Since trust is one facet of agreeableness, any effects of agreeableness on cooperation might partly be driven by trust.

Finally, Dal Bó and Fréchette (2018) survey the broader literature on the relationship between personal characteristics and cooperation in the indefinitely repeated prisoner's dilemma: noting that the current evidence is sparse, they conclude that there is as yet no robust evidence of a link between personal characteristics and cooperation when cooperation is an equilibrium, ${ }^{16}$ arguing instead that the main motivation behind cooperation is strategic. The role of trust that we uncover is consistent with a predominantly strategic rather than preference-based motivation for cooperation, since our evidence suggests that trusting subjects learn to cooperate, with the effect of trust on behavior mediated by beliefs.

The paper proceeds as follows: Section 2 describes the experimental design; Section 3 analyzes initial beliefs and behavior in the first supergame; Section 4 studies the evolution of beliefs and behavior over the course of the 25 supergames; Section 5 considers the relationship between personality and behavior and beliefs; Section 6 concludes; and the Web Appendix provides further details.

\footnotetext{
${ }^{12}$ In one-shot or finitely repeated prisoner's dilemmas, Haesevoets et al. (2018) find that a survey measure of trust predicts cooperation, Emonds et al. (2014) find that a survey measure of trust predicts cooperation among prosocial subjects, while Acedo-Carmona and Gomila (2014) find that subjects cooperate more when they are matched with people they know and trust personally, although Ahn et al. (2003) find no effect of a survey measure of trust. Papers that correlate survey measures of trust with contributions in one-shot or finitely repeated linear public goods games mostly find a positive effect of trust (Sato, 1988, 1989; Anderson et al., 2004; Gächter et al., 2004; Thöni et al., 2012; Peysakhovich et al., 2014), while Mulder et al. (2006) find that experiencing a treatment with sanctions undermines contributions of high trust subjects. Finally, in a real-effort game, Proto and Rustichini (2014) find that trust predicts whether subjects choose effort consistent with believing that others are cooperative.

${ }^{13} \mathrm{~A}$ few papers correlate behavior in trust games with that in the prisoner's dilemma, finding mixed results (Chaudhuri et al., 2002; Capraro et al., 2014; Haesevoets et al., 2015; Davis et al., 2016).

${ }^{14}$ In a prisoner's dilemma game involving deception (subjects were told that they were playing against another subject in the room, but in fact were playing against the experimenter), and in which subjects were given no information about the number of times the game would be repeated, Parks et al. (1996) find that when subjects received a message from the experimenter stating that they planned to cooperate (defect), high (low) trust subjects responded by increasing (decreasing) cooperation. Parks et al. (1996) also find that the response to messages depends on the consistency of the message and behavior.

${ }^{15}$ Proto et al. (2020) also find some effect of agreeableness on cooperation in the indefinitely repeated prisoner's dilemma. Kagel and McGee (2014) find that agreeableness predicts cooperation in the finitely repeated prisoner's dilemma.

${ }^{16}$ For example, Dreber et al. (2014) find that altruism measured in the dictator game correlates with cooperation, but only when cooperation is not an equilibrium.
} 


\section{Experimental design}

\section{$2.1 \quad$ Procedures}

We ran our experimental sessions at Purdue University's Vernon Smith Experimental Economics Laboratory (VSEEL) between mid-November 2018 and early February 2019. The study was reviewed by Purdue's Institutional Review Board, and all participants gave informed consent after reading the participant information sheet.

In total, 394 subjects participated, earning $\$ 23.57$ on average including a show-up fee of $\$ 5.00$ (the rate of exchange was $\$ 1.00$ for every two hundred experimental 'points'). Subjects were drawn randomly from the VSEEL student subject pool and invited to participate. ${ }^{17} \mathrm{We}$ excluded subjects who had participated in the related repeated prisoner's dilemma experiments reported in Romero and Rosokha (2018, 2019a,b) and Cason and Mui (2019).

The experiment was between subject, with three treatments that varied only in the structure of the stage-game payoff matrix. We ran 27 sessions, with nine sessions for each of the three treatments. ${ }^{18}$ Sessions lasted just under one hour and included 12, 14, or 16 subjects, with 14.6 subjects on average. ${ }^{19}$ The experiment was programmed in oTree (Chen et al., 2016). Web Appendix I provides screenshots from the experiment.

\subsection{Overview}

The experiment proceeded as follows:

1. Measurement of personal characteristics. We measured each subject's personality and cognitive ability. We included the following personality measures: anxiety; cautiousness; forgiveness; kindness; manipulativeness; and trust. We measured cognitive ability using a test of matrix reasoning.

2. Training. Subjects played ten 'practice' indefinitely repeated prisoner's dilemma games ('supergames') against themselves using the direct-response method. Subjects then spent three minutes reading the description of the ten available supergame strategies. Finally, subjects spent five minutes testing pairs of supergame strategies against each other in training supergames.

3. Supergames with strategy elicitation. Subjects played 25 supergames with random rematching. At the beginning of each supergame, each subject chose one of the ten available strategies to play the supergame, and then the subject's chosen strategy and that of her opponent were played out round-by-round on the subject's screen.

4. Belief elicitation. We elicited beliefs twice, in the first supergame and the final (25th) supergame. We elicited beliefs about the distribution of the ten strategies using the Quadratic Scoring Rule (QSR). To prevent any contamination of initial supergame strategies, we elicited beliefs in the first supergame immediately after subjects had chosen their strategy for the first supergame.

5. Demographic questionnaire. Subjects completed a short demographic questionnaire at the end of the experiment.

\footnotetext{
${ }^{17}$ The VSEEL subject pool is administered using ORSEE (Greiner, 2015).

${ }^{18}$ We ran three sessions (one for each treatment) on each of nine separate days. Session start times were constant across days, and we balanced start times across treatments. On the ninth day, one session did not fill up, and so we ran that session exactly one week later.

${ }^{19}$ Dal Bó and Fréchette (2011)'s sessions included 14.8 subjects on average.
} 


\subsection{Supergame design}

We call an indefinitely repeated prisoner's dilemma game a 'supergame'. Following Dal Bó and Fréchette (2011), our between-subject design used the stage-game payoff matrix in Figure 1 with $R \in\{32,40,48\}$ and a continuation probability $\delta=0.75$. This payoff matrix determines the two players' payoffs in each round of a supergame. After each round, the supergame ends with probability $1-\delta=0.25$.

Each value of $R \in\{32,40,48\}$ corresponds to one of our three between-subject treatments. Dal Bó and Fréchette (2011) found substantial variation in cooperation rates across these values of $R$ with $\delta=0.75$, even though subgame-perfect Nash equilibria with full cooperation exist in all three cases. ${ }^{20}$

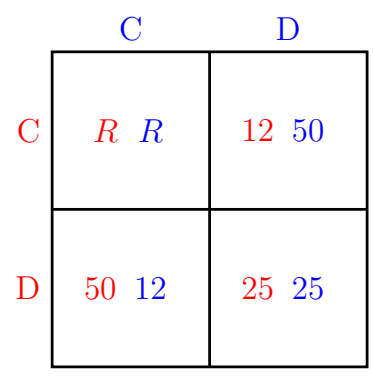

Figure 1: Payoff matrix in each round of a supergame

Notes: In the experiment, we used neutral labels 'A' and 'B' to represent 'C' (cooperate) and 'D' (defect).

\subsection{Choice of ten supergame strategies}

Our aim was to elicit initial supergame strategies and initial beliefs about the supergame strategies chosen by others, and to study how these choices and beliefs change with experience. ${ }^{21}$ Since we wanted to elicit both strategies and beliefs, we restricted attention to the ten supergame strategies in Table $1 .^{22}$

Our strategy definitions follow Fudenberg et al. (2012), except for the two strategies among our ten that they do not include, namely DG and RAND. ${ }^{23}$ Figure A.5 in Web Appendix I shows the wording of our ten strategies. The order that the ten strategies appeared on the subject's screen was randomized across subjects, and remained constant throughout the session. ${ }^{24}$

\footnotetext{
${ }^{20}$ Dal Bó and Fréchette (2011) also included treatments with $\delta=0.5$.

${ }^{21}$ We study both initial behavior and learning. Many experimental game-theoretic studies consider only initial behavior by suppressing feedback (e.g., Costa-Gomes et al., 2001).

${ }^{22}$ In indefinitely repeated prisoner's dilemma games, Romero and Rosokha (2018, 2019a), Cason and Mui (2019) and Dal Bó and Fréchette (2019) elicit supergame strategies from a larger strategy space, while Bruttel and Kamecke (2012) ask subjects to choose a memory-1 rule after three rounds of the supergame.

${ }^{23}$ For simplicity, players do not respond to their own defections under our definitions of G and G2. In our setting without mistakes in implementation, our definitions of G and G2 are behaviorally equivalent to those in Fudenberg et al. (2012): under both definitions of G, a player never deviates until her opponent has done so; and under both definitions of G2, a player never deviates until her opponent has deviated twice in a row. We use the simpler definitions because: (i) they are easier to understand; and (ii) to avoid subject confusion about why a strategy specifies a response to a player's own unilateral deviation(s) that can never occur under that strategy. Similarly, Dal Bó and Fréchette (2019, p.3935) use the term 'Grim' to denote a memory-1 strategy that, in the absence of mistakes in implementation, is behaviorally equivalent to Grim as defined in Fudenberg et al. (2012).

${ }^{24}$ We randomly created sixteen orders, one for each of the sixteen possible subjects in a session, such that every strategy appeared first in the order for at least one of the first twelve subjects (recall the minimum session size was twelve), and no strategy appeared first in the order for more than two subjects.
} 


\begin{tabular}{ll}
\hline Strategy & Description \\
\hline AD & Always Defect \\
DG & Defect in first round, and then play Grim (ignoring own first-round defection) \\
DTFT & Defect in first round, and then play Tit-for-Tat \\
RAND & In every round, choose C with probability 0.5 and D with probability 0.5 \\
G & Grim \\
2TFT & 2-Tits-for-1-Tat \\
TFT & Tit-for-Tat \\
G2 & Lenient Grim 2 \\
TF2T & Tit-for-2-Tats \\
AC & Always Cooperate \\
\hline
\end{tabular}

Table 1: Description of our ten supergame strategies

We selected strategies from the twenty considered by Fudenberg et al. (2012, Table 2) based on the results of the Strategy Frequency Elicitation Method (SFEM; see Dal Bó and Fréchette, 2011) applied to the data collected together by Dal Bó and Fréchette (2018) from 1,734 subjects playing indefinitely repeated prisoner's dilemma games, and then selecting the eight most popular strategies. ${ }^{25}$ These eight strategies include the five 'key' strategies identified by Dal Bó and Fréchette (2018, Table 10). ${ }^{26}$

We added DG and RAND to the eight strategies from Fudenberg et al. (2012) selected by our SFEM exercise, giving the ten strategies in Table 1. DG is the the natural extension of G corresponding to DTFT as the extension of TFT. ${ }^{27}$ RAND corresponds to 'RANDOM-50' in Dal Bó and Fréchette (2019). ${ }^{28}$ We included RAND as an option for subjects who had difficulty choosing among the other strategies (RAND is the equivalent of level-0 behavior in stage-game strategies). RAND also ensures that, despite the limited number of available strategies, subjects never perfectly learn their current opponent's deterministic strategy, ${ }^{29}$ which increases external validity of the learning process about the population across supergames. Finally, RAND creates more behavioral separation between G-type strategies (DG, G, G2) and TFT-type strategies (DTFT, 2TFT, TFT, TF2T) since random defection(s) under RAND induce persistent punishment in the first case but not the second.

\subsection{Strategy categories}

We find it useful to categorize our ten supergame strategies, as illustrated in Figure 2.

Along the horizontal axis, we categorize strategies according to when they first defect. The three 'unfriendly' strategies (AD, DG, DTFT) defect in the very first round. The three 'provocable' strategies (G, 2TFT, TFT) start by cooperating but defect immediately in response to the opponent's first defection. The three 'lenient' strategies (G2, TF2T, AC) start by cooperating

\footnotetext{
${ }^{25}$ The data include 32 combinations of paper and parameter values with $\delta>0$. The most popular strategies were determined by running SFEM for each combination and taking the average.

${ }^{26}$ Fudenberg et al. (2012) call DTFT 'Exploitative Tit-for-Tat', while Dal Bó and Fréchette (2018, 2019) call it 'Suspicious Tit-for-Tat'; we use the neutral term 'DTFT' to avoid implying a motive for choosing this strategy.

${ }^{27}$ Our strategy DG is not equivalent to Fudenberg et al. (2012, fn.25)'s D-Grim, which responds to a player's own first-round defection and so is behaviorally equivalent to $\mathrm{AD}$ in our setting without mistakes in implementation.

${ }^{28}$ The round-by-round randomization for RAND was implemented in real time as play progressed.

${ }^{29}$ The reason is that RAND replicates every deterministic strategy with positive probability.
} 
and do not defect immediately in response to the opponent's first defection. ${ }^{30}$

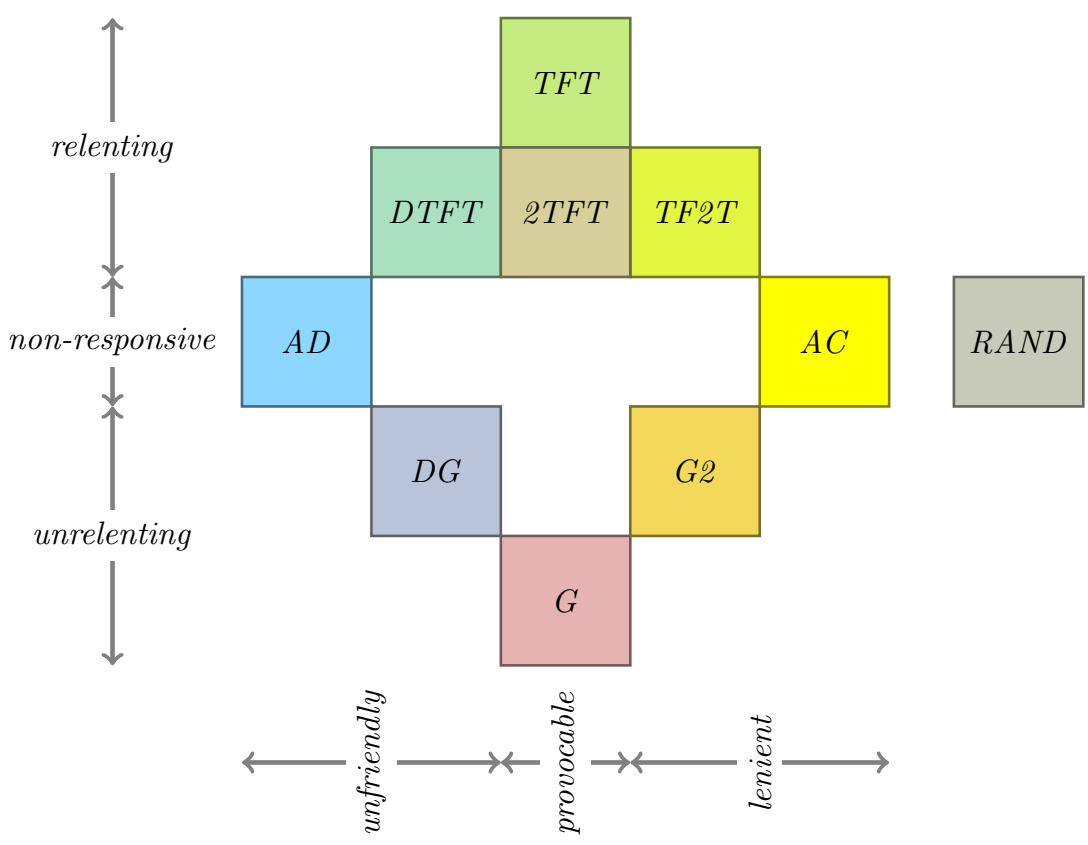

Figure 2: Strategy categories

Along the vertical axis, we categorize strategies according to whether they punish a rival's defection forever or whether, after punishing a rival's defection, they eventually relent and cooperate if the opponent cooperates. The three 'unrelenting' strategies are the G-type strategies (DG, G, G2). The four 'relenting' strategies are the TFT-type strategies (DTFT, 2TFT, TFT, $\mathrm{TF} 2 \mathrm{~T}){ }^{31}$ The three 'non-responsive' strategies (AD, RAND, AC) never respond to a rival's defection.

\subsection{Training}

As noted in Section 2.4, one of our main aims was to elicit initial supergame strategies and initial beliefs about the supergame strategies chosen by others. Thus, we did not allow subjects to interact in any way with each other before eliciting strategies and beliefs in the first supergame.

Nonetheless, we wanted subjects to understand the structure of the game and the nature of repeated game strategies before eliciting initial strategies and beliefs. To achieve this, we designed two forms of training (without incentives). First, subjects played ten 'practice' supergames against themselves using the direct-response method: in each round of each 'practice match', the subject chose an action for herself and an action for the 'other'; and at the end of each round the subject pressed a button to roll a computerized four-sided die that determined whether the supergame ended. Figures A.3 and A.4 in Web Appendix I show screenshots.

\footnotetext{
${ }^{30}$ Fudenberg et al. (2012) categorize strategies as lenient in the same way that we do here. According to Fudenberg et al. (2012)'s terminology, our unfriendly strategies are 'fully noncooperative', while our 'provocable' strategies are 'fully cooperative' but not lenient.

${ }^{31}$ We use the term 'relenting' rather than 'forgiving' because Axelrod (1980)'s concept of forgiving in the prisoner's dilemma includes both relenting after a punishment and being lenient by not immediately punishing a defection.
} 
Once subjects had become familiar with the structure of the game from this direct-response training, we introduced subjects to the ten available supergame strategies. In particular, subjects spent three minutes reading the descriptions of the ten strategies, and then spent five minutes testing pairs of strategies against each other in training supergames that were played out round-by-round on the subject's screen (each round lasted a short amount of time, to mimic the feedback from direct-response play). On average subjects tested 16.2 pairs of strategies (including repeat tests of the same pair). In each 'test match', the subject chose one of the ten 'plans' for herself and one of the ten for the 'other'. Figures A.5 and A.6 in Web Appendix I show screenshots.

\subsection{Supergames with strategy elicitation}

Subjects played 25 supergames, with random rematching between supergames and the same supergame lengths across treatments. ${ }^{32,33}$ At the beginning of each supergame, each subject chose one of the ten available strategies to play the supergame, and then the subject's chosen strategy and that of her opponent were played out round-by-round on the subject's screen. ${ }^{34}$ In order to mimic the feedback from direct-response play, each round lasted two seconds, and at the end of each round the subjects observed the outcome of the four-sided die role that determined whether the supergame ended. The full supergame history (round-by-round choices, payoffs and die rolls) was displayed during the supergame and after the supergame ended (until the subject chose to continue to the screen for the next supergame). Subjects observed the round-by-round choices made by their opponent's strategy, but they did not directly observe the strategy chosen by the opponent. ${ }^{35}$ Figures A.8 and A.11 in Web Appendix I show screenshots.

Standard theoretical analyses of repeated games (and the SFEM procedure for estimating strategies) assume that agents choose a supergame strategy, which specifies actions for the whole supergame. Eliciting such a supergame strategy is an example of the strategy method: Brandts and Charness (2011) survey the experimental evidence on the strategy method more generally. Compared to the direct-response data in Dal Bó and Fréchette (2011), Dal Bó and Fréchette (2019) find no evidence that eliciting supergame strategies systematically changes behavior in their setting (like us, Dal Bó and Fréchette, 2019, included treatments with $\delta=0.75$ and $R=32$ or $R=48$ ).

\footnotetext{
${ }^{32}$ We randomly drew the lengths of the 25 supergames in advance. In particular, we randomly drew nine sequences of 25 supergame lengths; that is, we drew a new sequence for each of the nine sessions of a particular treatment. To keep supergame lengths the same across treatments, we used the same nine sequences for each of the three treatments.

${ }^{33}$ Dal Bó and Fréchette $(2011,2019)$ also use random rematching. Dal Bó and Fréchette (2011, fn.4) provide evidence that random rematching does not induce repeated-game effects across supergames. Turnpike matching protocols (e.g., Gill and Prowse, 2012) preclude such repeated-game effects but constrain the feasible number of supergames.

${ }^{34}$ Previously chosen strategies did not act as defaults: subjects made an active choice of strategy at the beginning of each supergame.

${ }^{35}$ This choice preserves external validity: in real-world strategic interactions, people usually do not directly observe others' strategies.
} 


\subsection{Belief elicitation}

We used the Quadratic Scoring Rule (QSR) to elicit incentivized beliefs about the distribution of strategies in the first supergame and in the final (25th) supergame. The QSR is incentive compatible (Selten, 1998), which means that money-maximizing (risk-neutral) subjects are incentivized to report their true belief.

Figure A.9 in Web Appendix I shows how we described the belief elicitation procedure to the subjects. We endeavored to keep the description concise. The text of the second and third lines is similar to that used by Costa-Gomes and Weizsäcker (2008). Following Costa-Gomes and Weizsäcker (2008): (i) we told subjects that they would make the most money if they reported their true beliefs; but (ii) we also provided a complete description of the QSR. Figure A.10 shows the belief entry screen, which included a reminder of the main points.

Costa-Gomes and Weizsäcker (2008) find that when using the QSR to elicit beliefs about a distribution over three strategies in one-shot games, the belief elicitation has a mostly insignificant effect on behavior. ${ }^{36}$ More broadly, Schotter and Trevino (2014)'s survey concludes that eliciting beliefs either has no effect on behavior or hastens learning, and so is mostly innocuous.

Nonetheless, to prevent any contamination of initial supergame strategies, we elicited beliefs about behavior in the first supergame after subjects had chosen their strategy for the first supergame (but before the first supergame was played out), and subjects did not know that beliefs would be elicited when they chose their strategy. ${ }^{37}$ To minimize contamination of later supergame strategies, we elicited beliefs only twice, in the first supergame and in the final supergame. ${ }^{38}$ Furthermore, we gave the subjects no feedback about the accuracy of their guesses.

Given that we elicit a belief about a distribution over ten strategies, we wanted to keep the belief elicitation procedure as simple as possible. In this respect, the QSR has the advantage that it is deterministic: that is, the subject's payoff depends deterministically on their reported belief and the realized state. Schlag and van der Weele (2013) show theoretically that all deterministic scoring rules impair truth-telling incentives for risk-averse subjects. However, in our setting, we judged that introducing an element of randomization would make the belief elicitation procedure too complicated. ${ }^{39}$ Furthermore, in our setting with ten strategies, the bias toward flattening the reported distribution is unlikely to be important: Harrison et al. (2017) find that for empirically plausible levels of risk aversion, the bias is small unless the set of events over which beliefs are elicited is binary or close to binary. ${ }^{40}$

\footnotetext{
${ }^{36}$ Other papers that use the QSR to elicit beliefs about a distribution over three or more choices include Terracol and Vaksmann (2009), Danz et al. (2012), Hyndman et al. (2012) and Gee and Schreck (2018).

${ }^{37}$ Similarly, we elicited beliefs in the final supergame after subjects had chosen their strategy but before the supergame was played out. Schlag et al. (2015, p.479)'s survey finds no consensus on whether beliefs are influenced by first making a choice.

${ }^{38}$ After eliciting beliefs in the first supergame, subjects were told on a transition screen that they would not be asked a similar question until the end of the experiment.

${ }^{39}$ Furthermore, even if our subjects could understand the mechanics of a belief elicitation procedure with randomization, they might still not understand why the randomization gives the incentive to report truthfully with risk aversion. Schlag et al. (2015, p.482)'s survey discusses the contradictory evidence on whether randomized payments induce risk neutrality even in simple settings.

${ }^{40}$ We do not expect hedging due to risk aversion to be a significant concern in our complex setting. Schlag et al. (2015, p.481)'s survey summarizes evidence that hedging across actions and beliefs is more of a problem in simple environments. For example, Blanco et al. (2010) find hedging in a coordination game with obvious hedging incentives, but find no hedging in a more complicated prisoner's dilemma game. As noted above, Costa-Gomes and Weizsäcker (2008) use the QSR to elicit beliefs about a distribution over three strategies, and they find no evidence of hedging.
} 


\subsection{Measurement of personal characteristics and demographic questionnaire}

\subsubsection{Personality questionnaire}

We measured personality at the beginning of the experiment. In particular, we measured: anxiety; cautiousness; forgiveness; kindness; manipulativeness; and trust. We selected these six personality measures because we judged them most likely to help explain behavior and beliefs in the indefinitely repeated prisoner's dilemma. As part of this exercise, we carefully read through the questions underlying a large number of personality measures. By design, we selected short directed measures of personality rather than longer measures that confound different concepts. For this reason, our three measures that come from the Big Five (John et al., 2008) capture specific facets of the five broader personality measures: anxiety is one of six facets that make up neuroticism; cautiousness (sometimes called 'deliberation') is one of six facets that make up conscientiousness; and trust is one of six facets that make up agreeableness. ${ }^{41}$

We included forgiveness, kindness and trust because we judged that these measures linked well to the strategy categories described in Section 2.5 (unfriendly, provocable, lenient, and relenting/unrelenting); indeed, the questions underlying the forgiveness measure relate to aspects of leniency and of being relenting, and thus this measure captures the spirit of Axelrod (1980)'s concept of 'forgiving' (see footnote 31 above). We included manipulativeness because the underlying questions capture a willingness to exploit others. We included anxiety because we conjectured that anxiety might affect the ability to perform in strategic interactions. ${ }^{42}$ Finally, we included cautiousness because Proto et al. (2019) find a negative association between this facet of conscientiousness and cooperation in an indefinitely repeated prisoner's dilemma.

We gave subjects six minutes to complete the personality questionnaire (the screen showed a countdown clock). ${ }^{43}$ We randomly drew the order of the 52 questions, subject to the constraint that no two consecutive questions could come from the same personality measure (subjects all faced the same order). We told subjects that their answers would not affect the experiment in any way.

\footnotetext{
${ }^{41}$ The anxiety, cautiousness and trust measures include ten questions each and, as described above, are facets of the Big Five; the questions come from the 300-item IPIP-NEO (see Goldberg, 1999, and Johnson, 2014) and are at: https://ipip.ori.org/newNEOFacetsKey.htm. The manipulativeness measure includes six questions and is one of thirty-three scales from the Computerized Adaptive Test of Personality Disorder (CAT-PD); the questions come from the 212-item CAT-PD-SF (see Simms et al., 2011, and Wright and Simms, 2014) and are at: https: //ipip.ori.org/newCAT-PD-SFv1.1Keys.htm. The forgiveness and kindness measures include eight question each and are two of the twenty-four character strengths from the Values in Action Inventory of Strengths (VIA-IS); the questions come from the 192-item VIA-IS-R (see Peterson and Seligman, 2004, and McGrath, 2017) and for research purposes are available on request from the VIA Institute on Character (https://www. viacharacter.org).

${ }^{42}$ Anxiety is an important facet of neuroticism. Gill and Prowse (2016) find a negative association between neuroticism and performance in a repeated $p$-beauty contest game, Al-Ubaydli et al. (2016) find that neuroticism negatively predicts joint cooperation in a finitely repeated prisoner's dilemma, while DeYoung et al. (2010) find that neuroticism correlates with volume in areas of the brain associated with threat and punishment.

${ }^{43}$ We followed the time per-question recommended for the Big Five Inventory (John et al., 2008, p.137). All 52 questions use a five-point Likert scale. For consistency, we presented all questions in the form 'I ...', and we used the introductory wording and response categories recommended by IPIP at: https://ipip.ori.org/New IPIP-50-item-scale.htm. The 52 questions were split into five screens of ten questions and a final screen of two questions. Subjects could change their answers on a particular screen until they submitted their answers for that screen. Subjects were allowed to submit incomplete sets of answers, but were asked to confirm that they wanted to do so. We replaced missing responses by the sample average of nonmissing responses to that particular question.
} 


\subsubsection{Personality factors}

As described in Section 2.9.1, we selected short directed measures of personality from a number of different sources. As a result, some of our measures are highly correlated with each other (e.g., the highest correlation of 0.52 is between trust and forgiveness), although our personality measures are not correlated with cognitive ability (the highest correlation is 0.08). The high degree of correlation between our six measures of personality justifies the construction of a smaller number of uncorrelated factors to identify the effects of personality on behavior and beliefs. We undertake a principal factor analysis using maximum likelihood factoring and Varimax rotation, implemented to give factors that are uncorrelated with each other (see Luo et al., 2019). Before rotation, five factors have eigenvalues above one, and so these are retained in the rotation; retaining factors with eigenvalues above one is a standard criterion for choosing the number of factors due to Kaiser (1960).

The five factors are: anxiety; cautiousness; kindness; manipulativeness; and trust. Each factor loads heavily on one of the underlying personality measures, and so we name each factor after the underlying personality measure on which it loads. ${ }^{44}$ By construction, the factors are uncorrelated with each other, and have zero mean and unit variance.

\subsubsection{Cognitive ability test: Matrix reasoning}

After measuring personality but before subjects played any games, we measured cognitive ability using a matrix reasoning test that measures fluid intelligence. ${ }^{45}$ In particular, we used the elevenquestion matrix reasoning test developed by the International Cognitive Ability Resource Team (ICAR), which is similar to the Raven Progressive Matrices test (Raven et al., 2000). ${ }^{46}$ For each question, subjects have to identify (among six choices) the missing element that completes a visual pattern.

We gave subjects seven minutes to complete the test (the screen showed a countdown clock). We told subjects that their answers would not affect the experiment in any way. Following the convention in the psychometric literature, we did not provide monetary incentives for completing the test, and we did not tell subjects anything about their performance.

\subsubsection{Demographic questionnaire}

At the end of the experiment subjects completed a short demographic questionnaire. We asked subjects whether: (i) they were aged 'under 20' or '20 and over'; (ii) they were 'male' or 'female';

\footnotetext{
${ }^{44}$ The ten highest loading questions underlying the trust factor are the ten questions that measure trust. The nine highest loading questions underlying the anxiety (cautiousness) factor come from the ten questions that measure anxiety (cautiousness). The six highest loading questions underlying the kindness factor come from the eight questions that measure kindness. The four highest loading questions underlying the manipulativeness factor come from the six questions that measure manipulativeness (and the other two questions also appear among the ten highest loading questions); the raw factor loads negatively on manipulativeness, and so to create the manipulativeness factor we changed the sign of all the factor loadings.

${ }^{45}$ Fluid intelligence is "the ability to reason and solve problems involving new information, without relying extensively on an explicit base of declarative knowledge" (Carpenter et al., 1990). Matrix reasoning tests have been used in economics by, e.g., Burks et al. (2009), Charness et al. (2018), Gill and Prowse (2016), Fe et al. (2019) and Proto et al. (2019).

${ }^{46}$ See Condon and Revelle (2014). For research purposes, the questions are available on request from ICAR (https://icar-project.com).
} 
(iii) their major was in 'Economics or Management', 'STEM (Science, Technology, Engineering, Math)', 'Liberal Arts' or 'other'; (iv) they went to high school 'in US' or 'outside of US'. In each case, the subject could report 'prefer not to say'. Four subjects did not complete the questionnaire (answering 'prefer not to say' to one or more questions), and so we exclude those subjects from regressions that control for demographic characteristics. Those regressions also use a binary major categorization ('STEM' or 'not STEM').

\section{Initial beliefs and behavior}

\subsection{Strategy choices, average beliefs, optimism and cooperation}

We start by presenting raw data that describe the initial supergame strategies chosen by our subjects and their initial beliefs about the supergame strategies chosen by others. Figures 3(a) to 3(c) show the distribution of strategies chosen in Supergame 1 for each treatment. When the return to joint cooperation is low (i.e., $R=32$ ), unfriendly strategies are popular. As the return to joint cooperation increases (i.e., as $R$ increases from 32 to 48 ), the proportion of unfriendly strategies falls substantially, while provocable and lenient strategies become more popular. In Supergame 1, our subjects choose unfriendly strategies at broadly similar rates to Dal Bó and Fréchette (2019)'s subjects in their menu elicitation treatment when, as here, $\delta=0.75 .{ }^{47}$

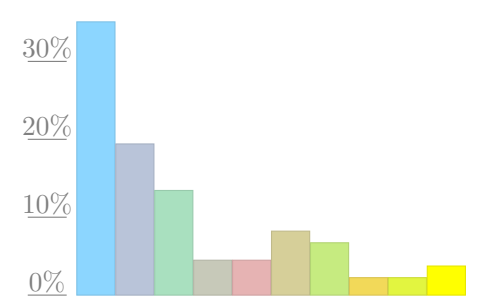

(a) Strategies: $R=32$

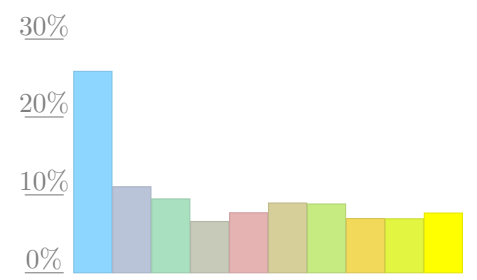

(d) Beliefs: $R=32$

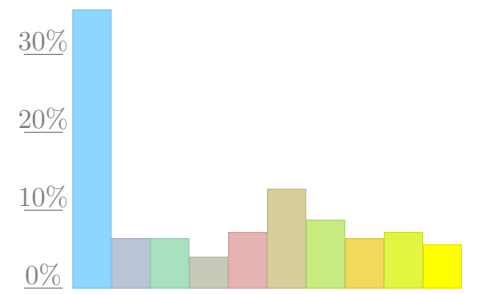

(b) Strategies: $R=40$

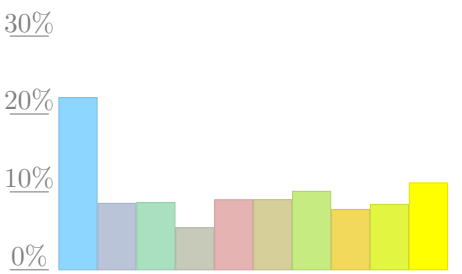

(e) Beliefs: $R=40$

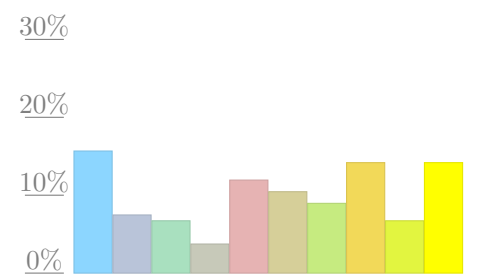

(c) Strategies: $R=48$

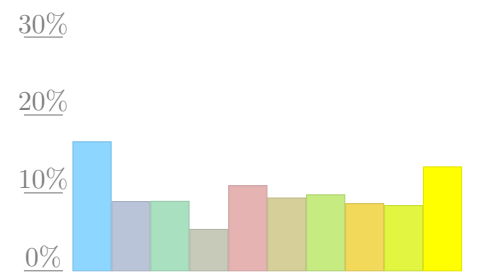

(f) Beliefs: $R=48$

\begin{tabular}{|c|c|c|c|c|c|c|c|c|c|}
\hline$A D$ & $D G$ & $D T F T$ & $R A N D$ & $G$ & $2 T F T$ & $T F T$ & G2 & TF2T & $A C$ \\
\hline
\end{tabular}

Figure 3: Strategies and average beliefs in Supergame 1

Notes: Figures 3(a) to 3(c) show the distribution of strategies chosen in Supergame 1 at the treatment level. Figures $3(\mathrm{~d})$ to $3(\mathrm{f})$ show the mean probability weight placed on each strategy across each subject's belief distribution in Supergame 1 at the treatment level.

\footnotetext{
${ }^{47}$ When $R=48(R=32), 30(68)$ percent of our subjects choose unfriendly strategies, while 27 (57) percent do so in Dal Bó and Fréchette (2019) (who elicit strategies after experience of direct-response play).
} 
Figures 3(d) to 3(f) show average beliefs in Supergame 1 for each treatment. Broadly speaking, beliefs match behavior quite well. This is true even though subjects did not interact in any way before eliciting strategies and beliefs in the first supergame. When the return to joint cooperation is low, subjects underestimate the proportion of unfriendly strategies, but when the return to joint cooperation is high, beliefs track behavior closely. Generally speaking, beliefs respond to the treatment less strongly than does behavior.

In order to delve more deeply into the data, we construct summary measures of initial beliefs and behavior. Briefly, Figure 4 shows that: (i) when the return to joint cooperation increases, optimism about how often others will cooperate responds more slowly than subjects' own willingness to cooperate and the actual level of cooperation in the population; (ii) when the return to joint cooperation is low, subjects are excessively optimistic, but beliefs become more accurate as the return to joint cooperation goes up; and (iii) within-treatment, subjects who are more optimistic tend also to be more cooperative.

I: Optimism

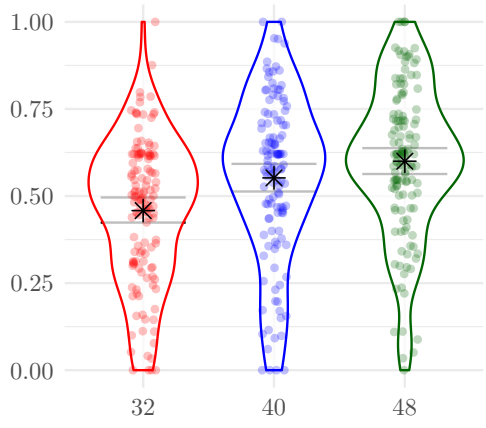

IV: OptimismRelTruth

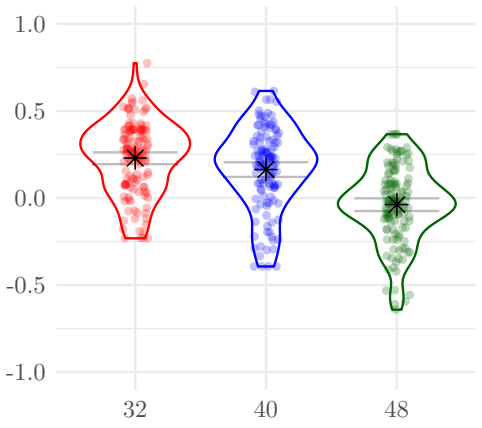

II: Cooperativeness

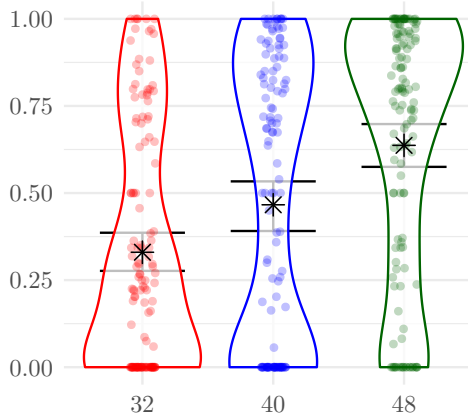

V: Cooperation

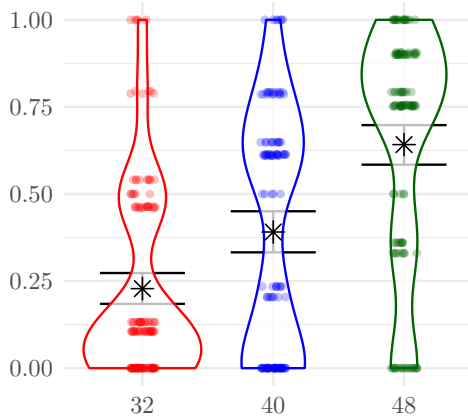

III

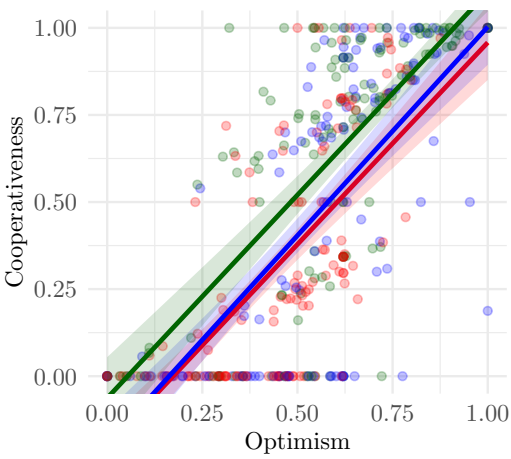

VI

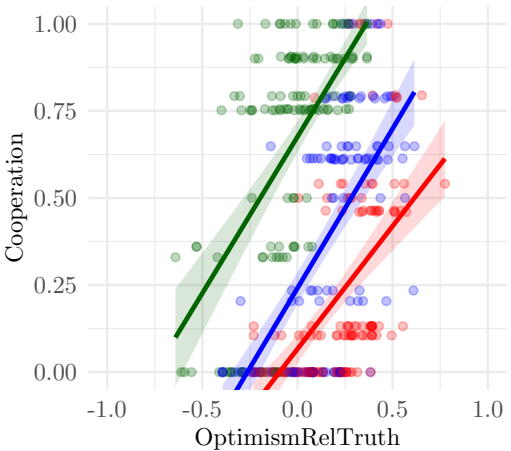

Figure 4: Beliefs and behavior in Supergame 1: Violin and scatter plots

Notes: 'Optimism' measures the expected cooperation rate of a subject's belief distribution playing against itself, while 'Cooperativeness' measures the expected cooperation rate of a subject's chosen strategy playing against the subject's belief distribution (the expected cooperation rate of a distribution of strategies playing against itself is the weighted sum of the expected cooperation rate of each strategy playing against the distribution, with the weight on each strategy given by the distribution). 'OptimismRelTruth' measures optimism minus the expected cooperation rate of the treatment-level strategy distribution (excluding the subject's own choice) playing against itself, while 'Cooperation' measures the expected cooperation rate of a subject's chosen strategy playing against the treatment-level strategy distribution (excluding the subject's own choice). In all cases, cooperation rates measure the expected number of rounds of cooperation divided by the expected number of rounds, and are based on analytical calculations of cooperation rates for every possible combination of strategies (see Table A.1 in Web Appendix III). In the violin plots, the unit of observation is an individual subject, stars are means and horizontal bars are 95 percent confidence intervals, calculated using non-parametric bootstrapping. The scatter plots report linear OLS regression lines and 95 percent confidence intervals. 
Turning to the first row of Figure 4, 'Optimism' measures how often a subject expects others to cooperate, while 'Cooperativeness' measures how often a subject expects her chosen strategy to cooperate given her beliefs about others (and so captures willingness to cooperate). We see that when the return to joint cooperation increases (i.e., when $R$ increases from 32 to 48), subjects become: (i) more optimistic (Panel I); and (ii) more willing to cooperate (Panel II). Interestingly, cooperativeness responds more strongly to the treatment than does optimism. Finally, within-treatment, there is a strong positive correlation between optimism and willingness to cooperate (Panel III).

Turning to the second row of Figure 4, 'OptimismRelTruth' measures optimism relative to how often others actually cooperate, while 'Cooperation' measures how often a subject's chosen strategy cooperates on average given how others actually behave. We see that when the return to joint cooperation is low $(R=32)$, subjects are too optimistic relative to the truth (Panel IV). Because subjects are overly optimistic when $R=32$, the level of cooperation (Panel V) is lower than the willingness to cooperate (Panel II). However, when $R=48$ optimism matches well the degree of cooperation actually present in the population (Panel IV), and so cooperation (in Panel V) and willingness to cooperate (Panel II) match up well. Finally, Panel VI shows that, within-treatment, subjects who are more optimistic relative to the truth also cooperate more.

Panel IV of Figure 4 suggests that the accuracy of beliefs increases as the return to joint cooperation goes up. To test this, we construct a measure of accuracy of beliefs about the withintreatment level of cooperation, and then regress this measure of accuracy on the treatment. ${ }^{48}$ Regression results show that accuracy does indeed increase as the return to joint cooperation goes up, with the effect statistically significant at the one-percent level. ${ }^{49}$ Furthermore, optimism strongly reduces accuracy when the return to joint cooperation is low, while optimism modestly increases accuracy when the return to joint cooperation is high. ${ }^{50}$ This relationship between accuracy and optimism is consistent with Panel IV, which shows a large degree of excess optimism when $R=32$ and a modest degree of excess pessimism when $R=48$.

\subsection{Responding to beliefs}

\subsubsection{Introducing good responding to beliefs}

The subjects in our experiment face a difficult choice among ten strategies. Furthermore, in the first supergame, we elicit initial supergame strategies and beliefs before subjects gain any experience of play against other subjects. As a result, it is not surprising that subjects frequently fail to best respond to their initial beliefs: on average, in the first supergame 25.4 percent of

\footnotetext{
${ }^{48}$ We base our measure on the absolute value of OptimismRelTruth, which captures the deviation from the truth of the subject's expectation about how much others cooperate (the notes to Figure 4 define OptimismRelTruth). In particular, we define accuracy to be the negative of the absolute value of OptimismRelTruth; we take the negative so that accuracy increases (toward zero) as beliefs become more accurate.

${ }^{49}$ We ran a linear OLS regression of accuracy in Supergame 1 on the treatment, controlling for the five personality factors, demographic characteristics and standardized cognitive ability (see Section 2.9), and using heteroskedasticity-robust standard errors and two-sided tests of significance. The positive effect of $R=48$ relative to $R=32$ is significant at the one-percent level.

${ }^{50}$ We ran the regression described in footnote 49 , including optimism (defined in the notes to Figure 4 ) and interacting it with the treatment. Setting $R=32(R=48)$ as the omitted category, we find a negative (positive) effect of optimism on accuracy, statistically significant at the one-percent (one-percent) level (the magnitude of the first effect is 2.6 times that of the second). We also find that the effect of optimism when $R=48$ is significantly different to that when $R=32$, again at the one-percent level.
} 
subjects best respond perfectly to their beliefs.

Since best responding perfectly is difficult in our environment, we consider a less stringent, more pragmatic, definition of best response that we call 'good response'. In particular, we say that a subject good responds to her beliefs if she chooses a strategy that achieves an expected payoff within 3.15 percent of that from the best response (given the subject's beliefs). We chose this threshold so that exactly 50 percent of our subjects good respond to their beliefs in the first supergame, which is similar to the rate of best responding in simpler environments (see Alempaki et al., 2019, Costa-Gomes and Weizsäcker, 2008, and the references therein).

Data from the first supergame support good responding as a useful measure. First, a payoff loss of up to 3.15 percent is small relative to the range of losses across subjects: Figure A.12 in Web Appendix II shows the cumulative distribution function of payoffs relative to best responding. Second, good responding matters for outcomes: in Section 3.4 we show that good responding is a strong predictor of earnings. ${ }^{51}$ Third, good responding changes with beliefs: in Section 3.2.2 we show that the frequency of good responding varies with the optimism of subjects' beliefs.

\subsubsection{Analysis of good responding}

Table 2 shows the frequency with which each strategy is a good response to subjects' beliefs, split by treatment. When the return to joint cooperation is low $(R=32)$, the unfriendly strategy $\mathrm{AD}$ is a good response for almost all subjects (97 percent), while DG and DTFT are good responses for around 35 percent of subjects. When $R=40$, the lenient strategies G2 and TF2T are good responses for around 75 percent of subjects, while the provocable strategies $\mathrm{G}, 2 \mathrm{TFT}$ and TFT are good responses for around 55 percent, and $\mathrm{AC}$ is a good response for around 45 percent. When the return to joint cooperation is high $(R=48)$, the lenient strategies G2 and TF2T are good responses for almost all subjects (94 percent), and AC is a good response for around 60 percent; perhaps surprisingly, when $R=48$ the provocable strategies $\mathrm{G}, 2 \mathrm{TFT}$ and TFT are good responses for only around 35 percent of subjects. ${ }^{52}$

\begin{tabular}{ccccccccccc}
$\mathrm{R}$ & $A D$ & $D G$ & $D T F T$ & $R A N D$ & $G$ & $2 T F T$ & $T F T$ & G2 & TF2T & $A C$ \\
\hline 32 & 0.97 & 0.37 & 0.34 & 0.03 & 0.13 & 0.13 & 0.12 & 0.10 & 0.09 & 0.04 \\
40 & 0.33 & 0.17 & 0.16 & 0.02 & 0.58 & 0.56 & 0.55 & 0.75 & 0.75 & 0.45 \\
48 & 0.07 & 0.09 & 0.09 & 0.01 & 0.34 & 0.33 & 0.31 & 0.94 & 0.94 & 0.60 \\
\hline
\end{tabular}

Table 2: Frequency each strategy is a good response in Supergame 1

Notes: For each strategy, the table shows the proportion of subjects for whom that strategy is in the subject's set of good responses (given the subject's beliefs), split by treatment. Good responding is defined in the second paragraph of Section 3.2.1. Table A.2 in Web Appendix III replicates the table for best responding.

\footnotetext{
${ }^{51}$ The relationship between good responding and earnings is not immediate, since good responding is defined relative to subjects' beliefs, while earnings depend on realized choices of others.

${ }^{52}$ Compared to lenient strategies, provocable strategies provide more protection against AD. However, unlike lenient strategies, provocable strategies never achieve mutual cooperation against DG and DTFT, which matters most when $R=48$.
} 
The frequency with which subjects good respond to their beliefs interacts with optimism in an interesting way. Recall from Section 3.1 that optimism measures how often a subject expects others to cooperate. Regression results show that optimism is unhelpful when the return to joint cooperation is low $(R=32)$, in the sense that optimism reduces the probability that subjects good respond to their beliefs, while optimism is helpful when the return to joint cooperation is high $(R=48) .{ }^{53}$ As evidenced by Table A.3 in Web Appendix III: (i) when the return to joint cooperation is low, optimists good respond less frequently because they often fail to understand that the unfriendly strategy AD is a good response to their (relatively) optimistic beliefs; and (ii) when the return to joint cooperation is high, pessimists good respond less frequently because they often fail to understand that the lenient strategies G2 and TF2T are good responses to their (relatively) pessimistic beliefs.

\subsection{Belief clustering and behavioral types}

\subsubsection{Belief clusters}

To understand more about the structure of subjects' initial beliefs, in this section we use a clustering algorithm to group subjects into clusters according to the similarity of their beliefs. In particular, we use the affinity-propagation algorithm developed by Frey and Dueck (2007), which has two advantages. ${ }^{54}$ First, affinity propagation computes the optimal number of clusters endogenously. Second, within each cluster, affinity propagation selects one subject's beliefs to be the 'exemplar' beliefs that are representative of beliefs in that cluster.

Table 3 presents the results of this clustering exercise. Cluster 1, the largest cluster, includes 56 subjects whose initial beliefs are close to uniform (the exemplar beliefs for this cluster are exactly uniform). The exemplar beliefs for clusters $3,5,6,7$ and 11 are also close to uniform, in the sense that the sum of the absolute deviations of the probability weights from the uniform distribution is 30 or less. The data show many other patterns of beliefs. A number of clusters have exemplar beliefs that place 50 percent or more weight on AD (e.g., clusters 4, 10 and 16), while others have exemplars that place 50 percent or more weight on AC (clusters 17, 21 and 24). An interesting belief pattern also emerges in which $\mathrm{AD}$ and $\mathrm{AC}$ both attract relatively high probability weights, with close-to-uniform beliefs among the remaining strategies (e.g., clusters

$8,12,15)$ : these clusters suggest that some subjects' initial beliefs tend to gravitate toward simple memory-0 strategies. The exemplar beliefs with 50 percent or more weight on AD or AC are also consistent with a focus among a subset of subjects on simple memory-0 strategies when forming beliefs.

\footnotetext{
${ }^{53}$ We ran the regression described in footnote 50, replacing accuracy as the dependent variable with an indicator taking value 1 if a subject chose a good response to her beliefs in Supergame 1. Setting $R=32(R=48)$ as the omitted category, we find a negative (positive) effect of optimism on the probability of good responding, statistically significant at the one-percent (one-percent) level. We also find that the effect of optimism when $R=48$ is significantly different to that when $R=32$, again at the one-percent level.

${ }^{54}$ Romero and Rosokha (2018) used affinity propagation to cluster strategies.
} 
Exemplar Beliefs

Good Responders

\begin{tabular}{|c|c|c|c|c|c|c|c|c|c|c|c|c|c|c|}
\hline Cluster & $\mathrm{N}$ & $A D$ & $D G$ & DTFT & $R A N D$ & $G$ & $2 T F T$ & $T F T$ & G2 & TF2T & $A C$ & 32 & 40 & 48 \\
\hline 1 & 56 & 10 & 10 & 10 & 10 & 10 & 10 & 10 & 10 & 10 & 10 & $0 / 16$ & $11 / 16$ & $10 / 24$ \\
\hline 2 & 34 & 5 & 9 & 9 & 5 & 10 & 17 & 16 & 17 & 9 & 3 & $2 / 5$ & $10 / 14$ & $7 / 15$ \\
\hline 3 & 31 & 18 & 9 & 11 & 12 & 9 & 9 & 8 & 10 & 8 & 6 & $10 / 19$ & $3 / 9$ & $1 / 3$ \\
\hline 4 & 30 & 50 & 8 & 10 & 5 & 5 & 5 & 5 & 5 & 5 & 2 & $14 / 15$ & $6 / 8$ & $3 / 7$ \\
\hline 5 & 25 & 20 & 15 & 10 & 5 & 10 & 10 & 10 & 5 & 5 & 10 & $2 / 8$ & $2 / 9$ & $0 / 8$ \\
\hline 6 & 21 & 5 & 20 & 15 & 5 & 10 & 10 & 10 & 10 & 10 & 5 & $6 / 8$ & $2 / 6$ & $2 / 7$ \\
\hline 7 & 20 & 10 & 10 & 20 & 5 & 10 & 10 & 15 & 5 & 10 & 5 & $5 / 9$ & $1 / 5$ & $1 / 6$ \\
\hline 8 & 15 & 23 & 10 & 5 & 5 & 5 & 7 & 5 & 10 & 7 & 23 & $0 / 5$ & $4 / 7$ & $1 / 3$ \\
\hline 9 & 14 & 40 & 10 & 10 & 5 & 5 & 5 & 5 & 5 & 10 & 5 & $3 / 5$ & $3 / 4$ & $3 / 5$ \\
\hline 10 & 13 & 75 & 3 & 3 & 3 & 3 & 3 & 3 & 3 & 3 & 1 & $5 / 5$ & $6 / 6$ & $1 / 2$ \\
\hline 11 & 13 & 10 & 10 & 10 & 5 & 10 & 10 & 10 & 5 & 25 & 5 & $0 / 2$ & $4 / 6$ & $5 / 5$ \\
\hline 12 & 12 & 32 & 5 & 5 & 2 & 5 & 5 & 5 & 5 & 5 & 31 & $4 / 4$ & $0 / 4$ & $0 / 4$ \\
\hline 13 & 12 & 30 & 15 & 20 & 5 & 5 & 5 & 5 & 5 & 5 & 5 & $4 / 4$ & $0 / 3$ & $0 / 5$ \\
\hline 14 & 11 & 5 & 5 & 5 & 5 & 10 & 5 & 20 & 5 & 10 & 30 & $0 / 1$ & $3 / 5$ & $4 / 5$ \\
\hline 15 & 10 & 49 & 3 & 4 & 3 & 3 & 3 & 5 & 3 & 2 & 25 & $3 / 4$ & $4 / 4$ & $0 / 2$ \\
\hline 16 & 10 & 91 & 1 & 1 & 1 & 1 & 1 & 1 & 1 & 1 & 1 & $4 / 4$ & $4 / 4$ & $2 / 2$ \\
\hline 17 & 8 & 5 & 5 & 5 & 0 & 5 & 5 & 5 & 5 & 10 & 55 & $0 / 0$ & $1 / 2$ & $5 / 6$ \\
\hline 18 & 8 & 10 & 10 & 7 & 1 & 10 & 10 & 10 & 30 & 7 & 5 & $0 / 2$ & $2 / 2$ & $2 / 4$ \\
\hline 19 & 8 & 15 & 8 & 15 & 3 & 25 & 7 & 10 & 10 & 5 & 2 & $1 / 3$ & $1 / 1$ & $1 / 4$ \\
\hline 20 & 5 & 5 & 8 & 10 & 0 & 40 & 15 & 10 & 5 & 5 & 2 & $0 / 0$ & $1 / 1$ & $1 / 4$ \\
\hline 21 & 4 & 10 & 0 & 0 & 0 & 0 & 0 & 0 & 0 & 0 & 90 & $0 / 0$ & $0 / 1$ & $0 / 3$ \\
\hline 22 & 4 & 15 & 1 & 8 & 2 & 1 & 1 & 50 & 1 & 6 & 15 & $0 / 1$ & $1 / 1$ & $1 / 2$ \\
\hline 23 & 4 & 10 & 5 & 10 & 0 & 5 & 50 & 10 & 5 & 5 & 0 & $0 / 1$ & $2 / 2$ & $1 / 1$ \\
\hline 24 & 4 & 35 & 0 & 0 & 0 & 0 & 0 & 0 & 0 & 0 & 65 & $0 / 1$ & $1 / 2$ & $0 / 1$ \\
\hline 25 & 3 & 20 & 50 & 7 & 2 & 5 & 2 & 2 & 5 & 5 & 2 & $1 / 1$ & $0 / 1$ & $0 / 1$ \\
\hline 26 & 3 & 10 & 2 & 2 & 2 & 2 & 39 & 39 & 2 & 2 & 0 & $2 / 2$ & $0 / 0$ & $1 / 1$ \\
\hline 27 & 3 & 5 & 3 & 5 & 1 & 10 & 2 & 2 & 1 & 70 & 1 & $0 / 1$ & $1 / 1$ & $1 / 1$ \\
\hline 28 & 3 & 38 & 0 & 0 & 3 & 21 & 2 & 28 & 0 & 0 & 8 & $0 / 3$ & $0 / 0$ & $0 / 0$ \\
\hline 29 & 3 & 10 & 0 & 0 & 0 & 70 & 0 & 0 & 0 & 0 & 20 & $0 / 0$ & $0 / 1$ & $2 / 2$ \\
\hline 30 & 2 & 0 & 60 & 0 & 0 & 40 & 0 & 0 & 0 & 0 & 0 & $0 / 1$ & $0 / 0$ & $0 / 1$ \\
\hline 31 & 1 & 30 & 0 & 0 & 50 & 0 & 0 & 0 & 0 & 0 & 20 & $1 / 1$ & $0 / 0$ & $0 / 0$ \\
\hline 32 & 1 & 0 & 100 & 0 & 0 & 0 & 0 & 0 & 0 & 0 & 0 & $0 / 1$ & $0 / 0$ & $0 / 0$ \\
\hline 33 & 1 & 20 & 0 & 80 & 0 & 0 & 0 & 0 & 0 & 0 & 0 & $0 / 1$ & $0 / 0$ & $0 / 0$ \\
\hline 34 & 1 & 1 & 1 & 1 & 1 & 1 & 1 & 91 & 1 & 1 & 1 & $0 / 0$ & $1 / 1$ & $0 / 0$ \\
\hline 35 & 1 & 50 & 0 & 0 & 0 & 0 & 50 & 0 & 0 & 0 & 0 & $1 / 1$ & $0 / 0$ & $0 / 0$ \\
\hline
\end{tabular}

Table 3: Belief clusters in Supergame 1

Notes: We use affinity propagation to group subjects into clusters according to the similarity of their beliefs, implemented in R using the APCluster package (Bodenhofer et al., 2011), and using default values for all arguments. As noted in the text, within each cluster affinity propagation selects one subject's beliefs to the representative exemplar. The final column shows the proportion of subjects within each cluster who good respond to their own beliefs, split by $R$; Section 3.2.1 introduces our notion of good responding. 


\subsubsection{Level- $k$ types}

The belief clusters motivate allocating some of our subjects to behavioral types based on their beliefs and behavior in the first supergame. In particular, in the typology of the level- $k$ model of boundedly rational thinking (Nagel, 1995, Stahl and Wilson, 1995), subjects whose beliefs are close to uniform and who good respond to their beliefs exhibit level-1 type beliefs and behavior (Section 3.2.1 introduces our notion of good responding). For example, Table 3 suggests that we can allocate 10 of the 21 subjects in cluster 6 to the level-1 category, since the exemplar beliefs for this cluster are close to uniform and 10 of the subjects in the cluster good respond to their beliefs.

Prompted by our clustering exercise, we develop a formal model of level- 1 and level-2 behavior in our setting. We focus on level-1 and level-2 types because previously estimated level- $k$ type distributions across contexts place most weight on these levels, with the proportion of level-0 types usually estimated to be zero or small (Crawford et al., 2013). We focus on level- $k$ behavior in the first supergame because the level- $k$ model is usually estimated from initial behavior in games absent any learning or feedback (e.g., Costa-Gomes et al., 2001); estimating level- $k$ behavior in the presence of feedback and learning adds substantial complication (e.g., Gill and Prowse, 2016).

In the level- $k$ typology, a non-strategic level-0 type who chooses uniformly among her strategies acts as the seed for the beliefs of the level- 1 type, while the level- 1 type acts as the seed for the beliefs of the level-2 type. The literature that estimates the number of level- $k$ types in settings with many strategies does not require that subjects perfectly conform to the level- $k$ prediction (see, e.g., Nagel, 1995, and the survey by Crawford et al., 2013). Motivated by that literature, we allow some noise in the belief formation process and in behavior given beliefs. In particular, we allow the level-1 type to form beliefs that are $\alpha$-near to uniform, and we allow her to $\alpha$-near best respond to her beliefs, where $\alpha$-near is defined in terms of relative payoff deviations. The notes to Figure 5 describe the formal model, which defines the level-2 type in similar terms, and explains how we create a payoff-based distance metric for beliefs using the QSR that we used to incentivize belief elicitation (see Section 2.8).

Figure 5 presents the proportion of types in the first supergame as a function of the noise parameter $\alpha$. Noise goes to zero as $\alpha$ tends to 1 , and we estimate the proportion of level-1 and level-2 types for a range of values of $\alpha$. The stacked graph shows the proportion of subjects that we identify uniquely as level-1 types (black), the proportion of subjects that we identify uniquely as level-2 types (dark gray), and the proportion of subjects that fit our level-1 and level-2 type categories (light gray). At the value of $\alpha$ that maximizes the proportion of subjects that are identified uniquely, we identify 18 percent of subjects as uniquely level- 1 types and 26 percent as uniquely level-2 types.

Since the number of subjects that we allocate to the level-1 and level-2 types depends on the amount of noise that we allow, our estimates should be viewed as establishing a proof-of-concept, rather than pinning down precisely the amount of level- $k$ behavior in our sample. For simplicity, we measure noise using a single parameter $\alpha$ that captures both noise in beliefs and noise in behavior in terms of relative payoff deviations, but other choices are possible. For example, the model could be extended to include separate parameters to capture noise in the belief 
formation process and noise in behavior given beliefs; and instead of measuring noise in terms of payoff deviations, an alternative would be to measure noise in terms of deviations measured in cooperation space (using our notions of cooperativeness and optimism from Section 3.1). Our methodology could also be extended to include behavioral types beyond the level- $k$ model, such as a non-strategic 'maxmin' type who is far from best responding to her beliefs, but instead chooses among strategies to maximize the minimum possible payoff, or a 'worldly' type whose beliefs are close to the true distribution in the population.

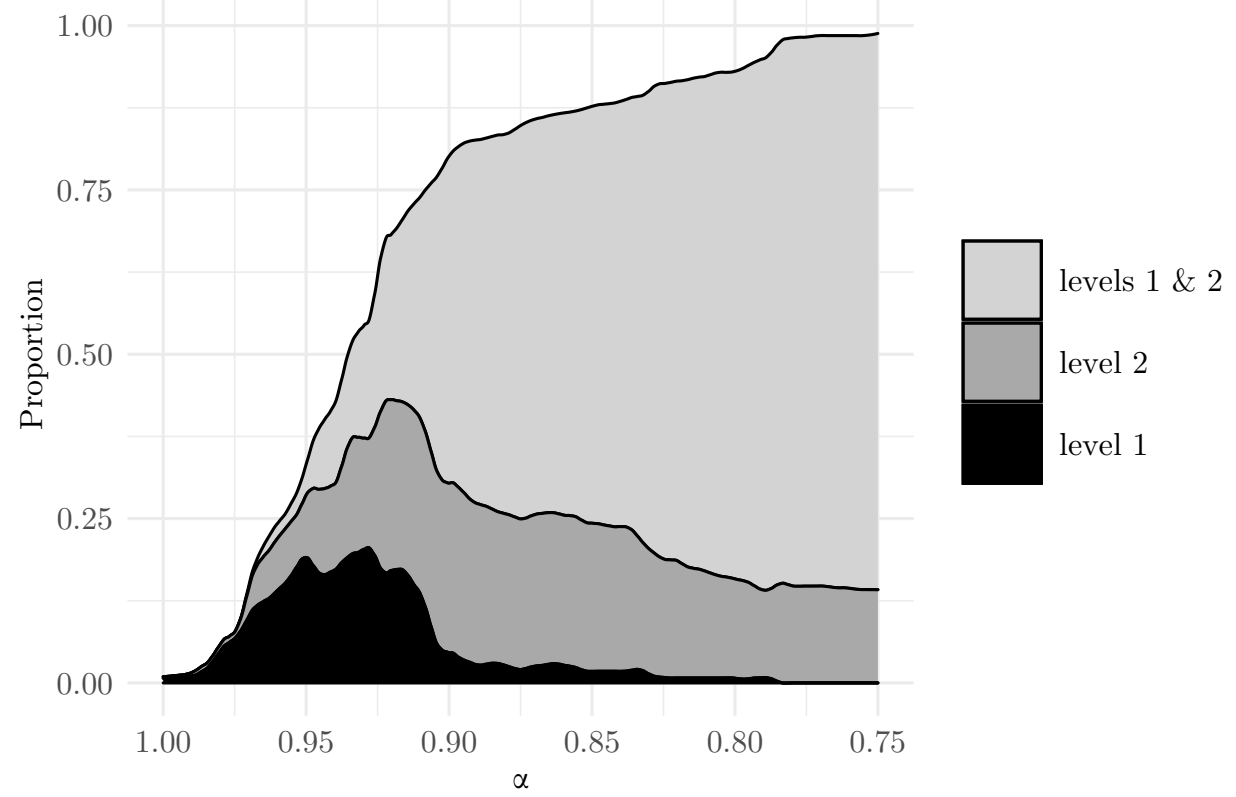

Figure 5: Level- $k$ types in Supergame 1

Notes: The shaded areas are explained in the main text above. We smoothed the graphs using Loess regressions with a smoothing span of 0.05 . In our model, the ' $\alpha$-level-1' type forms beliefs that are $\alpha$-near to uniform, and $\alpha$-near best responds to her beliefs. The ' $\alpha$-level-2' type forms beliefs that are $\alpha$-near to at least one distribution that places probability weight only on strategies that are themselves $\alpha$-near best responses to uniform beliefs; the $\alpha$-level-2 type also $\alpha$-near best responds to her beliefs. Given the QSR that we used for belief elicitation (see Section 2.8), we say that belief $b$ is ' $\alpha$-near' to distribution $x$ if, taking $x$ to be the true distribution, reporting $b$ achieves expected payoffs that are a proportion $\alpha$ or higher of the expected payoffs from reporting $x$. We say that a subject ' $\alpha$-near' best responds to her beliefs if she chooses a strategy that achieves expected payoffs given her beliefs that are a proportion $\alpha$ or higher of the expected payoffs from the best response to her beliefs.

\subsection{The determinants of earnings}

In this section, we analyze the determinants of earnings. In particular, we want to understand how earnings in the first supergame depend on subjects' initial beliefs and behavior given those beliefs. Earnings in Supergame 1 are noisy, since they depend on the behavior of the specific opponent that a subject is matched with. To reduce this noise, we analyze subjects' expected earnings given their choice of strategy and how others behave within-treatment (recall that subjects had not yet interacted with each other when we elicited strategies and beliefs in the first supergame).

To put our analysis in context, Panel I of Figure 6 shows expected earnings in the first supergame by treatment, while Panel II shows expected earnings as a proportion of the maximum available (from choosing the strategy that performs best in expectation given how others actually 
behave). The first panel shows that, unsurprisingly, expected earnings increase with the return to joint cooperation. The second panel shows that subjects generally leave little money on the table: on average, subjects achieve expected earnings of around 95 percent of the maximum. ${ }^{55}$
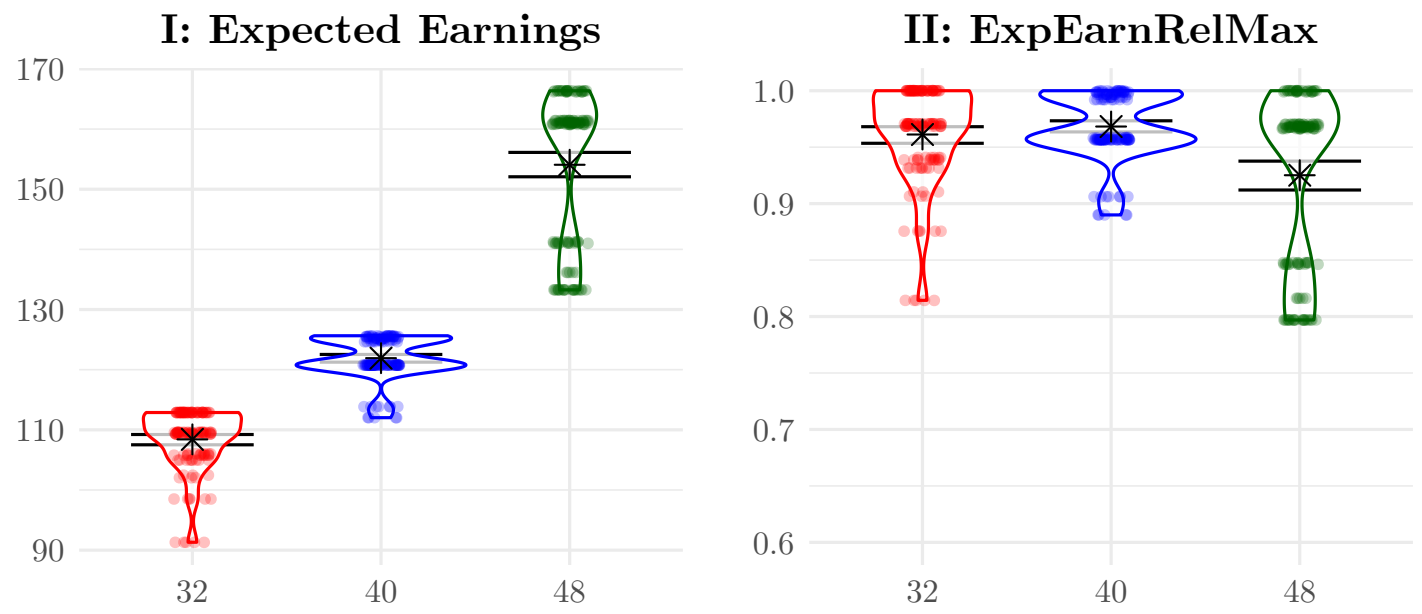

Figure 6: Earnings in Supergame 1: Violin plots

Notes: We define 'Expected earnings' to be the expected earnings in points of a subject's chosen strategy playing against the treatment-level strategy distribution (excluding the subject's own choice); we derive Expected earnings using analytical calculations of payoffs for every possible combination of strategies (see Tables A.4 to A.6 in Web Appendix III). We define 'ExpEarnRelMax' to be Expected earnings as a proportion of the expected earnings from the best response to the treatment-level strategy distribution (excluding the subject's own choice). In the violin plots, stars are means and horizontal bars are 95 percent confidence intervals, calculated using non-parametric bootstrapping.

We now turn to our analysis of the determinants of earnings. Table 4 reports the results of regressions of expected earnings in Supergame 1 on the variables of interest; throughout, the omitted category is $R=32$. Confirming Figure 6 , the first two rows of Table 4 show that expected earnings increase with the return to joint cooperation. More interestingly, the table tells us that expected earnings depend on both the accuracy of subjects' beliefs and the ability of subjects to choose well given those beliefs.

The third row of Table 4 shows that expected earnings increase with the accuracy of beliefs about the level of cooperation (the final paragraph of Section 3.1 introduces our notion of accuracy). ${ }^{56}$ Thus, the quality of subjects' initial beliefs helps to determine how much they earn in the first prisoner's dilemma supergame. Furthermore, the fourth row shows that expected earnings are higher for subjects who good respond to their beliefs (Section 3.2.1 introduces our notion of good responding). Thus, the ability of subjects to select strategies that perform well given their beliefs also helps to determine how much they earn. This relationship between good responding and earnings is not immediate, since good responding is defined relative to subjects' beliefs, while earnings depend on the actual choices of others. Table A.7 in Web Appendix III shows that our results are robust when we replace our binary measure of good responding with

\footnotetext{
${ }^{55} \mathrm{~A}$ subject who achieved expected earnings of 100 percent of the maximum would still leave money on the table relative to the best response to the specific strategy chosen by her randomly selected opponent.

${ }^{56}$ To help interpret the effect size, note that our measure of accuracy is defined from -1 to 0 . In footnote 48 we define accuracy to be the negative of the absolute value of OptimismRelTruth; Panel IV of Figure 4 shows the distribution of OptimismRelTruth.
} 
a continuous measure of the proximity of a subject's strategy to the best response to her beliefs (based on expected payoffs relative to those from best responding).

\begin{tabular}{lccc}
\hline \hline & $(1)$ & $(2)$ & $(3)$ \\
\hline R40 & $13.02^{* * *}$ & $12.82^{* * *}$ & $12.61^{* * *}$ \\
R48 & $(0.55)$ & $(0.53)$ & $(0.53)$ \\
Accuracy of beliefs & $44.57^{* * *}$ & $46.59^{* * *}$ & $\begin{array}{c}45.52^{* * *} \\
(1.07)\end{array}$ \\
Good responder to beliefs & $12.18)$ & $(1.03)$ & $10.26^{* * *}$ \\
& $(2.66)$ & & $(2.68)$ \\
Mean of dependent variable & 128.15 & 128.15 & 128.15 \\
$\mathrm{~N}$ & 390 & 390 & 390 \\
\hline \hline
\end{tabular}

Table 4: Expected earnings in Supergame 1

Notes: Each column reports a linear OLS regression of expected earnings in Supergame 1, controlling for the five personality factors, demographic characteristics and standardized cognitive ability (see Section 2.9), and with $R=32$ as the omitted category. Expected earnings is defined in the notes to Figure 6. Accuracy of beliefs is defined in footnote 48. Good responding is a binary variable defined in the second paragraph of Section 3.2.1. $N=390$ because four subjects did not complete the demographic questionnaire. Heteroskedasticity-robust standard errors are shown in parentheses. $* * *,{ }^{*}$ and ${ }^{*}$ denote significance at the 1 percent, 5 percent and 10 percent levels (two-sided tests).

Next, we consider the relationship between expected earnings and optimism. Recall from Section 3.1 that optimism measures how often a subject expects others to cooperate. We find that the direction of the effect depends on the return to joint cooperation. When the return to joint cooperation is low, optimism reduces expected earnings; this follows from the fact that optimism reduces both accuracy (Section 3.1) and good responding (Section 3.2.2) when $R=32$. By contrast, when the return to joint cooperation is high, optimism increases expected earnings; this follows from the fact that optimism increases both accuracy (Section 3.1) and good responding (Section 3.2.2) when $R=48 .^{57}$

\section{Evolution of beliefs and behavior}

Next, we turn to the evolution of beliefs and behavior over the course of the 25 supergames.

\subsection{Evolution of cooperation}

Figure 7 describes the evolution of cooperation at the treatment and session levels. The figure shows that the differences across treatments in the level of cooperation that we found in Supergame 1 persist over the 25 supergames as subjects gain experience (Tables 5 and 6 below ev-

\footnotetext{
${ }^{57}$ We ran the regression described in footnote 50, replacing accuracy as the dependent variable with expected earnings. Setting $R=32(R=48)$ as the omitted category, we find a negative (positive) effect of optimism on expected earnings, statistically significant at the one-percent (one-percent) level. We also find that the effect of optimism when $R=48$ is significantly different to that when $R=32$, again at the one-percent level.
} 
idence strongly statistically significant effects of the treatment on cooperation). ${ }^{58}$ Furthermore, in each treatment, the aggregate level of cooperation is fairly stable over the 25 supergames. The figure also emphasizes a considerable degree of across-session heterogeneity in cooperation. Although the average level of cooperation remains broadly stable, at the individual level we find that subjects' beliefs and behavior respond to experience; the next section describes these results.

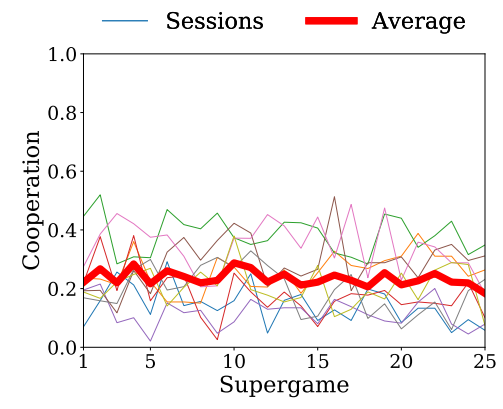

(a) $R=32$

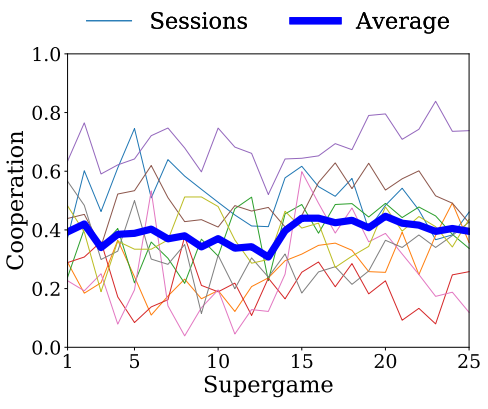

(b) $R=40$

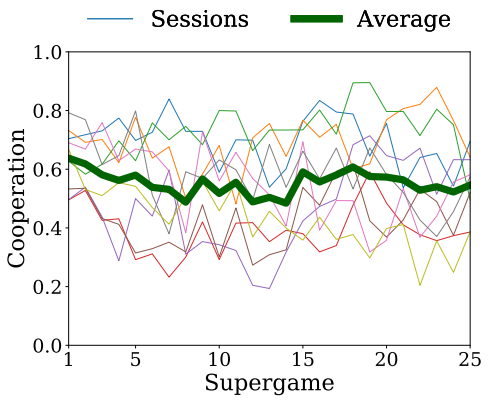

(c) $R=48$

Figure 7: Evolution of cooperation across supergames

Notes: 'Cooperation' is defined as in the notes to Figure 4 for Supergame 1, except that we now measure the cooperation of a subject's strategy in a given supergame using the session-level strategy distribution in that supergame (again excluding the subject's own choice) instead of the treatment-level distribution.

\subsection{Learning from experience}

When studying the effect of experience, the previous literature focuses on behavior in the first round of each supergame, and finds that subjects are more likely to cooperate in the first round of a supergame when the previous supergame lasted longer and when their opponent in the previous supergame cooperated in the first round of that earlier supergame (Dal Bó and Fréchette, 2011, 2018). We start by showing that this previous finding replicates in our setting with strategy elicitation over consecutive supergames, and we also show that the effects of experience on first-round cooperation are robust when we control for initial beliefs.

We then go beyond this analysis of first-round behavior in three ways. First, because we elicited strategies in consecutive supergames, we are able to show that experience affects cooperation at the level of the whole supergame strategy, and we also use transitions between strategies to help understand how experience changes cooperation. Second, because we elicited beliefs in the first supergame, we can show that cooperation depends on both experience and initial beliefs. Third, because we also elicited beliefs in the final supergame, we can show that beliefs themselves respond to experience and that beliefs in the final supergame predict cooperation. Thus, we use beliefs to provide new evidence about the mechanism that underlies learning from experience.

Table 5 shows that subjects are more likely to choose a strategy that cooperates in the first round of a supergame when the previous supergame was longer and when the strategy chosen by the subject's opponent in the previous supergame cooperated in the first round of that earlier

\footnotetext{
${ }^{58}$ As we noted in Section 3.1, in Supergame 1 our subjects choose unfriendly strategies at broadly similar rates to Dal Bó and Fréchette (2019)'s subjects in their menu elicitation treatment (see footnote 47).
} 
supergame. Using our data from strategy elicitation, we find effect sizes of experience that are close to those found by Dal Bó and Fréchette (2018, Table 9) using meta-data from roundby-round choices. Following Dal Bó and Fréchette (2018), our analysis of learning controls for first-round cooperation in the first supergame (shown in the panel) and the supergame number (not shown in the panel). Furthermore, our analysis controls for initial beliefs by including the subject's optimism in the first supergame (recall from Section 3.1 that optimism measures how often a subject expects others to cooperate). We find that optimism in the first supergame strongly predicts first-round cooperation in later supergames, even after controlling for the subject's first-round cooperation in the first supergame. At the same time, our other parameter estimates are broadly robust to including optimism as a control for initial beliefs. For simplicity, we use linear regressions to estimate parameters; Table A.8 in Web Appendix III shows that our results are robust when instead we use Probit regressions.

\begin{tabular}{|c|c|c|c|c|c|}
\hline & (1) & $(2)$ & (3) & (4) & $(5)$ \\
\hline R40 & $\begin{array}{c}0.152^{* *} \\
(0.060)\end{array}$ & $\begin{array}{c}0.138^{* *} \\
(0.055)\end{array}$ & $\begin{array}{c}0.067 \\
(0.048)\end{array}$ & $\begin{array}{c}0.084 \\
(0.056)\end{array}$ & $\begin{array}{c}0.040 \\
(0.043)\end{array}$ \\
\hline R48 & $\begin{array}{c}0.304^{* * *} \\
(0.044)\end{array}$ & $\begin{array}{c}0.277^{* * *} \\
(0.039)\end{array}$ & $\begin{array}{c}0.153^{* * *} \\
(0.043)\end{array}$ & $\begin{array}{c}0.203^{* * *} \\
(0.045)\end{array}$ & $\begin{array}{c}0.113^{* * *} \\
(0.038)\end{array}$ \\
\hline Length of Supergame $t-1$ & $\begin{array}{c}0.007^{* * *} \\
(0.001)\end{array}$ & & & & $\begin{array}{c}0.007^{* * *} \\
(0.001)\end{array}$ \\
\hline $\begin{array}{l}\text { Other's Round } 1 \text { coop } \\
\text { in Supergame } t-1\end{array}$ & & $\begin{array}{c}0.087^{* * *} \\
(0.019)\end{array}$ & & & $\begin{array}{c}0.080^{* * *} \\
(0.016)\end{array}$ \\
\hline $\begin{array}{l}\text { Own Round } 1 \text { coop } \\
\text { in Supergame } 1\end{array}$ & & & $\begin{array}{c}0.387^{* * *} \\
(0.036)\end{array}$ & & $\begin{array}{c}0.299^{* * *} \\
(0.035)\end{array}$ \\
\hline $\begin{array}{l}\text { Own optimism } \\
\text { in Supergame } 1\end{array}$ & & & & $\begin{array}{c}0.696^{* * *} \\
(0.071)\end{array}$ & $\begin{array}{c}0.345^{* * *} \\
(0.061)\end{array}$ \\
\hline Mean of dependent variable & 0.464 & 0.464 & 0.464 & 0.464 & 0.464 \\
\hline $\mathrm{N}$ & 9360 & 9360 & 9360 & 9360 & 9360 \\
\hline
\end{tabular}

Table 5: Round 1 cooperation in Supergame $t$

Notes: Each column reports a linear OLS regression of Round 1 cooperation in Supergame $t$ (for $t>1$ ), controlling for the five personality factors, demographic characteristics and standardized cognitive ability (see Section 2.9), and the supergame number, and with $R=32$ as the omitted category. 'Round 1 coop in Supergame $t$ ' is a variable taking value 1 if the relevant subject cooperated in the first round of Supergame $t$, and taking value 0 if not, where the cooperation decision was determined by the subject's chosen strategy. 'Optimism in Supergame $t$ ' is the optimism of the relevant subject's beliefs in Supergame $t$ (optimism is defined in the notes to Figure 4). 'Other' refers to the subject's opponent in a given supergame. 'Own' refers to the subject herself. 'Length of Supergame $t$ ' is the number of rounds that Supergame $t$ lasted for. $N$ is in multiples of 390 because four subjects did not complete the demographic questionnaire. Heteroskedasticity-robust standard errors with clustering at the session level are shown in parentheses. ***,** and ${ }^{*}$ denote significance at the 1 percent, 5 percent and 10 percent levels (two-sided tests). 
Panel I of Table 6 moves beyond this analysis of first-round cooperation by measuring cooperation at the level of the whole supergame strategy, which we call 'strategy cooperation' for short. Here we want a measure of cooperation that does not depend on the behavior of others, and so we measure strategy cooperation by how much a strategy cooperates on average against a uniform distribution over the ten available strategies. ${ }^{59}$ Once again, we control for the supergame number (not shown in the panel). Panel I shows clear evidence of learning at the level of the whole supergame strategy. In particular, the panel shows that strategy cooperation increases in both the length of the previous supergame and in the cooperation of the whole supergame strategy chosen by the opponent in the previous supergame. Of course, subjects do not directly observe the strategy chosen by their opponent: Table A.9 in Web Appendix III shows that the response to the opponent's cooperation is robust to using a model in which subjects make inferences based on realized play. ${ }^{60}$ Panel I further shows that optimism in the first supergame predicts strategy cooperation in later supergames, even after controlling for the subject's strategy cooperation in the first supergame. In summary, Panel I shows that experience and initial beliefs both predict cooperation at the level of the whole supergame strategy.

In Panel II of Table 6 we extend our analysis of learning to the evolution of beliefs themselves. In particular, we study how optimism changes with experience. Since we elicited beliefs only in the first and final supergames, we regress optimism in the final (25th) supergame on the average length of the previous 24 supergames played by the subject and the average strategy cooperation of the subject's 24 previous opponents. Panel II shows that beliefs respond to experience. In particular, the panel shows that optimism in the final supergame increases in the average cooperation of the whole supergame strategies chosen by the subject's previous opponents. ${ }^{61}$ When we include both measures of experience in the same regression and control for the subject's strategy cooperation and optimism in the first supergame, the effect of supergame length is marginally statistically significant, but the effect of others' strategy cooperation remains large and strongly statistically significant. ${ }^{62}$ In summary, Panel II shows that subjects learn, in the sense that their beliefs respond to what they experienced over the course of the experiment. Furthermore, the subjects' updated beliefs in the final supergame strongly predict cooperation: a one-unit increase in optimism in Supergame 25 is associated with an increase of 0.625 in strategy cooperation in the same supergame. ${ }^{63}$

\footnotetext{
${ }^{59}$ In particular, here we cannot measure the cooperation of a strategy in a given supergame by its realized cooperation rate; if we did, then we would create a confounding positive correlation between a subject's cooperation in Supergame $t$ and her opponent's cooperation in Supergame $t-1$ driven by the fact that subjects' own propensity to cooperate would influence the measurement of the cooperation of their opponent's strategy. Similarly, here we cannot measure the cooperation of a strategy using the session-level strategy distribution because of session-level heterogeneity in the level of cooperation exhibited in Figure 7, which would influence the measurement of subjects' own cooperation and that of their opponent.

${ }^{60}$ The model with inferences is not our preferred specification because the model needs to make an assumption about prior beliefs and because a subject's own behavior influences her inferences (although the direction of the effect is ambiguous).

${ }^{61}$ Just like for Panel I, Table A.9 in Web Appendix III shows that this response to the opponents' cooperation is robust to using a model in which subjects make inferences based on realized play.

${ }^{62}$ We note that average supergame length and average strategy cooperation are correlated because all subjects in a session experienced the same supergame lengths, and we know from Panel I that strategy cooperation responds to the supergame length in the previous period.

${ }^{63}$ When we run an OLS regression of strategy cooperation in Supergame 25 on optimism in Supergame 25, controlling for the five personality factors, demographic characteristics and standardized cognitive ability (see Section 2.9 ), the coefficient on optimism is 0.625 , with the effect statistically significant at the one-percent level.
} 


\section{I: Strategy cooperation in Supergame $t$}

\begin{tabular}{|c|c|c|c|c|c|}
\hline & (1) & $(2)$ & (3) & (4) & (5) \\
\hline R40 & $\begin{array}{c}0.103^{* *} \\
(0.041)\end{array}$ & $\begin{array}{c}0.096^{* *} \\
(0.038)\end{array}$ & $\begin{array}{l}0.059^{*} \\
(0.032)\end{array}$ & $\begin{array}{c}0.049 \\
(0.037)\end{array}$ & $\begin{array}{c}0.039 \\
(0.029)\end{array}$ \\
\hline R48 & $\begin{array}{c}0.209^{* * * *} \\
(0.033)\end{array}$ & $\begin{array}{c}0.194^{* * *} \\
(0.030)\end{array}$ & $\begin{array}{c}0.090^{* * *} \\
(0.029)\end{array}$ & $\begin{array}{c}0.128^{* * *} \\
(0.029)\end{array}$ & $\begin{array}{c}0.068^{* *} \\
(0.026)\end{array}$ \\
\hline Length of Supergame $t-1$ & $\begin{array}{c}0.004^{* * *} \\
(0.001)\end{array}$ & & & & $\begin{array}{c}0.004^{* * *} \\
(0.001)\end{array}$ \\
\hline $\begin{array}{l}\text { Other's strategy coop } \\
\text { in Supergame } t-1\end{array}$ & & $\begin{array}{c}0.072^{* * *} \\
(0.018)\end{array}$ & & & $\begin{array}{c}0.066^{* * *} \\
(0.014)\end{array}$ \\
\hline $\begin{array}{l}\text { Own strategy coop } \\
\text { in Supergame } 1\end{array}$ & & & $\begin{array}{c}0.422^{* * *} \\
(0.034)\end{array}$ & & $\begin{array}{c}0.334^{* * *} \\
(0.036)\end{array}$ \\
\hline $\begin{array}{l}\text { Own optimism } \\
\text { in Supergame } 1\end{array}$ & & & & $\begin{array}{c}0.556^{* * *} \\
(0.048)\end{array}$ & $\begin{array}{c}0.232^{* * *} \\
(0.039)\end{array}$ \\
\hline Mean of dependent variable & 0.467 & 0.467 & 0.467 & 0.467 & 0.467 \\
\hline $\mathrm{N}$ & 9360 & 9360 & 9360 & 9360 & 9360 \\
\hline
\end{tabular}

\section{II: Optimism in Supergame 25}

\begin{tabular}{|c|c|c|c|c|c|}
\hline & $(1)$ & $(2)$ & $(3)$ & $(4)$ & $(5)$ \\
\hline $\mathrm{R} 40$ & $\begin{array}{c}0.110^{* *} \\
(0.045)\end{array}$ & $\begin{array}{c}0.025 \\
(0.025)\end{array}$ & $\begin{array}{l}0.086^{*} \\
(0.042)\end{array}$ & $\begin{array}{c}0.062 \\
(0.043)\end{array}$ & $\begin{array}{l}-0.016 \\
(0.024)\end{array}$ \\
\hline $\mathrm{R} 48$ & $\begin{array}{c}0.244^{* * *} \\
(0.043)\end{array}$ & $\begin{array}{c}0.069^{* *} \\
(0.034)\end{array}$ & $\begin{array}{l}0.178^{* * *} \\
(0.045)\end{array}$ & $\begin{array}{l}0.171^{* * *} \\
(0.041)\end{array}$ & $\begin{array}{c}0.005 \\
(0.035)\end{array}$ \\
\hline Length of Supergames 1 to 24 & $\begin{array}{c}0.040 \\
(0.024)\end{array}$ & & & & $\begin{array}{l}0.025^{*} \\
(0.013)\end{array}$ \\
\hline $\begin{array}{l}\text { Others' strategy coop } \\
\text { in Supergames } 1 \text { to } 24\end{array}$ & & $\begin{array}{l}0.830^{* * *} \\
(0.110)\end{array}$ & & & $\begin{array}{l}0.760 * * * \\
(0.097)\end{array}$ \\
\hline $\begin{array}{l}\text { Own strategy coop } \\
\text { in Supergame } 1\end{array}$ & & & $\begin{array}{l}0.232^{* * *} \\
(0.036)\end{array}$ & & $\begin{array}{c}0.069^{* *} \\
(0.033)\end{array}$ \\
\hline $\begin{array}{l}\text { Own optimism } \\
\text { in Supergame } 1\end{array}$ & & & & $\begin{array}{c}0.493^{* * *} \\
(0.042)\end{array}$ & $\begin{array}{l}0.411^{* * *} \\
(0.040)\end{array}$ \\
\hline Mean of dependent variable & 0.430 & 0.430 & 0.430 & 0.430 & 0.430 \\
\hline $\mathrm{N}$ & 390 & 390 & 390 & 390 & 390 \\
\hline
\end{tabular}

Table 6: Effect of experience on behavior and beliefs

Notes: Each column reports a linear OLS regression of the variable in the panel title (for $t>1$ in the case of Panel I), controlling for the five personality factors, demographic characteristics and standardized cognitive ability (see Section 2.9), and with $R=32$ as the omitted category. The regressions in Panel I also include the supergame number as a control. 'Strategy coop in Supergame $t$ ' measures the expected cooperation rate of the relevant subject's chosen strategy in Supergame $t$ playing against the uniform distribution over the ten strategies (the notes to Figure 4 define 'cooperation rate'), while 'Strategy coop in Supergames 1 to 24' is the mean over the first 24 supergames. 'Optimism in Supergame t' is the optimism of the relevant subject's beliefs in Supergame $t$ (optimism is defined in the notes to Figure 4). 'Other' refers to the subject's opponent in a given supergame. 'Own' refers to the subject herself. 'Length of Supergame $t$ ' is the number of rounds that Supergame $t$ lasted for, while 'Length of Supergames 1 to 24 ' is the mean over the first 24 supergames. $N$ is in multiples of 390 because four subjects did not complete the demographic questionnaire. Heteroskedasticity-robust standard errors with clustering at the session level are shown in parentheses. ${ }^{* * *},{ }^{* *}$ and ${ }^{*}$ denote significance at the 1 percent, 5 percent and 10 percent levels (two-sided tests). 
Recall from Section 3.1 that 'OptimismRelTruth' measures optimism relative to how often others actually cooperate. Our finding from Table 6 that optimism responds to experience suggests that OptimismRelTruth moves toward zero over the course of the 25 supergames as beliefs about how often others actually cooperate become more accurate. Since subjects learn within their session, in Figure 8 we measure OptimismRelTruth at the session level. Figure 8 confirms that, on average, beliefs do indeed move toward the truth in all three treatments. Confirming our finding from Section 3.1, when the return to joint cooperation is low $(R=$ 32 ), subjects' initial beliefs are too optimistic relative to the truth; however, with experience OptimismRelTruth falls toward zero as this excess optimism declines. When the return to joint cooperation is high $(R=48)$, initial beliefs are slightly too pessimistic, and with experience OptimismRelTruth rises toward zero as this modest excess pessimism disappears on average.
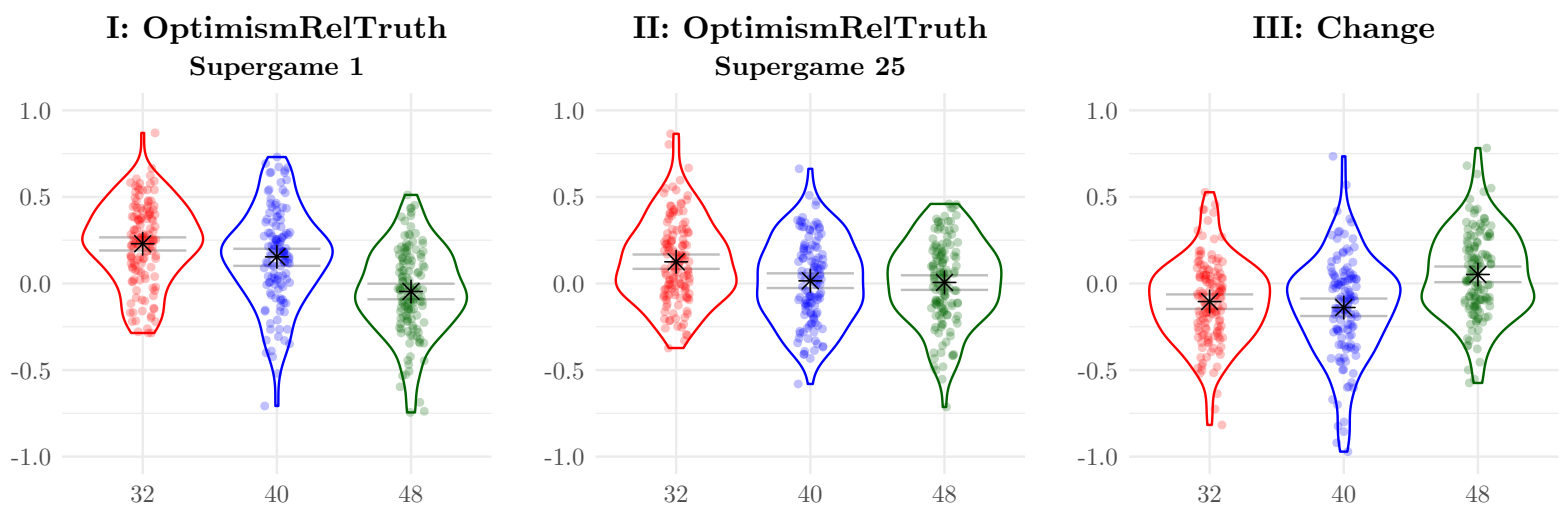

Figure 8: Evolution of OptimismRelTruth at the session level: Violin plots

Notes: 'OptimismRelTruth' is defined as in the notes to Figure 4 for Supergame 1, except that we now use the session-level strategy distribution (again excluding the subject's own choice) instead of the treatment-level distribution. In the violin plots, the unit of observation is an individual subject, stars are means and horizontal bars are 95 percent confidence intervals, calculated using non-parametric bootstrapping.

\subsection{Experimentation and strategy revisions}

In this section we delve deeper into the evolution of behavior by studying the factors that drive experimentation and strategy revisions over the course of the 25 supergames. Figure 9 shows that, on average, subjects tried four of the ten available strategies at least once, with considerable heterogeneity across subjects. Furthermore, 33 percent of the time subjects changed their choice of strategy from one supergame to the next. 


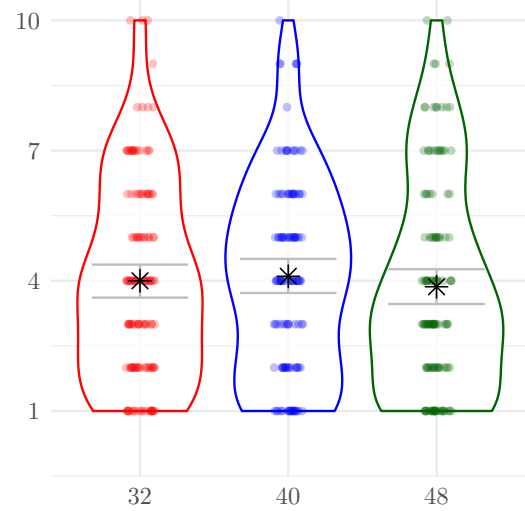

Figure 9: Number of strategies tried: Violin plots

Notes: 'Number of strategies tried' is the number of strategies that the subject chose at least once in the 25 supergames. In the violin plots, the unit of observation is an individual subject, stars are means and horizontal bars are 95 percent confidence intervals, calculated using non-parametric bootstrapping.

To help understand why subjects change their strategy from one supergame to the next, in Table 7 we regress an indicator for changing strategy on the same variables that we analyzed in Panel I of Table 6 when studying learning from experience. To those variables, we add an indicator for good responding to beliefs in the first supergame, which we interpret here as a measure of quality of thinking (Section 3.2.1 introduces our notion of good responding). We also add the quality of the strategy chosen by the subject in the previous supergame, which we measure by how well that strategy performs in expectation given the subject's experience. In particular, 'Quality of Supergame $t-1$ strategy' is proportional to the earnings of the strategy chosen in the previous supergame when it plays against the distribution of strategies chosen by the subject's opponents up to and including the previous supergame (the notes to Table 7 provide the formal definition).

To summarize the main findings in Table 7 , subjects change strategy less frequently: (i) when their opponent cooperated more in the previous supergame; (ii) when the subject exhibits a higher quality of thinking; (iii) when the subject chose a higher quality strategy in the previous supergame; and (iv) when the subject has gained experience by playing more supergames.

In more detail, the third row of Table 7 shows that the likelihood of changing strategy does not depend on the length of the previous supergame. The fourth row shows that the likelihood of changing strategy falls in the cooperation of the whole supergame strategy chosen by the subject's opponent in the previous supergame (we introduced the notion of 'strategy cooperation' in Section 4.2 when discussing the results from Panel I of Table 6). The seventh row shows that subjects who good respond to their beliefs in the first supergame, and so have a higher quality of thinking, are less likely to change strategy from one supergame to the next. The eighth row shows that subjects who chose a higher quality strategy in the previous supergame are less likely to change strategy. In the ninth row the coefficient on the supergame number is negative, and so subjects who have played more supergames tend to change strategy less frequently. ${ }^{64}$ Just as in Panel I of Table 6, these results control for the subject's behavior and

\footnotetext{
${ }^{64}$ Related work also finds that strategy revisions become less frequent over time (Cason and Mui, 2019, across supergames; Romero and Rosokha, 2019a, within supergames; and Dal Bó and Fréchette, 2019, for non-binding strategies). Cason and Mui (2019) also find that subjects who earn more in one supergame are less likely to change strategy from that supergame to the next.
} 
beliefs in the first supergame (fifth and sixth rows).

\begin{tabular}{|c|c|c|c|c|c|c|c|c|}
\hline & (1) & $(2)$ & $(3)$ & (4) & $(5)$ & (6) & (7) & (8) \\
\hline $\mathrm{R} 40$ & $\begin{array}{c}0.014 \\
(0.032)\end{array}$ & $\begin{array}{c}0.036 \\
(0.032)\end{array}$ & $\begin{array}{c}0.014 \\
(0.033)\end{array}$ & $\begin{array}{c}0.009 \\
(0.033)\end{array}$ & $\begin{array}{c}0.019 \\
(0.032)\end{array}$ & $\begin{array}{l}0.057^{*} \\
(0.031)\end{array}$ & $\begin{array}{c}0.014 \\
(0.032)\end{array}$ & $\begin{array}{l}0.057^{*} \\
(0.032)\end{array}$ \\
\hline $\mathrm{R} 48$ & $\begin{array}{l}-0.026 \\
(0.035)\end{array}$ & $\begin{array}{c}0.018 \\
(0.035)\end{array}$ & $\begin{array}{l}-0.028 \\
(0.037)\end{array}$ & $\begin{array}{l}-0.034 \\
(0.034)\end{array}$ & $\begin{array}{l}-0.034 \\
(0.035)\end{array}$ & $\begin{array}{c}0.103^{* *} \\
(0.044)\end{array}$ & $\begin{array}{l}-0.026 \\
(0.035)\end{array}$ & $\begin{array}{c}0.076 \\
(0.046)\end{array}$ \\
\hline Length of Supergame $t-1$ & $\begin{array}{l}-0.000 \\
(0.002)\end{array}$ & & & & & & & $\begin{array}{c}0.000 \\
(0.002)\end{array}$ \\
\hline $\begin{array}{l}\text { Other's strategy coop } \\
\text { in Supergame } t-1\end{array}$ & & $\begin{array}{c}-0.209^{* * *} \\
(0.017)\end{array}$ & & & & & & $\begin{array}{c}-0.176^{* * *} \\
(0.014)\end{array}$ \\
\hline $\begin{array}{l}\text { Own strategy coop } \\
\text { in Supergame } 1\end{array}$ & & & $\begin{array}{c}0.007 \\
(0.038)\end{array}$ & & & & & $\begin{array}{c}0.002 \\
(0.038)\end{array}$ \\
\hline $\begin{array}{l}\text { Own optimism } \\
\text { in Supergame } 1\end{array}$ & & & & $\begin{array}{c}0.056 \\
(0.063)\end{array}$ & & & & $\begin{array}{c}0.079 \\
(0.060)\end{array}$ \\
\hline $\begin{array}{c}\text { Good responder to beliefs } \\
\text { in Supergame } 1\end{array}$ & & & & & $\begin{array}{c}-0.073^{* * *} \\
(0.025)\end{array}$ & & & $\begin{array}{c}-0.067^{* * *} \\
(0.023)\end{array}$ \\
\hline $\begin{array}{l}\text { Quality of Supergame } t-1 \\
\text { strategy }\end{array}$ & & & & & & $\begin{array}{c}-0.323^{* * *} \\
(0.060)\end{array}$ & & $\begin{array}{c}-0.212^{* * *} \\
(0.054)\end{array}$ \\
\hline Supergame number & & & & & & & $\begin{array}{c}-0.005^{* * *} \\
(0.001)\end{array}$ & $\begin{array}{c}-0.005^{* * *} \\
(0.001)\end{array}$ \\
\hline Mean of dependent variable & 0.332 & 0.332 & 0.332 & 0.332 & 0.332 & 0.332 & 0.332 & 0.332 \\
\hline $\mathrm{N}$ & 9360 & 9360 & 9360 & 9360 & 9360 & 9360 & 9360 & 9360 \\
\hline
\end{tabular}

Table 7: Strategy changed from Supergame $t-1$ to Supergame $t$

Notes: Each column reports a linear OLS regression of a binary variable that takes value 1 if the subject changed her strategy from Supergame $t-1$ to Supergame $t$, and taking value 0 if not, controlling for the five personality factors, demographic characteristics and standardized cognitive ability (see Section 2.9), and with $R=32$ as the omitted category. 'Length of Supergame $t-1$ ', 'Other's strategy coop in Supergame $t-1$ ', 'Own strategy coop in Supergame 1' and 'Own optimism in Supergame 1' appear in Panel I of Table 6 (see the table notes for definitions). Good responding is a binary variable defined in the second paragraph of Section 3.2.1. 'Quality of Supergame $t-1$ strategy' is proportional to the expected earnings of the subject's chosen strategy in Supergame $t-1$ playing against a distribution made up of the $t-1$ strategies chosen by the subject's opponents in Supergames 1 to $t-1$; each unit of quality corresponds to earnings of 100 points, and we derive this measure using analytical calculations of payoffs for every possible combination of strategies (see Tables A.4 to A.6 in Web Appendix III). $N$ is in multiples of 390 because four subjects did not complete the demographic questionnaire. Heteroskedasticityrobust standard errors with clustering at the session level are shown in parentheses. ***, ** and ${ }^{*}$ denote significance at the 1 percent, 5 percent and 10 percent levels (two-sided tests).

In Table 8 we study transitions from one strategy category to another (Figure 2 defines the strategy categories). Panel I uses the observations where the subject chose a strategy from the unfriendly category in the previous supergame, and we consider the factors that drive the subject to continue choosing an unfriendly strategy in the next supergame, to change to a provocable strategy, or to change to a lenient strategy. Panel II (III) repeats the exercise, using observations where the subject chose a strategy from the provocable (lenient) category in the previous supergame. The regressions reported in Table 8 include the same independent variables as the regressions reported in Table 7 (to save space we do not report the treatment coefficients).

The first row of Panels I-III of Table 8 show that when the previous supergame was longer, subjects are less likely to stay unfriendly (first column of Panel I), and more likely to stay provocable and lenient (second column of Panel II and third column of Panel III). Furthermore, the increased likelihood of staying provocable comes at the expense of changes from provocable to unfriendly strategies (first and second columns of Panel II). These findings help us to understand 
why previous supergame length has no effect on the likelihood of changing strategy (Table 7), while at the same time increasing cooperation (Table 6).

\begin{tabular}{|c|c|c|c|}
\hline & $\begin{array}{c}(1) \\
\text { Stay } \\
\text { unfriendly }\end{array}$ & $\begin{array}{c}(2) \\
\text { Change to } \\
\text { provocable }\end{array}$ & $\begin{array}{c}(3) \\
\text { Change to } \\
\text { lenient }\end{array}$ \\
\hline Length of Sup. $t-1$ & $\begin{array}{c}-0.006^{* * *} \\
(0.001)\end{array}$ & $\begin{array}{c}0.005^{* * *} \\
(0.002)\end{array}$ & $\begin{array}{l}0.002^{*} \\
(0.001)\end{array}$ \\
\hline $\begin{array}{l}\text { Other's strategy coop } \\
\text { in Sup. } t-1\end{array}$ & $\begin{array}{c}0.068^{* * *} \\
(0.017)\end{array}$ & $\begin{array}{c}-0.025^{*} \\
(0.014)\end{array}$ & $\begin{array}{c}-0.025^{* *} \\
(0.011)\end{array}$ \\
\hline $\begin{array}{l}\text { Own strategy coop } \\
\text { in Sup. } 1\end{array}$ & $\begin{array}{c}-0.155^{* * *} \\
(0.040)\end{array}$ & $\begin{array}{c}0.109^{* * *} \\
(0.026)\end{array}$ & $\begin{array}{l}0.050^{*} \\
(0.027)\end{array}$ \\
\hline $\begin{array}{l}\text { Own optimism } \\
\text { in Sup. } 1\end{array}$ & $\begin{array}{c}-0.161^{* * *} \\
(0.054)\end{array}$ & $\begin{array}{c}0.048 \\
(0.037)\end{array}$ & $\begin{array}{c}0.100^{* * *} \\
(0.027)\end{array}$ \\
\hline $\begin{array}{l}\text { Good responder to } \\
\text { beliefs in Sup. } 1\end{array}$ & $\begin{array}{l}-0.004 \\
(0.022)\end{array}$ & $\begin{array}{l}-0.007 \\
(0.017)\end{array}$ & $\begin{array}{c}0.020 \\
(0.013)\end{array}$ \\
\hline $\begin{array}{l}\text { Quality of Sup. } t-1 \\
\text { strategy }\end{array}$ & $\begin{array}{l}-0.010 \\
(0.084)\end{array}$ & $\begin{array}{l}-0.025 \\
(0.070)\end{array}$ & $\begin{array}{c}0.006 \\
(0.037)\end{array}$ \\
\hline Supergame number & $\begin{array}{c}0.004^{* * * *} \\
(0.001)\end{array}$ & $\begin{array}{c}-0.002^{* *} \\
(0.001)\end{array}$ & $\begin{array}{c}-0.001 * * * \\
(0.000)\end{array}$ \\
\hline Mean of DV & 0.827 & 0.102 & 0.045 \\
\hline $\mathrm{N}$ & 4820 & 4820 & 4820 \\
\hline
\end{tabular}

\begin{tabular}{|c|c|c|c|}
\hline & $\begin{array}{c}(1) \\
\text { Change to } \\
\text { unfriendly }\end{array}$ & $\begin{array}{c}(2) \\
\text { Stay } \\
\text { provocable }\end{array}$ & $\begin{array}{c}(3) \\
\text { Change to } \\
\text { lenient }\end{array}$ \\
\hline Length of Sup. $t-1$ & $\begin{array}{c}-0.009^{* * *} \\
(0.002)\end{array}$ & $\begin{array}{c}0.009^{* * *} \\
(0.003)\end{array}$ & $\begin{array}{l}-0.001 \\
(0.001)\end{array}$ \\
\hline $\begin{array}{l}\text { Other's strategy coop } \\
\text { in Sup. } t-1\end{array}$ & $\begin{array}{c}-0.236^{* * *} \\
(0.031)\end{array}$ & $\begin{array}{c}0.250^{* * *} \\
(0.031)\end{array}$ & $\begin{array}{l}-0.006 \\
(0.013)\end{array}$ \\
\hline $\begin{array}{l}\text { Own strategy coop } \\
\text { in Sup. } 1\end{array}$ & $\begin{array}{c}-0.175^{* * *} \\
(0.040)\end{array}$ & $\begin{array}{c}0.171^{* * *} \\
(0.058)\end{array}$ & $\begin{array}{c}0.023 \\
(0.022)\end{array}$ \\
\hline $\begin{array}{r}\text { Own optimism } \\
\text { in Sup. } 1\end{array}$ & $\begin{array}{c}-0.111^{*} \\
(0.057)\end{array}$ & $\begin{array}{c}0.079 \\
(0.073)\end{array}$ & $\begin{array}{c}0.029 \\
(0.029)\end{array}$ \\
\hline $\begin{array}{l}\text { Good responder to } \\
\text { beliefs in Sup. } 1\end{array}$ & $\begin{array}{l}-0.023 \\
(0.019)\end{array}$ & $\begin{array}{c}0.027 \\
(0.024)\end{array}$ & $\begin{array}{c}0.001 \\
(0.009)\end{array}$ \\
\hline $\begin{array}{l}\text { Quality of Sup. } t-1 \\
\text { strategy }\end{array}$ & $\begin{array}{l}-0.124 \\
(0.076)\end{array}$ & $\begin{array}{l}0.128 \\
(0.087)\end{array}$ & $\begin{array}{l}-0.020 \\
(0.026)\end{array}$ \\
\hline Supergame number & $\begin{array}{c}-0.003^{* * *} \\
(0.001)\end{array}$ & $\begin{array}{c}0.005^{* * *} \\
(0.001)\end{array}$ & $\begin{array}{c}-0.002^{* * *} \\
(0.001)\end{array}$ \\
\hline Mean of DV & 0.185 & 0.746 & 0.052 \\
\hline $\mathrm{N}$ & 2676 & 2676 & 2676 \\
\hline
\end{tabular}

\begin{tabular}{|c|c|c|c|}
\hline & $\begin{array}{c}\text { (1) } \\
\text { Change to } \\
\text { unfriendly }\end{array}$ & $\begin{array}{c}(2) \\
\text { Change to } \\
\text { provocable }\end{array}$ & $\begin{array}{c}(3) \\
\text { Stay } \\
\text { lenient }\end{array}$ \\
\hline Length of Sup. $t-1$ & $\begin{array}{l}-0.002 \\
(0.003)\end{array}$ & $\begin{array}{l}-0.003 \\
(0.002)\end{array}$ & $\begin{array}{l}0.006^{*} \\
(0.003)\end{array}$ \\
\hline $\begin{array}{l}\text { Other's strategy coop } \\
\text { in Sup. } t-1\end{array}$ & $\begin{array}{c}-0.202^{* * *} \\
(0.046)\end{array}$ & $\begin{array}{l}-0.047 \\
(0.032)\end{array}$ & $\begin{array}{c}0.260^{* * *} \\
(0.042)\end{array}$ \\
\hline $\begin{array}{l}\text { Own strategy coop } \\
\text { in Sup. } 1\end{array}$ & $\begin{array}{c}-0.190^{* * *} \\
(0.049)\end{array}$ & $\begin{array}{l}-0.047 \\
(0.049)\end{array}$ & $\begin{array}{c}0.250^{* * *} \\
(0.076)\end{array}$ \\
\hline $\begin{array}{l}\text { Own optimism } \\
\text { in Sup. } 1\end{array}$ & $\begin{array}{l}-0.175 \\
(0.114)\end{array}$ & $\begin{array}{l}-0.004 \\
(0.092)\end{array}$ & $\begin{array}{c}0.183 \\
(0.151)\end{array}$ \\
\hline $\begin{array}{l}\text { Good responder to } \\
\text { beliefs in Sup. } 1\end{array}$ & $\begin{array}{l}-0.034 \\
(0.027)\end{array}$ & $\begin{array}{c}0.007 \\
(0.022)\end{array}$ & $\begin{array}{c}0.029 \\
(0.035)\end{array}$ \\
\hline $\begin{array}{l}\text { Quality of Sup. } t-1 \\
\text { strategy }\end{array}$ & $\begin{array}{l}-0.010 \\
(0.063)\end{array}$ & $\begin{array}{c}-0.117^{* *} \\
(0.048)\end{array}$ & $\begin{array}{c}0.135 \\
(0.084)\end{array}$ \\
\hline Supergame number & $\begin{array}{c}-0.003^{*} \\
(0.001)\end{array}$ & $\begin{array}{c}-0.004^{* * *} \\
(0.001)\end{array}$ & $\begin{array}{c}0.006^{* * *} \\
(0.002)\end{array}$ \\
\hline Mean of DV & 0.167 & 0.090 & 0.720 \\
\hline $\mathrm{N}$ & 1495 & 1495 & 1495 \\
\hline
\end{tabular}

Table 8: Strategy category transitions from Supergame $t-1$ to Supergame $t$

Notes: Panel I uses all observations from Supergames 1 to 24 where the subject chose a strategy from the unfriendly category (Figure 2 defines the strategy categories). The first column of Panel I reports a linear OLS regression of a binary variable that takes value 1 if the subject continued to choose a strategy from the unfriendly category in the next supergame, and taking value 0 otherwise; note that the variable takes value 1 even if the subject changed strategy within the unfriendly category. The second (third) column of Panel I reports a linear OLS regression of a binary variable that takes value 1 if the subject changed her strategy to one from the provocable (lenient) category in the next supergame, and taking value 0 otherwise. Panels II and III are constructed similarly. Transition probabilities do not sum to one because subjects can change to RAND, which is not included in the unfriendly, provocable or lenient categories. All regressions control for the five personality factors, demographic characteristics and standardized cognitive ability (see Section 2.9), and the treatment (treatment coefficients are omitted here to save space). The independent variables are the same as those in Table 7; see the notes to that table. Heteroskedasticity-robust standard errors with clustering at the session level are shown in parentheses. $* * *, * *$ and $*$ denote significance at the 1 percent, 5 percent and 10 percent levels (two-sided tests). 
The second row of Panels I-III of Table 8 show that when a subject's opponent cooperated more in the previous supergame, the subject is more likely to stay within the unfriendly, provocable and lenient categories (first column of Panel I, second column of Panel II, and third column of Panel III). Even though subjects are somewhat more likely to stay unfriendly, they are also much less likely to change from provocable or lenient strategies to unfriendly ones (first columns of Panels II and III). These findings shed light on the mechanism by which the opponent's cooperation in the previous supergame reduces the likelihood of changing strategy (Table 7), while at the same time increasing the subject's own cooperation (Table 6).

Although the effects are not individually statistically significant, the fifth and six rows of Panels I-III of Table 8 show that quality of thinking and the quality of the strategy chosen in the previous supergame reduce the likelihood of staying unfriendly (first column of Panel I), but increase the likelihood of staying provocable and lenient by more (second column of Panel II and third column of Panel III). These findings help to explain how quality of thinking and the quality of the strategy chosen in the previous supergame reduce the likelihood of changing strategy (Table 7). Finally, the seventh row shows that as subjects gain experience by playing more supergames, they are more likely to stay unfriendly, provocable and lenient; thus, the finding that subjects who have played more supergames change strategy less frequently (Table 7 ) holds at the level of all three strategy categories.

\section{Personality}

In this section we consider the relationship between personality and behavior and beliefs. To do so, we revisit the regressions reported in Table 6 of Section 4.2, which we used to study the effect of experience on cooperation at the level of the whole supergame strategy (strategy cooperation) and on optimism (recall from from Section 3.1 that optimism measures how often a subject expects others to cooperate). Those regressions controlled for personality and demographics, and so we can study the relationship between personality and strategy cooperation and optimism by examining the coefficients on personality from those regressions. Columns 1 and 3 of Table 9 report the coefficients on personality from the regressions reported in Column 5 of Panels I and II of Table 6, which control for experience and for initial behavior and beliefs in Supergame 1, while Column 2 replicates Column 1 using only the last five supergames.

Column 1 of Table 9 shows that trust predicts cooperation: a one-standard-deviation increase in trust is associated with a two-percentage point increase in strategy cooperation over the course of the experiment, with the effect statistically significant at the five-percent level. Column 2 shows that the relationship between trust and cooperation persists in the last five supergames. Importantly, Column 3 shows that trust also positively predicts optimism in the final supergame, which suggests that the relationship between trust and cooperation is partly mediated by beliefs about how much others will cooperate (recall from footnote 63 that optimism in the final supergame strongly predicts strategy cooperation in the final supergame). ${ }^{65}$ Table A.10 in Web Appendix III shows that the effects of trust on cooperation and optimism are

\footnotetext{
${ }^{65}$ Column 3 also shows an effect of kindness on optimism, but kindness does not appear to have a robust effect on behavior and beliefs: there is no corresponding effect of kindness on cooperation in Columns 1 and 2 of Table 9; and the effect on optimism is smaller and not statistically significant at the ten-percent level when we do not control for experience or for initial behavior and beliefs (see Table A.10 in Web Appendix III).
} 
robust when we do not control for experience or for initial behavior and beliefs in Supergame $1 .^{66}$

\begin{tabular}{|c|c|c|c|}
\hline & $\begin{array}{l}(1) \\
\text { Strategy cooperation } \\
\text { (Supergames 2-25) }\end{array}$ & $\begin{array}{c}(2) \\
\text { Strategy cooperation } \\
\text { (Supergames 21-25) }\end{array}$ & $\begin{array}{c}(3) \\
\text { Optimism } \\
\text { (Supergame 25) }\end{array}$ \\
\hline Anxiety & $\begin{array}{l}-0.004 \\
(0.009)\end{array}$ & $\begin{array}{l}-0.022 \\
(0.014)\end{array}$ & $\begin{array}{c}0.003 \\
(0.010)\end{array}$ \\
\hline Cautiousness & $\begin{array}{l}-0.009 \\
(0.008)\end{array}$ & $\begin{array}{l}-0.010 \\
(0.012)\end{array}$ & $\begin{array}{l}-0.008 \\
(0.012)\end{array}$ \\
\hline Kindness & $\begin{array}{l}0.008 \\
(0.011)\end{array}$ & $\begin{array}{c}0.001 \\
(0.015)\end{array}$ & $\begin{array}{l}0.017^{*} \\
(0.008)\end{array}$ \\
\hline Manipulativeness & $\begin{array}{c}0.004 \\
(0.010)\end{array}$ & $\begin{array}{c}0.006 \\
(0.013)\end{array}$ & $\begin{array}{l}-0.003 \\
(0.011)\end{array}$ \\
\hline Trust & $\begin{array}{c}0.021^{* *} \\
(0.009)\end{array}$ & $\begin{array}{c}0.022^{* *} \\
(0.009)\end{array}$ & $\begin{array}{c}0.017^{* *} \\
(0.007)\end{array}$ \\
\hline Mean of dependent variable & 0.467 & 0.461 & 0.430 \\
\hline $\mathrm{N}$ & 9360 & 1950 & 390 \\
\hline Control for beliefs in Sup. 1 & Yes & Yes & Yes \\
\hline Control for behavior in Sup. 1 & Yes & Yes & Yes \\
\hline Controls for experience & Yes & Yes & Yes \\
\hline
\end{tabular}

Table 9: Effect of personality on behavior and beliefs

Notes: The regression reported in Column 1 (Column 3) is exactly the same as the one reported in Column 5 of Panel I (Column 5 of Panel II) of Table 6 (that table and its notes describe all the independent variables); here we report only the coefficients on the five personality factors (see Section 2.9). The regression reported in Column 2 is the same as that reported in Column 1, except that it uses observations of the dependent variable only from the last five supergames. 'Strategy cooperation' is defined in the notes to Table 6 and 'optimism' is defined in the notes to Figure 4.

Interestingly, we find no evidence that trust predicts behavior or beliefs in the first supergame, and so our data suggest that trusting subjects learn to cooperate. When we regress strategy cooperation and optimism in Supergame 1 on our personality factors, the coefficients on trust are small and far from statistical significance (see Table A.11 in Web Appendix III).

To understand how trusting subjects learn from experience, we study how trust interacts with good and bad news to drive cooperation. We say that a subject received 'good news' when her opponent's strategy cooperation in the previous supergame was above the treatment-level median, and we say that she received 'bad news' when her opponent's strategy cooperation in the previous supergame was below the median. Recall that Column 5 of Panel I of Table 6 reports the effect of the opponent's strategy cooperation in the previous supergame on a subject's own strategy cooperation; Figure 10 shows that this effect depends on whether the news was good or bad and on the subject's level of trust (the notes to the figure explain how the estimates come from a piece-wise linear spline regression). In particular, Figure 10 shows that subjects high in trust respond more strongly to their opponent's cooperation in the previous supergame when the news was good than when the news was bad; this tendency to amplify good news and discount bad news tends to drive cooperation up. By contrast, subjects low in trust respond more strongly to their opponent's cooperation in the previous supergame when the news was

\footnotetext{
${ }^{66}$ The effect sizes are similar, the coefficients on trust in Columns 2 and 3 remain significant at the five-percent level, while the coefficient on trust in Column 1 is significant at the ten-percent level $(p=0.0503)$.
} 
bad than when the news was good; this tendency to discount good news and amplify bad news tends to drive cooperation down.

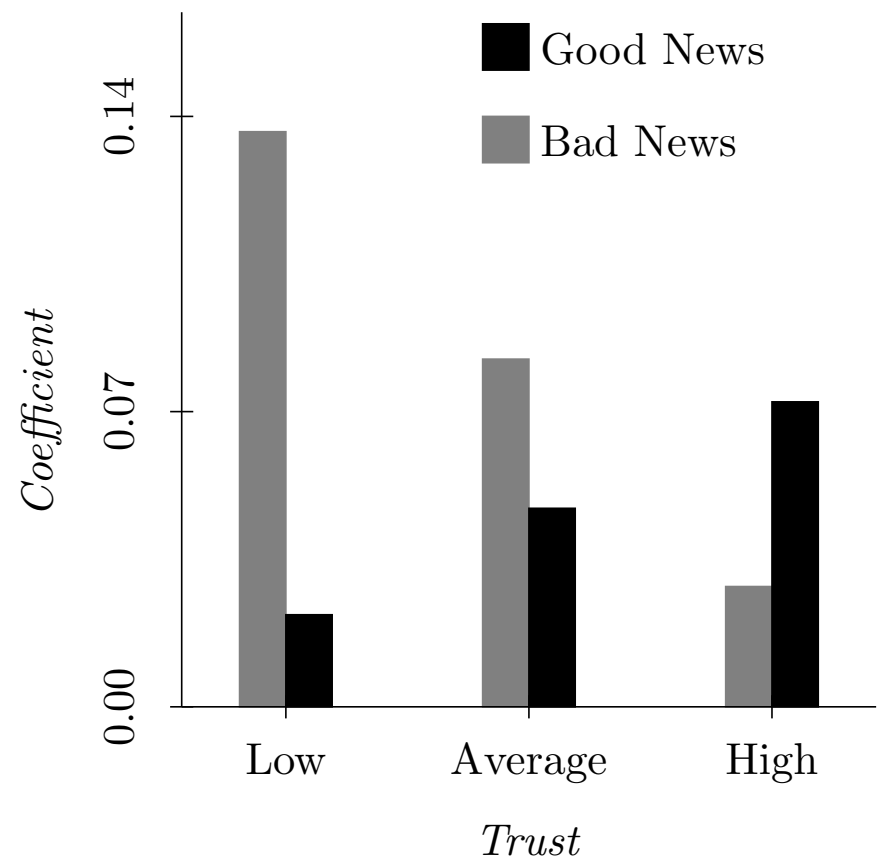

Figure 10: Effect of opponent's strategy cooperation in Supergame $t-1$ on strategy cooperation in Supergame $t$

Notes: We start with the regression reported in Column 5 of Panel I of Table 6 from Section 4.2, which regresses 'Strategy coop in Supergame $t$ ' on 'Other's strategy coop in Supergame $t-1$ ' and other variables, controlling for the five personality factors, demographic characteristics and standardized cognitive ability (see Section 2.9), and the supergame number; the notes to Table 6 define relevant terms. Let $x_{R}$ for $R \in\{32,40,48\}$ be the treatment-specific median of 'Other's strategy coop in Supergame $t-1$ ' across all subjects in that treatment and $t>1$. We say that a subject receives 'good news' ('bad news') when 'Other's strategy coop in Supergame $t-1$ ' $\geq(<) x_{R}$. We run a piece-wise linear spline regression by including $\max \left\{0\right.$, ('Other's strategy coop in Supergame $t-1$ ' $\left.\left.-x_{R}\right)\right\}$ in the regression reported in Column 5 of Panel I of Table 6; furthermore, we interact trust with 'Other's strategy coop in Supergame $t-1$ ' and with $\max \left\{0,\left(\right.\right.$ 'Other's strategy coop in Supergame $t-1$ ' $\left.\left.-x_{R}\right)\right\}$. Both interactions are statistically significant at the five-percent level; this can be seen from Column 3 of Table A.12 in Web Appendix III, which reports coefficients from the spline regression and labels $\max \left\{0\right.$, ('Other's strategy coop in Supergame $t-1$ ' $-x_{R}$ ) $\}$ as ('Other's strategy coop in Sup. $t-1$ ' $\left.-x_{R}\right)+$ for conciseness. Recalling that the trust factor is standardized by construction, we define high (average) (low) trust as trust $=1(=0)(=-1)$, and we then calculate the coefficients in the figure based on the coefficients from Column 3 of Table A.12 in Web Appendix III. For example, when trust $=1$, the coefficient for bad news is $0.082+(1 \times-0.054)=0.028$ and the coefficient for good news is $(0.082+(1 \times-0.054))+(-0.035+(1 \times 0.079))=0.072$. 


\section{Conclusion}

By eliciting beliefs over supergame strategies in the indefinitely repeated prisoner's dilemma, in this paper we have advanced our understanding of how people form and use beliefs in repeated interactions that last for an uncertain length of time. Our analysis suggests that beliefs matter. For example, people form initial beliefs that match actual behavior quite well on average, beliefs are correlated with behavior, initial beliefs have a persistent effect on cooperation, and beliefs change with experience and become more accurate over time. Future research should build on our findings by, for example, establishing whether it is feasible to elicit beliefs over supergame strategies using a larger strategy space, studying how the role of beliefs interacts with the continuation probability, and eliciting second-order beliefs alongside the first-order beliefs that we analyze here. Our methodology that uses elicited beliefs over supergame strategies to help identify level- $k$ types could also be applied to other types of repeated games to understand better the role of bounded rationality in driving behavior in settings that involve repeated interactions.

Even though we selected directed measures of personality that we judged most likely to help explain cooperation in the indefinitely repeated prisoner's dilemma, only trust predicts behavior and beliefs in our data. As we discuss in the introduction, the role of trust that we uncover is consistent with a strategic motivation for cooperation mediated by beliefs. Our results thus suggest that personal traits only predict coordination on cooperative equilibria when the personal trait interacts with strategic motives. Indeed, Proto et al. $(2019,2020)$ find that cognitive ability predicts cooperation in the indefinitely repeated prisoner's dilemma because more intelligent subjects make fewer errors when implementing strategies, and Dal Bó and Fréchette (2018) conclude from their literature survey that strategic motives predominate in explaining cooperation in indefinitely repeated games when cooperation can be sustained as an equilibrium. Future research could further our understanding of the role of trust by matching trusting subjects together or by designing mechanisms by which people high in trust can identify similar others and self-select to play repeated games together. 


\section{References}

Acedo-Carmona, C. and Gomila, A. (2014). Personal trust increases cooperation beyond general trust. PloS ONE, 9(8): e105559

Aghion, P., Algan, Y., Cahuc, P., and Shleifer, A. (2010). Regulation and distrust. Quarterly Journal of Economics, 125(3): 1015-1049

Ahn, T.K., Ostrom, E., Schmidt, D., and Walker, J. (2003). Trust in two-person games: Game structures and linkages. In E. Ostrom and J. Walker, editors, Trust and Reciprocity: Interdisciplinary Lessons from Experimental Research, 323-51. Russell Sage

Al-Ubaydli, O., Jones, G., and Weel, J. (2016). Average player traits as predictors of cooperation in a repeated prisoner's dilemma. Journal of Behavioral and Experimental Economics, 64: $50-60$

Alempaki, D., Colman, A., Kölle, F., Loomes, G., and Pulford, B.D. (2019). Investigating the failure to best respond in experimental games. CEDEX Discussion Paper 2019-13

Algan, Y. and Cahuc, P. (2010). Inherited trust and growth. American Economic Review, 100(5): 2060-92

Anderson, L.R., Mellor, J.M., and Milyo, J. (2004). Social capital and contributions in a public-goods experiment. American Economic Review: Papers 8 Proceedings, 94(2): 373-376

Aoyagi, M., Bhaskar, V., and Fréchette, G.R. (2019). The impact of monitoring in infinitely repeated games: Perfect, public, and private. American Economic Journal: Microeconomics, 11(1): 1-43

Aoyagi, M., Fréchette, G.R., and Yuksel, S. (2020). Beliefs in repeated games. Mimeo, NYU (dated 07/09/2020)

Axelrod, R. (1980). Effective choice in the prisoner's dilemma. Journal of Conflict Resolution, 24(1): $3-25$

Bigoni, M., Casari, M., Skrzypacz, A., and Spagnolo, G. (2015). Time horizon and cooperation in continuous time. Econometrica, 83(2): 587-616

Blanco, M., Engelmann, D., Koch, A.K., and Normann, H.T. (2010). Belief elicitation in experiments: is there a hedging problem? Experimental Economics, 13(4): 412-438

Blonski, M., Ockenfels, P., and Spagnolo, G. (2011). Equilibrium selection in the repeated prisoner's dilemma: Axiomatic approach and experimental evidence. American Economic Journal: Microeconomics, 3(3): 164-92

Bodenhofer, U., Kothmeier, A., and Hochreiter, S. (2011). APCluster: an R package for affinity propagation clustering. Bioinformatics, 27(17): 2463-2464

Brandts, J. and Charness, G. (2011). The strategy versus the direct-response method: a first survey of experimental comparisons. Experimental Economics, 14(3): 375-398

Bruttel, L. and Kamecke, U. (2012). Infinity in the lab. How do people play repeated games? Theory and Decision, 72(2): 205-219

Burks, S., Carpenter, J., Goette, L., and Rustichini, A. (2009). Cognitive skills affect economic preferences, strategic behavior, and job attachment. Proceedings of the National Academy of Sciences, 106(19): 7745-7750

Capraro, V., Smyth, C., Mylona, K., and Niblo, G.A. (2014). Benevolent characteristics promote cooperative behaviour among humans. PLoS ONE, 9(8): e102881

Carpenter, P., Just, M.A., and Shell, P. (1990). What one intelligence test measures: A theoretical account of the processing in the Raven Progressive Matrices test. Psychological Review, 97(3): 404-413 
Cason, T.N. and Mui, V.L. (2019). Individual versus group choices of repeated game strategies: A strategy method approach. Games and Economic Behavior, 114: 128-145

Castagnetti, A. and Proto, E. (2020). Anger and strategic behavior: A level- $k$ analysis. Mimeo, University of Glasgow (dated 05/21/2020)

Charness, G., Rigotti, L., and Rustichini, A. (2016). Social surplus determines cooperation rates in the one-shot prisoner's dilemma. Games and Economic Behavior, 100: 113-124

Charness, G., Rustichini, A., and Van de Ven, J. (2018). Self-confidence and strategic behavior. Experimental Economics, 21(1): 72-98

Chaudhuri, A., Sopher, B., and Strand, P. (2002). Cooperation in social dilemmas, trust and reciprocity. Journal of Economic Psychology, 23(2): 231-249

Chen, D.L., Schonger, M., and Wickens, C. (2016). oTree-An open-source platform for laboratory, online, and field experiments. Journal of Behavioral and Experimental Finance, 9: $88-97$

Condon, D.M. and Revelle, W. (2014). The International Cognitive Ability Resource: Development and initial validation of a public-domain measure. Intelligence, 43: 52-64

Costa-Gomes, M., Crawford, V.P., and Broseta, B. (2001). Cognition and behavior in normal-form games: An experimental study. Econometrica, 69(5): 1193-1235

Costa-Gomes, M.A. and Weizsäcker, G. (2008). Stated beliefs and play in normal-form games. Review of Economic Studies, 75(3): 729-762

Crawford, V.P., Costa-Gomes, M.A., and Iriberri, N. (2013). Structural models of nonequilibrium strategic thinking: Theory, evidence, and applications. Journal of Economic Literature, 51(1): 5-62

Croson, R.T. (2000). Thinking like a game theorist: factors affecting the frequency of equilibrium play. Journal of Economic Behavior \& Organization, 41(3): 299-314

Dal Bó, P. (2005). Cooperation under the shadow of the future: Experimental evidence from infinitely repeated games. American Economic Review, 95(5): 1591-1604

Dal Bó, P. and Fréchette, G.R. (2011). The evolution of cooperation in infinitely repeated games: Experimental evidence. American Economic Review, 101(1): 411-29

Dal Bó, P. and Fréchette, G.R. (2018). On the determinants of cooperation in infinitely repeated games: A survey. Journal of Economic Literature, 56(1): 60-114

Dal Bó, P. and Fréchette, G.R. (2019). Strategy choice in the infinitely repeated prisoner's dilemma. American Economic Review, 109(11): 3929-52

Danz, D.N., Fehr, D., and Kübler, D. (2012). Information and beliefs in a repeated normalform game. Experimental Economics, 15(4): 622-640

Davis, D., Ivanov, A., and Korenok, O. (2016). Individual characteristics and behavior in repeated games: An experimental study. Experimental Economics, 19(1): 67-99

DeYoung, C.G., Hirsh, J.B., Shane, M.S., Papademetris, X., Rajeevan, N., and Gray, J.R. (2010). Testing predictions from personality neuroscience: Brain structure and the Big Five. Psychological Science, 21(6): 820-828

Dreber, A., Fudenberg, D., and Rand, D.G. (2014). Who cooperates in repeated games: The role of altruism, inequity aversion, and demographics. Journal of Economic Behavior \& Organization, 98: 41-55

Duffy, J. and Fehr, D. (2018). Equilibrium selection in similar repeated games: experimental evidence on the role of precedents. Experimental Economics, 21(3): 573-600 
Duffy, J. and Ochs, J. (2009). Cooperative behavior and the frequency of social interaction. Games and Economic Behavior, 66(2): 785-812

Emonds, G., Declerck, C.H., Boone, C., Seurinck, R., and Achten, R. (2014). Establishing cooperation in a mixed-motive social dilemma. an fMRI study investigating the role of social value orientation and dispositional trust. Social Neuroscience, 9(1): 10-22

Engel, C. and Zhurakhovska, L. (2016). When is the risk of cooperation worth taking? The prisoner's dilemma as a game of multiple motives. Applied Economics Letters, 23(16): $1157-1161$

Fe, E., Gill, D., and Prowse, V. (2019). Cognitive skills, strategic sophistication, and life outcomes. CAGE Working Paper 448

Frey, B.J. and Dueck, D. (2007). Clustering by passing messages between data points. Science, 315(5814): $972-976$

Fudenberg, D., Rand, D.G., and Dreber, A. (2012). Slow to anger and fast to forgive: Cooperation in an uncertain world. American Economic Review, 102(2): 720-49

Gächter, S., Herrmann, B., and Thöni, C. (2004). Trust, voluntary cooperation, and socioeconomic background: survey and experimental evidence. Journal of Economic Behavior 83 Organization, 55(4): 505-531

Gee, L.K. and Schreck, M.J. (2018). Do beliefs about peers matter for donation matching? Experiments in the field and laboratory. Games and Economic Behavior, 107: 282-297

Gill, D. and Prowse, V. (2012). A structural analysis of disappointment aversion in a real effort competition. American Economic Review, 102(1): 469-503

Gill, D. and Prowse, V. (2016). Cognitive ability, character skills, and learning to play equilibrium: A level- $k$ analysis. Journal of Political Economy, 126(4): 1619-1676

Goldberg, L.R. (1999). A broad-bandwidth, public domain, personality inventory measuring the lower-level facets of several five-factor models. In I. Mervielde, I. Deary, F. De Fruyt, and F. Ostendorf, editors, Personality Psychology in Europe, volume 7(1), 7-28. Tilburg University Press

Greiner, B. (2015). Subject pool recruitment procedures: organizing experiments with ORSEE. Journal of the Economic Science Association, 1(1): 114-125

Haesevoets, T., Reinders Folmer, C., Bostyn, D.H., and Van Hiel, A. (2018). Behavioural consistency within the prisoner's dilemma game: The role of personality and situation. European Journal of Personality, 32(4): 405-426

Haesevoets, T., Reinders Folmer, C., and Van Hiel, A. (2015). Cooperation in mixedmotive games: The role of individual differences in selfish and social orientation. European Journal of Personality, 29(4): 445-458

Harrison, G.W., Martínez-Correa, J., Swarthout, J.T., and Ulm, E.R. (2017). Scoring rules for subjective probability distributions. Journal of Economic Behavior \& Organization, 134: $430-448$

Heuer, L. and Orland, A. (2019). Cooperation in the Prisoner's Dilemma: an experimental comparison between pure and mixed strategies. Royal Society Open Science, 6: 182142

Hyndman, K., Ozbay, E.Y., Schotter, A., and Ehrblatt, W.Z. (2012). Convergence: An experimental study of teaching and learning in repeated games. Journal of the European Economic Association, 10(3): 573-604

John, O.P., Naumann, L.P., and Soto, C.J. (2008). Paradigm shift to the integrative Big Five trait taxonomy. Handbook of Personality: Theory and Research, 3(2): 114-158 
Johnson, J.A. (2014). Measuring thirty facets of the Five Factor Model with a 120-item public domain inventory: Development of the IPIP-NEO-120. Journal of Research in Personality, 51: $78-89$

Kagel, J. and McGee, P. (2014). Personality and cooperation in finitely repeated prisoner's dilemma games. Economics Letters, 124(2): 274-277

Kagel, J.H. and McGee, P. (2016). Team versus individual play in finitely repeated prisoner dilemma games. American Economic Journal: Microeconomics, 8(2): 253-76

Kaiser, H.F. (1960). The application of electronic computers to factor analysis. Educational and Psychological Measurement, 20(1): 141-151

Li, S.X. and Liu, T.X. (2017). Group identity and cooperation in infinitely repeated games. Mimeo, Texas A\&M (dated 01/15/2017)

Lopez-de Silanes, F., La Porta, R., Shleifer, A., and Vishny, R. (1997). Trust in large organizations. American Economic Review: Papers 83 Proceedings, 87(2): 333-338

Luo, L., Arizmendi, C., and Gates, K.M. (2019). Exploratory factor analysis (EFA) programs in R. Structural Equation Modeling: A Multidisciplinary Journal, 26(5): 819-826

McGrath, R. (2017). The VIA assessment suite for adults: Development and initial evaluation. Technical Report, VIA Institute on Character

Messé, L.A. and Sivacek, J.M. (1979). Predictions of others' responses in a mixed-motive game: Self-justification or false consensus? Journal of Personality and Social Psychology, 37(4): $602-607$

Miettinen, T. and Suetens, S. (2008). Communication and guilt in a prisoner's dilemma. Journal of Conflict Resolution, 52(6): 945-960

Mulder, L.B., Van Dijk, E., De Cremer, D., and Wilke, H.A. (2006). Undermining trust and cooperation: The paradox of sanctioning systems in social dilemmas. Journal of Experimental Social Psychology, 42(2): 147-162

Nagel, R. (1995). Unraveling in guessing games: An experimental study. American Economic Review, 85(5): 1313-1326

Parks, C.D., Henager, R.F., and Scamahorn, S.D. (1996). Trust and reactions to messages of intent in social dilemmas. Journal of Conflict Resolution, 40(1): 134-151

Peeters, R. and Vorsatz, M. (2018). Simple guilt and cooperation. University of Otago Economics Discussion Paper 1801

Peterson, C. and Seligman, M.E. (2004). Character Strengths and Virtues: A Handbook and Classification. Oxford University Press

Peysakhovich, A., Nowak, M.A., and Rand, D.G. (2014). Humans display a 'cooperative phenotype' that is domain general and temporally stable. Nature Communications, 5(1): 1-8

Polonio, L., Di Guida, S., and Coricelli, G. (2015). Strategic sophistication and attention in games: An eye-tracking study. Games and Economic Behavior, 94: 80-96

Proto, E. and Rustichini, A. (2014). Cooperation and personality. Warwick Economic Research Paper 1045

Proto, E., Rustichini, A., and Sofianos, A. (2019). Intelligence, personality, and gains from cooperation in repeated interactions. Journal of Political Economy, 127(3): 1351-1390

Proto, E., Rustichini, A., and Sofianos, A. (2020). Intelligence, errors and strategic choices in the repeated prisoners' dilemma. IZA Discussion Paper 12925 
Raven, J., Raven, J.C., and Court, J.H. (2000). Manual for Raven's Progressive Matrices and Vocabulary Scales. San Antonio: Pearson

Ridinger, G. and McBride, M. (2017). Theory-of-mind ability and cooperation. Mimeo, UC Irvine (dated 09/2017)

Romero, J. and Rosokha, Y. (2018). Constructing strategies in the indefinitely repeated prisoner's dilemma game. European Economic Review, 104: 185-219

Romero, J. and Rosokha, Y. (2019a). The evolution of cooperation: The role of costly strategy adjustments. American Economic Journal: Microeconomics, 11(1): 299-328

Romero, J. and Rosokha, Y. (2019b). Mixed strategies in the indefinitely repeated prisoner's dilemma. Mimeo, Purdue University

Sato, K. (1988). Trust and group size in a social dilemma. Japanese Psychological Research, 30(2): 88-93

Sato, K. (1989). Trust and feedback in a social dilemma. Japanese Journal of Experimental Social Psychology, 29(2): 123-128

Schlag, K.H. and van der Weele, J.J. (2013). Eliciting probabilities, means, medians, variances and covariances without assuming risk neutrality. Theoretical Economics Letters, $3(1): 38-42$

Schlag, K.H., Tremewan, J., and Van der Weele, J.J. (2015). A penny for your thoughts: A survey of methods for eliciting beliefs. Experimental Economics, 18(3): 457-490

Schotter, A. and Trevino, I. (2014). Belief elicitation in the laboratory. Annual Review of Economics, 6(1): 103-128

Selten, R. (1998). Axiomatic characterization of the quadratic scoring rule. Experimental Economics, 1(1): 43-61

Simms, L.J., Goldberg, L.R., Roberts, J.E., Watson, D., Welte, J., and Rotterman, J.H. (2011). Computerized adaptive assessment of personality disorder: Introducing the CAT-PD project. Journal of Personality Assessment, 93(4): 380-389

Stahl, D. and Wilson, P. (1995). On players' models of other players: Theory and experimental evidence. Games and Economic Behavior, 10(1): 218-254

Stewart, N., Gächter, S., Noguchi, T., and Mullett, T.L. (2016). Eye movements in strategic choice. Journal of Behavioral Decision Making, 29(2-3): 137-156

Sutter, M. and Untertrifaller, A. (2020). Children's heterogeneity in cooperation and parental background: An experimental study. Journal of Economic Behavior 8 Organization, 171: 286-296

Terracol, A. and Vaksmann, J. (2009). Dumbing down rational players: Learning and teaching in an experimental game. Journal of Economic Behavior $\mathscr{E}$ Organization, 70(1-2): $54-71$

Thöni, C., Tyran, J.R., and Wengström, E. (2012). Microfoundations of social capital. Journal of Public Economics, 96(7-8): 635-643

Wright, A.G. and Simms, L.J. (2014). On the structure of personality disorder traits: Conjoint analyses of the CAT-PD, PID-5, and NEO-PI-3 trait models. Personality Disorders: Theory, Research, and Treatment, 5(1): 43-54

Zhang, D., Lin, Y., Jing, Y., Feng, C., and Gu, R. (2019). The dynamics of belief updating in human cooperation: Findings from inter-brain ERP hyperscanning. NeuroImage, 198: 1-12 


\title{
Web Appendix
}

\author{
(Intended for Online Publication)
}




\section{Web Appendix I}

Screenshots from the experiment 


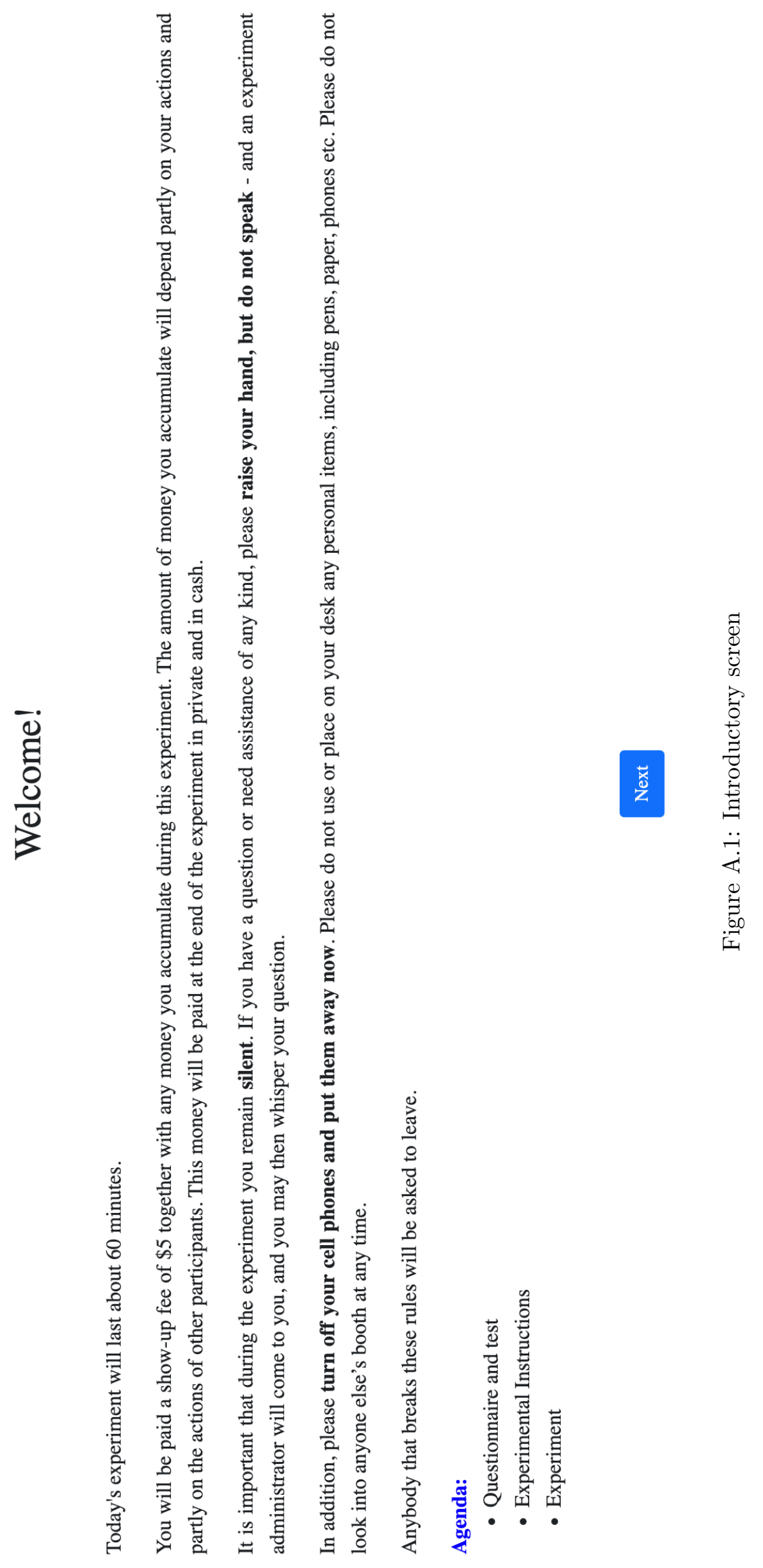

Web Appendix I, p. 2 

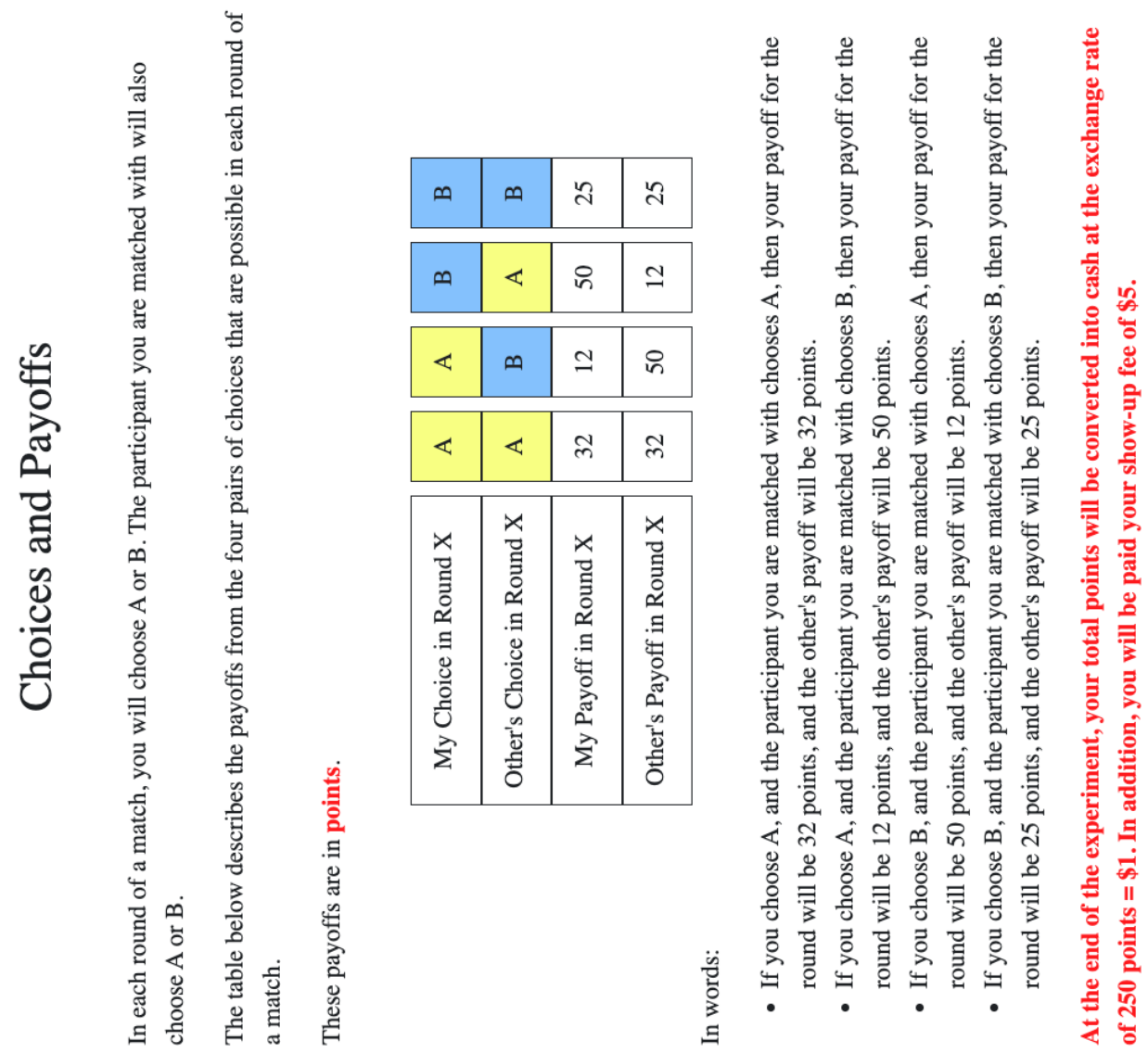

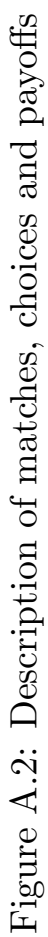

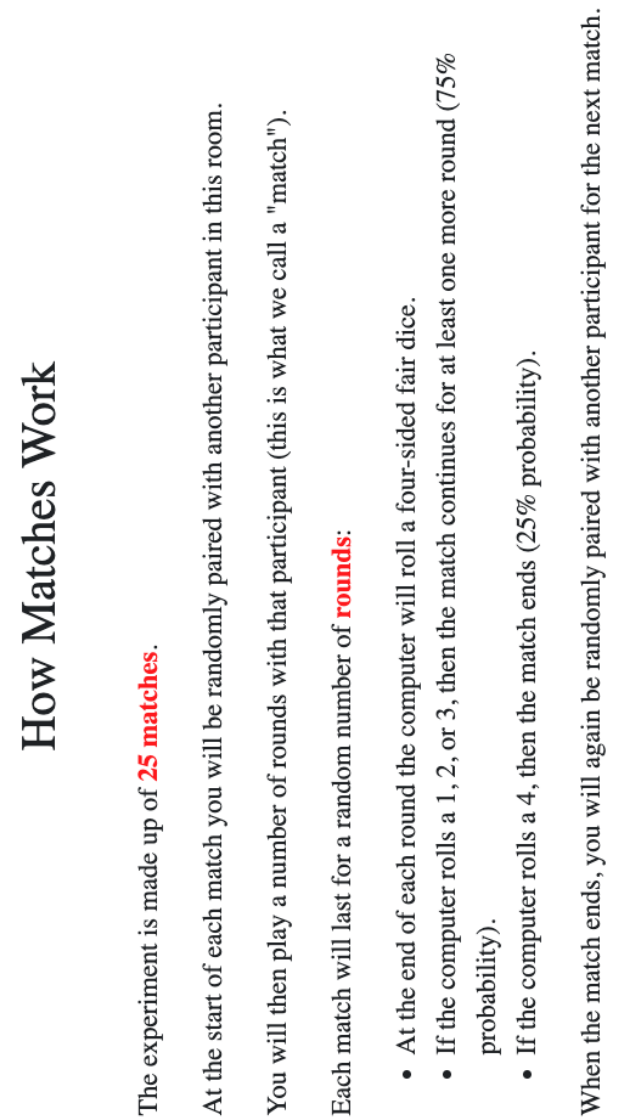

है

๑ m

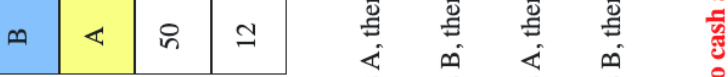

\begin{tabular}{|c|c|c|c|}
\hline$\varangle$ & $\infty$ & $\simeq$ & in \\
\hline$\varangle$ & $\varangle$ & లె & లె \\
\hline 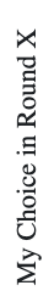 & 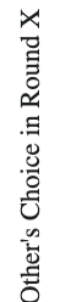 & 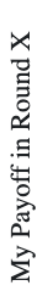 & 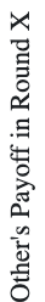 \\
\hline
\end{tabular}

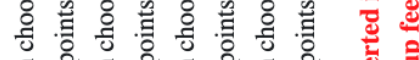

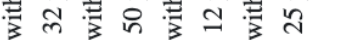

Web Appendix I, p. 3 

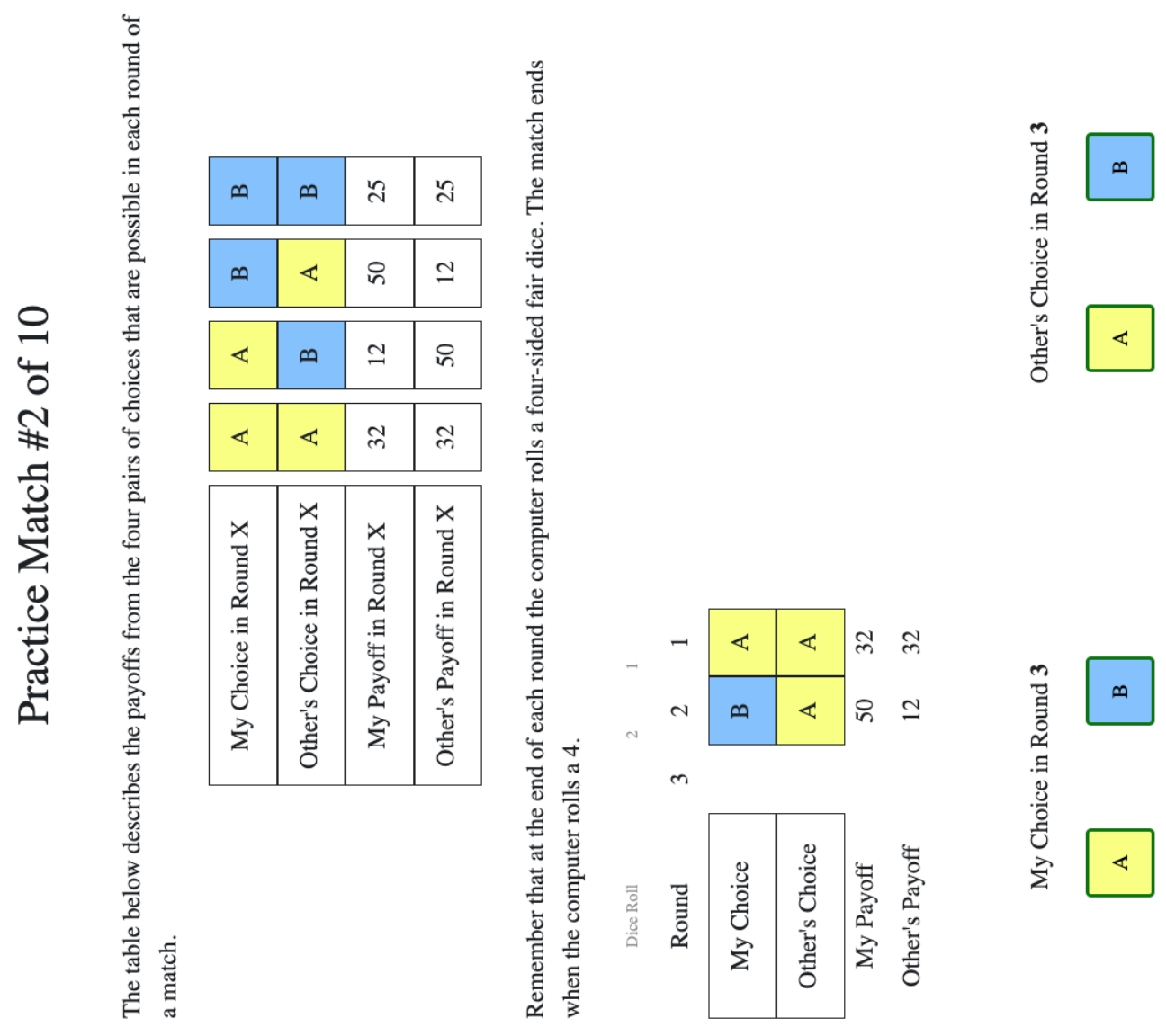

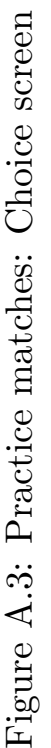

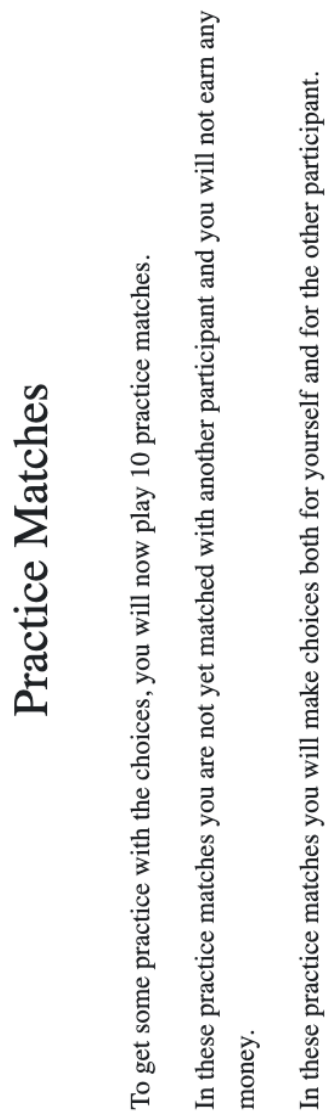

Web Appendix I, p. 4 

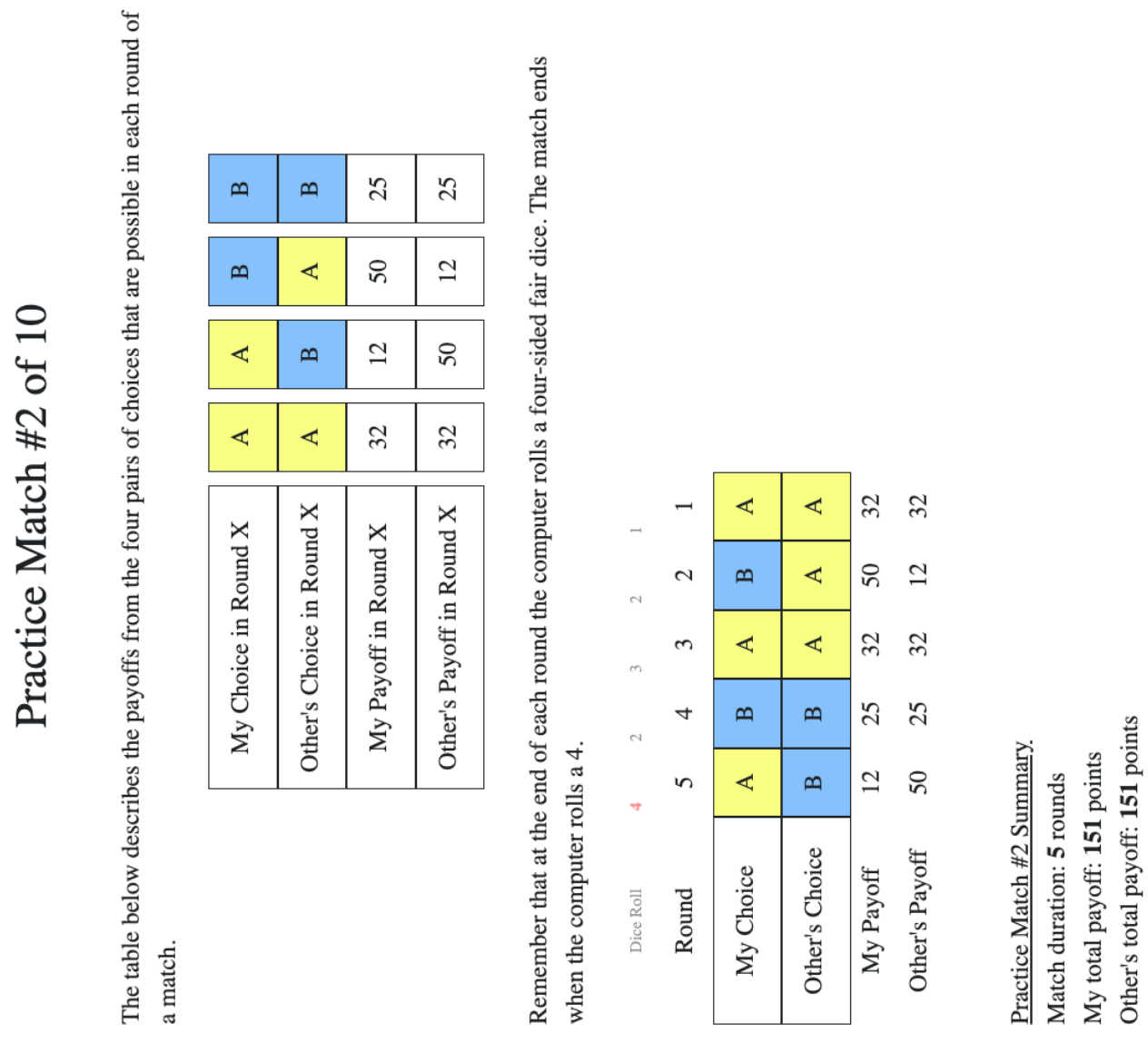

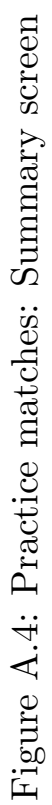

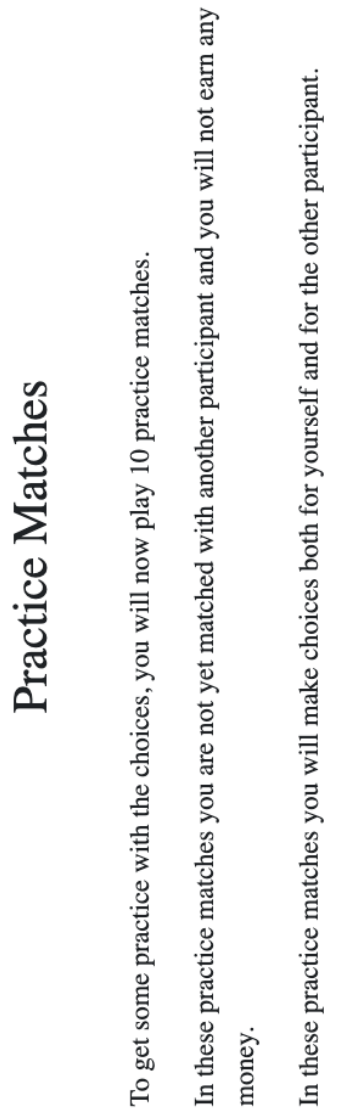

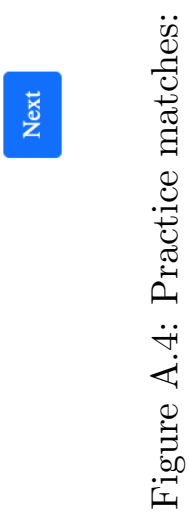

Web Appendix I, p. 5 


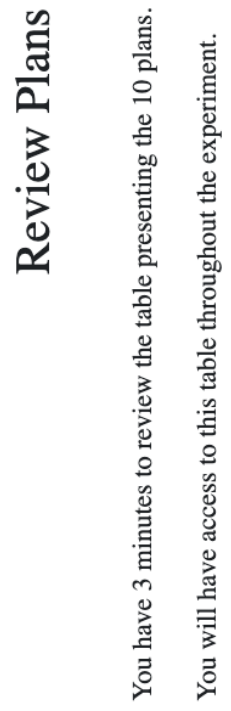

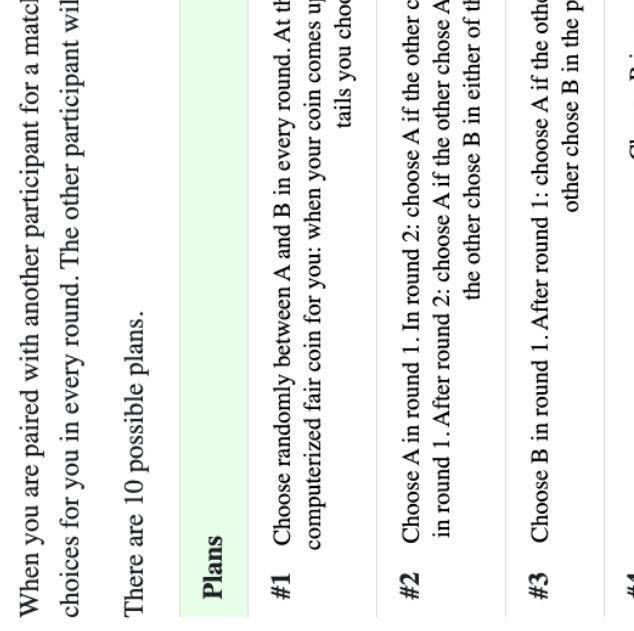




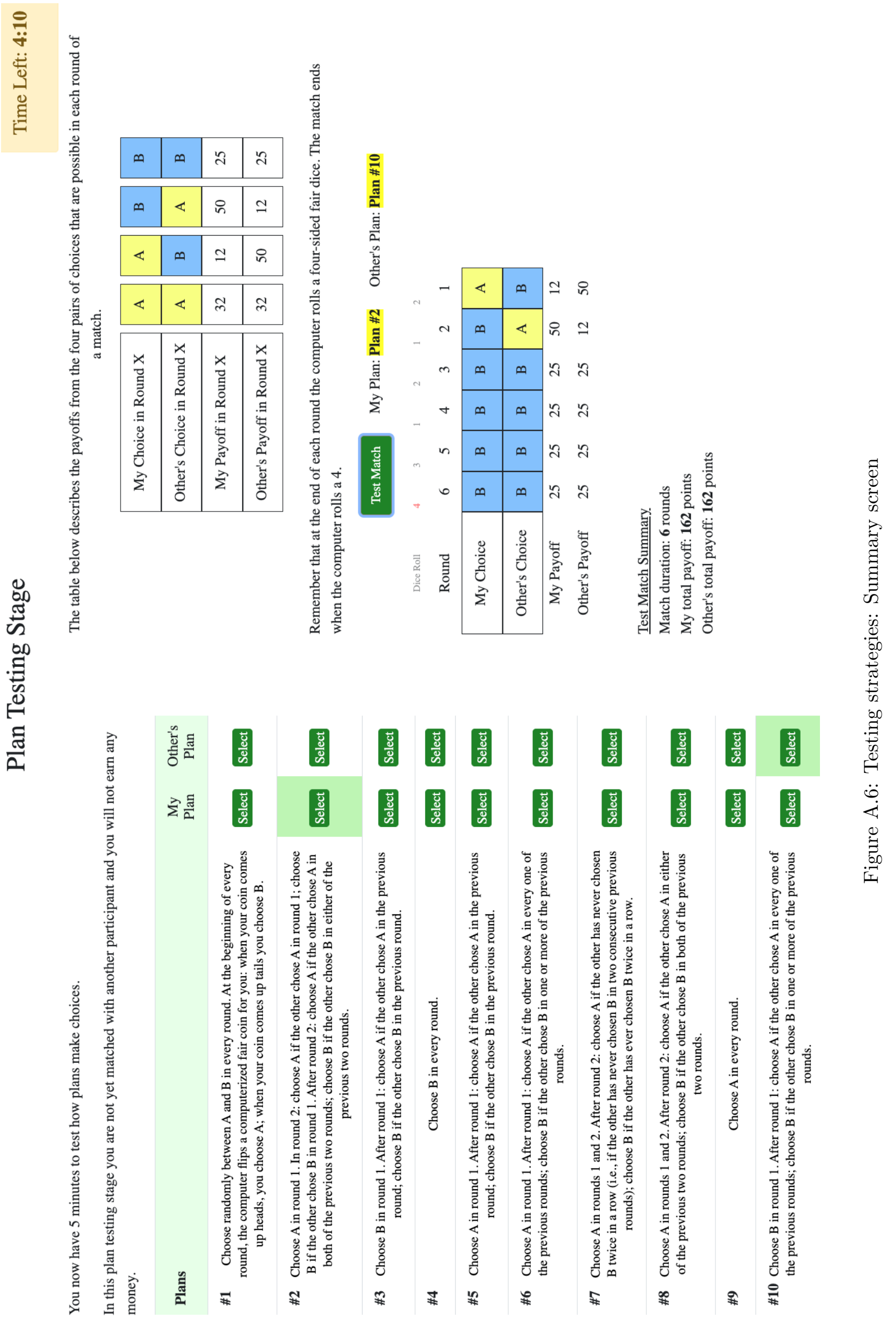

Web Appendix I, p. 7 


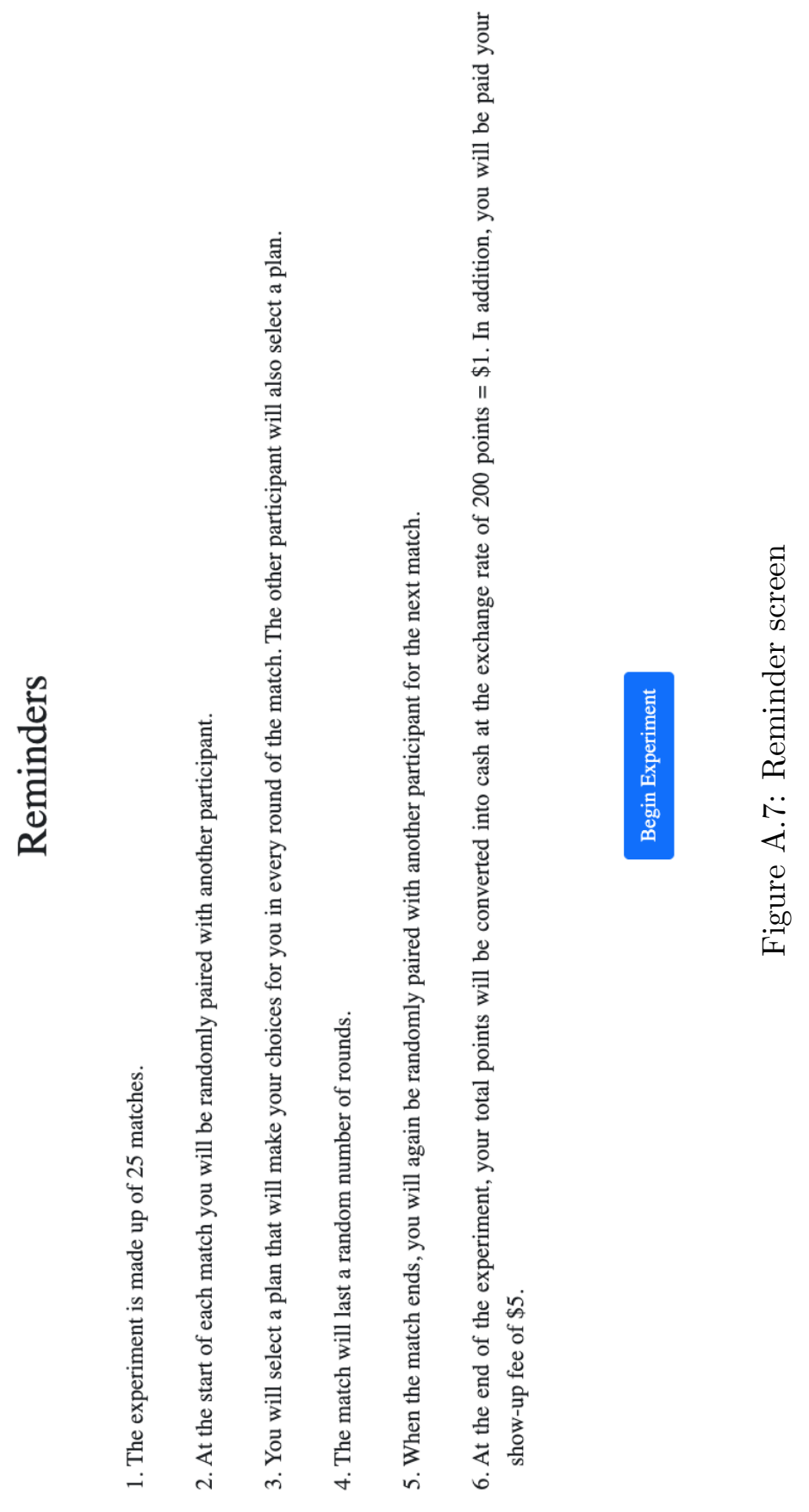

Web Appendix I, p. 8 


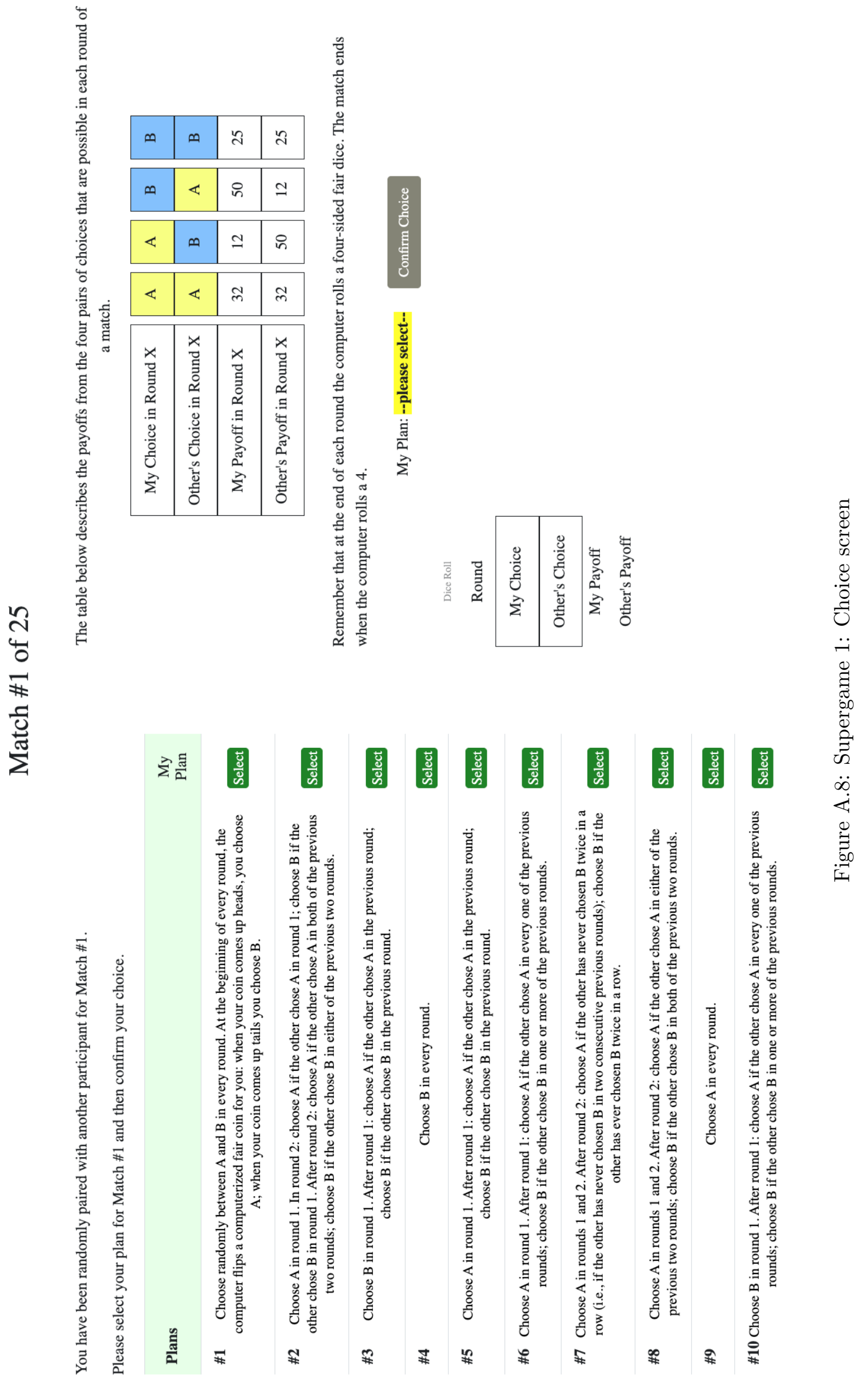

Web Appendix I, p. 9 


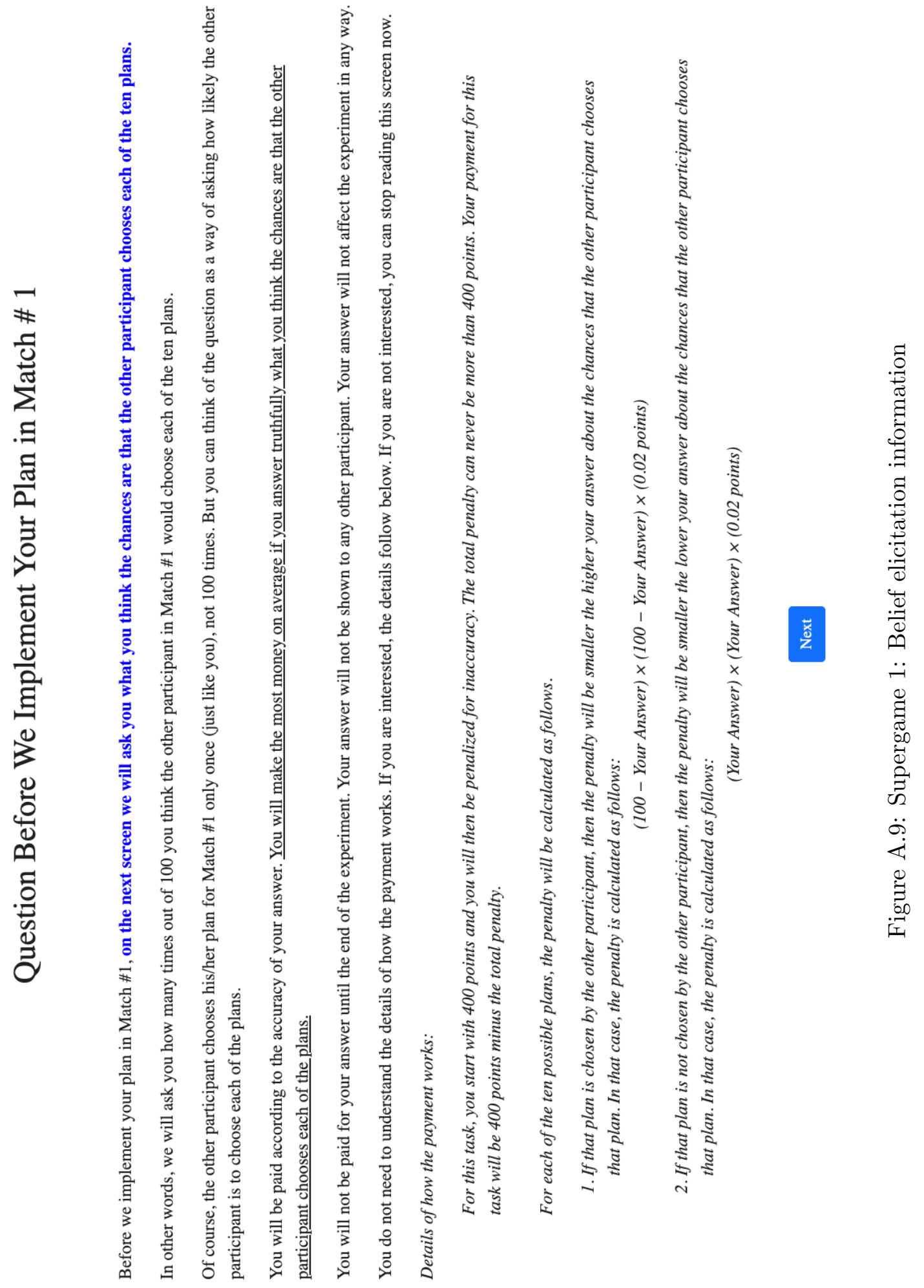

Web Appendix I, p. 10 


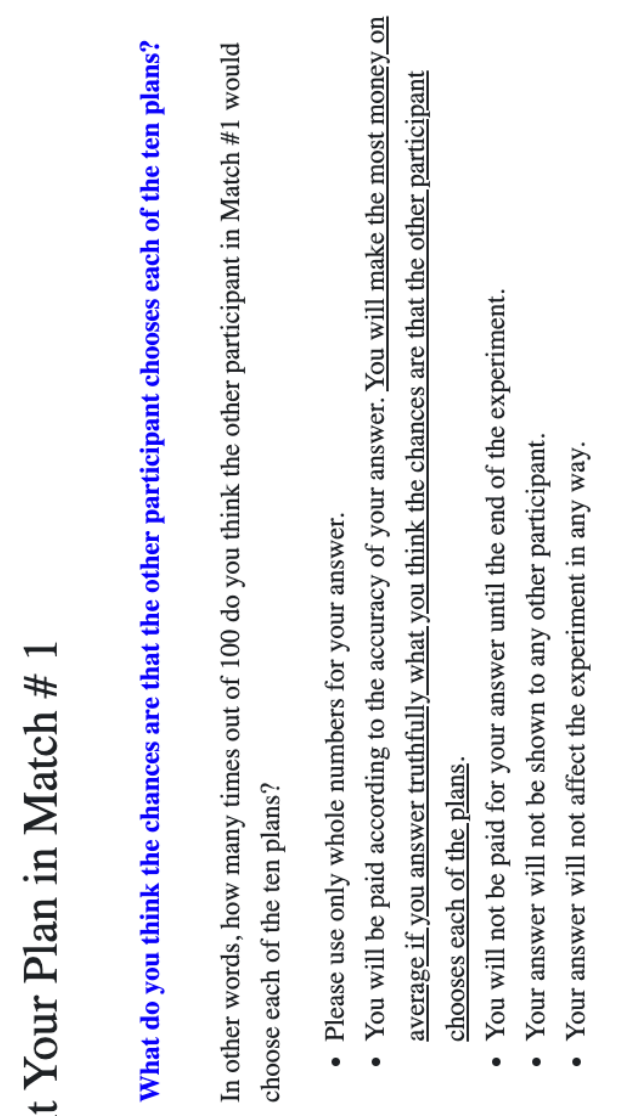

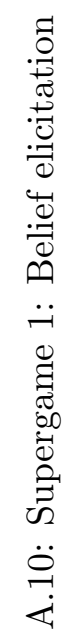

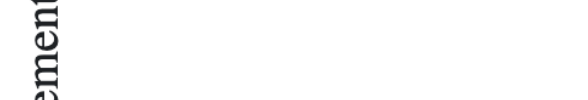

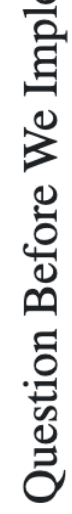

Web Appendix I, p. 11 


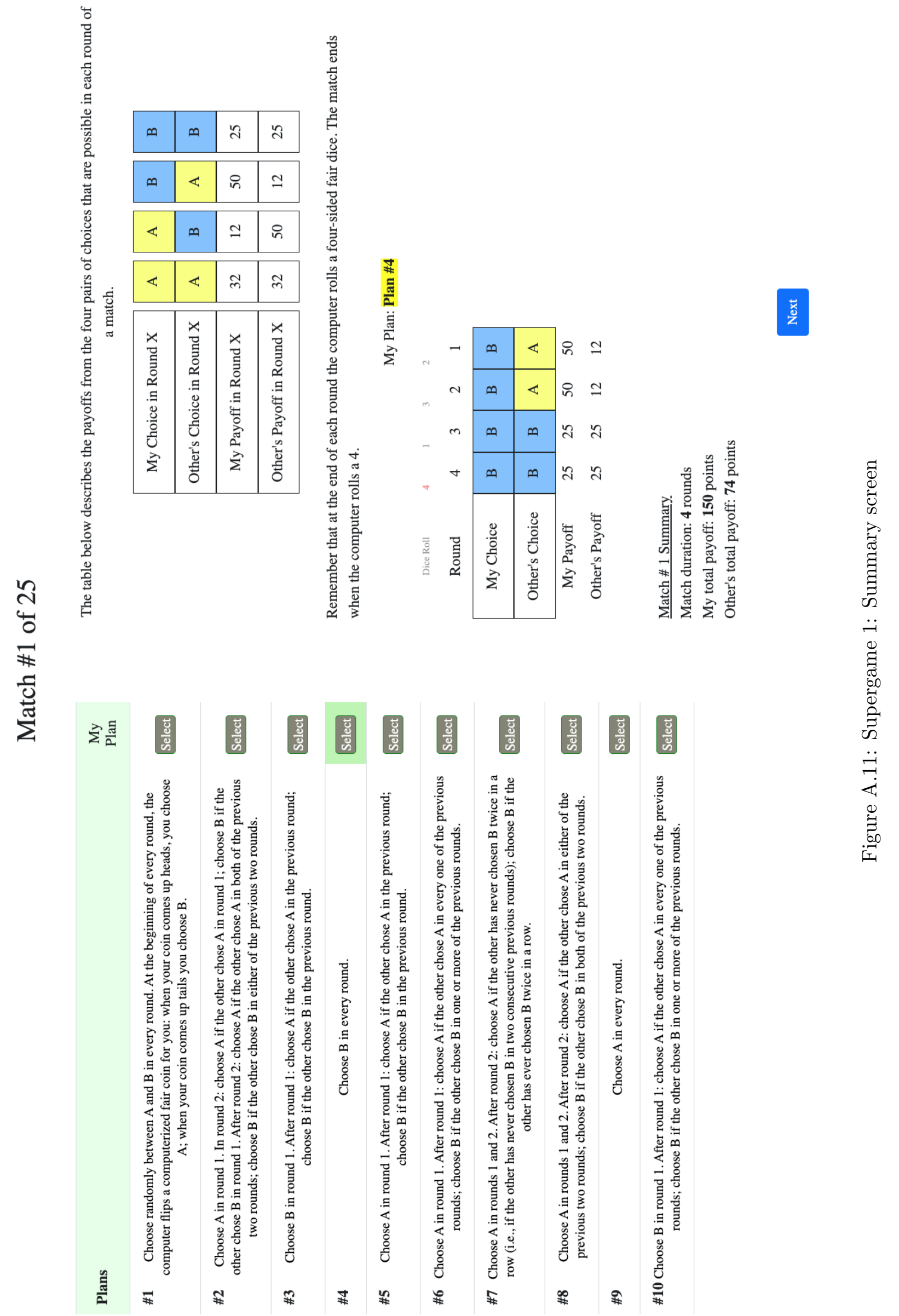

Web Appendix I, p. 12 


\section{Web Appendix II}

\section{Additional figures}

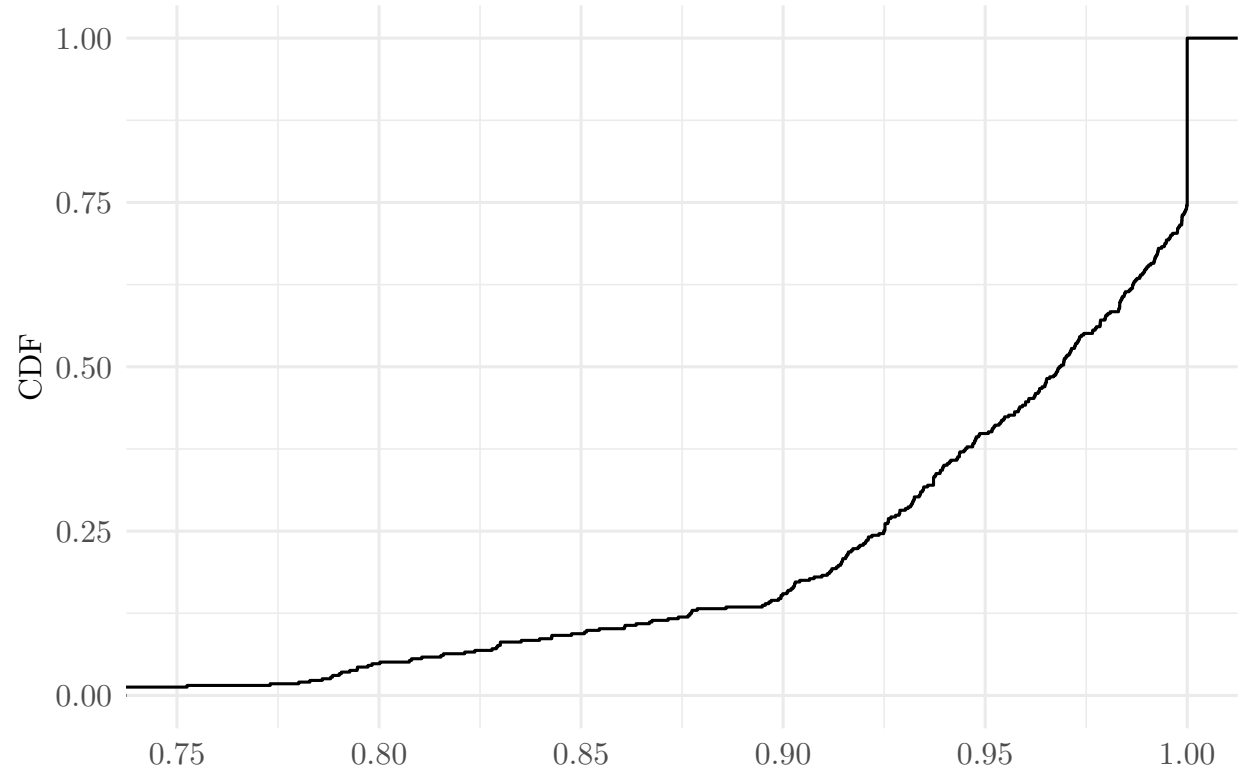

Figure A.12: CDF of payoffs relative to best responding to beliefs in Supergame 1

Notes: The figure shows the cumulative distribution function across subjects of the expected payoff of the subject's chosen strategy given her beliefs as a proportion of the expected payoff of the best response to her beliefs. 


\section{Web Appendix III}

\section{Additional tables}

$\begin{array}{cccccccccccc} & A D & D G & D T F T & R A N D & G & \text { 2TFT } & \text { TFT } & \text { G2 } & \text { TF2T } & \text { AC } \\ \text { AD } & 0.0000 & 0.0000 & 0.0000 & 0.0000 & 0.0000 & 0.0000 & 0.0000 & 0.0000 & 0.0000 & 0.0000 \\ D G & 0.0000 & 0.0000 & 0.0000 & 0.1500 & 0.1875 & 0.1875 & 0.1875 & 0.7500 & 0.7500 & 0.7500 \\ \text { DTFT } & 0.0000 & 0.0000 & 0.0000 & 0.3750 & 0.1875 & 0.1875 & 0.4286 & 0.7500 & 0.7500 & 0.7500 \\ \text { RAND } & 0.5000 & 0.5000 & 0.5000 & 0.5000 & 0.5000 & 0.5000 & 0.5000 & 0.5000 & 0.5000 & 0.5000 \\ \text { G } & 0.2500 & 0.2500 & 0.2500 & 0.4000 & 1.0000 & 1.0000 & 1.0000 & 1.0000 & 1.0000 & 1.0000 \\ \text { 2TFT } & 0.2500 & 0.2500 & 0.2500 & 0.4844 & 1.0000 & 1.0000 & 1.0000 & 1.0000 & 1.0000 & 1.0000 \\ \text { TFT } & 0.2500 & 0.3906 & 0.5714 & 0.6250 & 1.0000 & 1.0000 & 1.0000 & 1.0000 & 1.0000 & 1.0000 \\ \text { G2 } & 0.4375 & 1.0000 & 1.0000 & 0.7097 & 1.0000 & 1.0000 & 1.0000 & 1.0000 & 1.0000 & 1.0000 \\ \text { TF2T } & 0.4375 & 1.0000 & 1.0000 & 0.8594 & 1.0000 & 1.0000 & 1.0000 & 1.0000 & 1.0000 & 1.0000 \\ \text { AC } & 1.0000 & 1.0000 & 1.0000 & 1.0000 & 1.0000 & 1.0000 & 1.0000 & 1.0000 & 1.0000 & 1.0000\end{array}$

Table A.1: Cooperation rates

Notes: Each cell reports the cooperation rate of the strategy on the vertical axis when playing against the strategy on the horizontal axis. Cooperation rates measure the expected number of rounds of cooperation divided by the expected number of rounds, and are based on analytical calculations.

\begin{tabular}{ccccccccccc}
$\mathrm{R}$ & $A D$ & $D G$ & $D T F T$ & $R A N D$ & $G$ & $2 T F T$ & TFT & G2 & TF2T & AC \\
\hline 32 & 0.91 & 0.02 & 0.05 & 0.01 & 0.01 & 0.01 & 0.02 & 0.02 & 0.02 & 0.02 \\
40 & 0.23 & 0.08 & 0.04 & 0.00 & 0.05 & 0.01 & 0.01 & 0.67 & 0.15 & 0.05 \\
48 & 0.04 & 0.03 & 0.01 & 0.00 & 0.10 & 0.04 & 0.05 & 0.85 & 0.18 & 0.04 \\
\hline
\end{tabular}

Table A.2: Frequency each strategy is a best response in Supergame 1

Notes: This table replicates Table 2, but using best responding instead of good responding. 


\begin{tabular}{|c|c|c|c|c|c|c|c|c|c|c|c|}
\hline & $\mathrm{R}$ & $A D$ & $D G$ & DTFT & $R A N D$ & $G$ & $2 T F T$ & $T F T$ & $G^{2}$ & TF2T & $A C$ \\
\hline \multirow{3}{*}{$\begin{array}{l}\overline{4} \\
\ddot{n}\end{array}$} & 32 & 0.52 & 0.82 & 0.78 & 0.50 & 0.78 & 0.76 & 0.88 & 0.71 & 0.75 & 0.67 \\
\hline & 40 & 0.76 & 1.00 & 1.00 & 1.00 & 0.71 & 0.72 & 0.70 & 0.55 & 0.55 & 0.61 \\
\hline & 48 & 0.56 & 0.42 & 0.42 & 0.00 & 0.67 & 0.68 & 0.71 & 0.41 & 0.41 & 0.51 \\
\hline \multirow{2}{*}{ 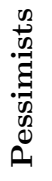 } & 32 & 0.80 & 0.88 & 0.86 & - & 0.62 & 0.62 & 0.86 & 0.50 & 0.50 & 0.33 \\
\hline & 40 & 0.84 & 1.00 & 1.00 & - & 0.62 & 0.64 & 0.57 & 0.34 & 0.34 & 0.12 \\
\hline$\ddot{ت}$ & 48 & 1.00 & 0.71 & 0.71 & - & 0.41 & 0.43 & 0.47 & 0.22 & 0.22 & 0.16 \\
\hline \multirow{2}{*}{ 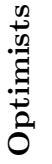 } & 32 & 0.26 & 0.71 & 0.67 & 0.50 & 0.90 & 0.89 & 0.89 & 0.88 & 0.88 & 1.00 \\
\hline & 40 & 0.50 & 1.00 & 1.00 & 1.00 & 0.77 & 0.76 & 0.76 & 0.68 & 0.68 & 0.69 \\
\hline$\ddot{\ddot{\Xi}}$ & 48 & 0.00 & 0.00 & 0.00 & 0.00 & 0.91 & 0.91 & 0.91 & 0.60 & 0.60 & 0.61 \\
\hline
\end{tabular}

Table A.3: Probability of good responding in Supergame 1 (conditional on each strategy being a good response)

Notes: For each strategy, the table shows the proportion of subjects who good respond to their beliefs, conditional on that strategy being in the set of good responses to the subject's beliefs. Good responding is defined in the second paragraph of Section 3.2.1. Panels II and III split subjects according to whether they are above or below the median level of optimism within-treatment, where optimism is defined in the notes to Figure 4 (subjects at the median are allocated to the above-median category).

$\begin{array}{ccccccccccc} & \text { AD } & D G & \text { DTFT } & \text { RAND } & G & \text { 2TFT } & \text { TFT } & \text { G2 } & \text { TF2T } & \text { AC } \\ \text { AD } & 100.00 & 100.00 & 100.00 & 150.00 & 125.00 & 125.00 & 125.00 & 143.75 & 143.75 & 200.00 \\ \text { DG } & 100.00 & 100.00 & 100.00 & 140.70 & 115.25 & 115.25 & 129.31 & 146.00 & 146.00 & 146.00 \\ \text { DTFT } & 100.00 & 100.00 & 100.00 & 126.75 & 115.25 & 115.25 & 134.86 & 146.00 & 146.00 & 146.00 \\ \text { RAND } & 74.00 & 87.50 & 107.75 & 119.00 & 110.00 & 117.59 & 130.25 & 137.87 & 151.34 & 164.00 \\ \text { G } & 87.00 & 105.75 & 105.75 & 125.20 & 128.00 & 128.00 & 128.00 & 128.00 & 128.00 & 128.00 \\ \text { 2TFT } & 87.00 & 105.75 & 105.75 & 119.97 & 128.00 & 128.00 & 128.00 & 128.00 & 128.00 & 128.00 \\ \text { TFT } & 87.00 & 98.44 & 113.14 & 111.25 & 128.00 & 128.00 & 128.00 & 128.00 & 128.00 & 128.00 \\ \text { G2 } & 77.25 & 108.00 & 108.00 & 106.00 & 128.00 & 128.00 & 128.00 & 128.00 & 128.00 & 128.00 \\ \text { TF2T } & 77.25 & 108.00 & 108.00 & 96.72 & 128.00 & 128.00 & 128.00 & 128.00 & 128.00 & 128.00 \\ \text { AC } & 48.00 & 108.00 & 108.00 & 88.00 & 128.00 & 128.00 & 128.00 & 128.00 & 128.00 & 128.00\end{array}$

Table A.4: Payoffs when $R=32$

Notes: Each cell reports the expected payoff in points of the strategy on the vertical axis when playing against the strategy on the horizontal axis. Expected payoffs are based on analytical calculations. 


$\begin{array}{ccccccccccc} & A D & D G & \text { DTFT } & \text { RAND } & G & \text { 2TFT } & \text { TFT } & \text { G2 } & \text { TF2T } & \text { AC } \\ \text { AD } & 100.00 & 100.00 & 100.00 & 150.00 & 125.00 & 125.00 & 125.00 & 143.75 & 143.75 & 200.00 \\ \text { DG } & 100.00 & 100.00 & 100.00 & 143.10 & 115.25 & 115.25 & 129.31 & 170.00 & 170.00 & 170.00 \\ \text { DTFT } & 100.00 & 100.00 & 100.00 & 132.75 & 115.25 & 115.25 & 134.86 & 170.00 & 170.00 & 170.00 \\ \text { RAND } & 74.00 & 89.90 & 113.75 & 127.00 & 116.40 & 125.34 & 140.25 & 149.23 & 165.09 & 180.00 \\ \text { G } & 87.00 & 105.75 & 105.75 & 131.60 & 160.00 & 160.00 & 160.00 & 160.00 & 160.00 & 160.00 \\ \text { 2TFT } & 87.00 & 105.75 & 105.75 & 127.72 & 160.00 & 160.00 & 160.00 & 160.00 & 160.00 & 160.00 \\ \text { TFT } & 87.00 & 98.44 & 113.14 & 121.25 & 160.00 & 160.00 & 160.00 & 160.00 & 160.00 & 160.00 \\ \text { G2 } & 77.25 & 132.00 & 132.00 & 117.35 & 160.00 & 160.00 & 160.00 & 160.00 & 160.00 & 160.00 \\ \text { TF2T } & 77.25 & 132.00 & 132.00 & 110.47 & 160.00 & 160.00 & 160.00 & 160.00 & 160.00 & 160.00 \\ \text { AC } & 48.00 & 132.00 & 132.00 & 104.00 & 160.00 & 160.00 & 160.00 & 160.00 & 160.00 & 160.00\end{array}$

Table A.5: Payoffs when $R=40$

Notes: Each cell reports the expected payoff in points of the strategy on the vertical axis when playing against the strategy on the horizontal axis. Expected payoffs are based on analytical calculations.

$\begin{array}{cccccccccccc} & A D & D G & D T F T & R A N D & G & 2 T F T & \text { TFT } & \text { G2 } & \text { TF2T } & A C \\ \text { AD } & 100.00 & 100.00 & 100.00 & 150.00 & 125.00 & 125.00 & 125.00 & 143.75 & 143.75 & 200.00 \\ \text { DG } & 100.00 & 100.00 & 100.00 & 145.50 & 115.25 & 115.25 & 129.31 & 194.00 & 194.00 & 194.00 \\ \text { DTFT } & 100.00 & 100.00 & 100.00 & 138.75 & 115.25 & 115.25 & 134.86 & 194.00 & 194.00 & 194.00 \\ \text { RAND } & 74.00 & 92.30 & 119.75 & 135.00 & 122.80 & 133.09 & 150.25 & 160.58 & 178.84 & 196.00 \\ \text { G } & 87.00 & 105.75 & 105.75 & 138.00 & 192.00 & 192.00 & 192.00 & 192.00 & 192.00 & 192.00 \\ \text { 2TFT } & 87.00 & 105.75 & 105.75 & 135.47 & 192.00 & 192.00 & 192.00 & 192.00 & 192.00 & 192.00 \\ \text { TFT } & 87.00 & 98.44 & 113.14 & 131.25 & 192.00 & 192.00 & 192.00 & 192.00 & 192.00 & 192.00 \\ \text { G2 } & 77.25 & 156.00 & 156.00 & 128.71 & 192.00 & 192.00 & 192.00 & 192.00 & 192.00 & 192.00 \\ \text { TF2T } & 77.25 & 156.00 & 156.00 & 124.22 & 192.00 & 192.00 & 192.00 & 192.00 & 192.00 & 192.00 \\ \text { AC } & 48.00 & 156.00 & 156.00 & 120.00 & 192.00 & 192.00 & 192.00 & 192.00 & 192.00 & 192.00\end{array}$

Table A.6: Payoffs when $R=48$

Notes: Each cell reports the expected payoff in points of the strategy on the vertical axis when playing against the strategy on the horizontal axis. Expected payoffs are based on analytical calculations. 
(1)

$(2)$

\begin{tabular}{lcc}
\hline R40 & $12.79^{* * *}$ & $12.58^{* * *}$ \\
& $(0.49)$ & $(0.52)$ \\
R48 & $48.05^{* * *}$ & $46.99^{* * *}$ \\
& $(0.84)$ & $(0.94)$ \\
Accuracy of beliefs & & $10.01^{* * *}$ \\
Proximity to best response & $88.41)$ \\
& $(7.20)$ & $\begin{array}{c}87.14^{* * * *} \\
(7.43)\end{array}$ \\
\hline Mean of dependent variable & 128.15 & 128.15 \\
$\mathrm{~N}$ & 390 & 390 \\
\hline \hline
\end{tabular}

Table A.7: Expected earnings in Supergame 1 (robustness)

Notes: The regressions reported here are the same as those reported in Columns 2 and 3 of Table 4 except that we replace 'Good responder to beliefs' with 'Proximity to best response', which measures the expected payoff of a subject's chosen strategy given her beliefs as a proportion of the expected payoff of the best response to her beliefs. To help interpret the effect size, note that our measure of proximity to the best response is defined from 0 to 1. Figure A.12 in Web Appendix II shows the cumulative distribution function of proximity.

\begin{tabular}{|c|c|c|c|c|c|}
\hline & $(1)$ & $(2)$ & $(3)$ & $(4)$ & $(5)$ \\
\hline $\mathrm{R} 40$ & $\begin{array}{c}0.148^{* * *} \\
(0.056)\end{array}$ & $\begin{array}{c}0.135^{* * *} \\
(0.051)\end{array}$ & $\begin{array}{c}0.064 \\
(0.046)\end{array}$ & $\begin{array}{c}0.077 \\
(0.053)\end{array}$ & $\begin{array}{c}0.035 \\
(0.042)\end{array}$ \\
\hline R48 & $\begin{array}{c}0.300 * * * \\
(0.042)\end{array}$ & $\begin{array}{c}0.275^{* * *} \\
(0.038)\end{array}$ & $\begin{array}{c}0.154^{* * *} \\
(0.043)\end{array}$ & $\begin{array}{c}0.199^{* * *} \\
(0.045)\end{array}$ & $\begin{array}{c}0.111^{* * *} \\
(0.038)\end{array}$ \\
\hline Length of Supergame $t-1$ & $\begin{array}{c}0.007^{* * *} \\
(0.001)\end{array}$ & & & & $\begin{array}{c}0.006^{* * *} \\
(0.001)\end{array}$ \\
\hline $\begin{array}{l}\text { Other's Round } 1 \text { coop } \\
\quad \text { in Supergame } t-1\end{array}$ & & $\begin{array}{c}0.087^{* * *} \\
(0.019)\end{array}$ & & & $\begin{array}{c}0.079 * * * \\
(0.016)\end{array}$ \\
\hline $\begin{array}{l}\text { Own Round } 1 \text { coop } \\
\text { in Supergame } 1\end{array}$ & & & $\begin{array}{c}0.385^{* * *} \\
(0.036)\end{array}$ & & $\begin{array}{c}0.286^{* * *} \\
(0.034)\end{array}$ \\
\hline $\begin{array}{l}\text { Own optimism } \\
\text { in Supergame } 1\end{array}$ & & & & $\begin{array}{c}0.691^{* * *} \\
(0.073)\end{array}$ & $\begin{array}{c}0.353^{* * *} \\
(0.064)\end{array}$ \\
\hline Mean of dependent variable & 0.464 & 0.464 & 0.464 & 0.464 & 0.464 \\
\hline $\mathrm{N}$ & 9360 & 9360 & 9360 & 9360 & 9360 \\
\hline
\end{tabular}

Table A.8: Round 1 cooperation in Supergame $t$ (robustness)

Notes: This table replicates Table 5, except that we use Probit regressions instead of linear OLS regressions. The table reports average marginal effects and heteroskedasticity-robust standard errors with clustering at the session level. 
I: Strategy cooperation in Supergame $t$

\begin{tabular}{|c|c|c|c|c|c|}
\hline & $(1)$ & $(2)$ & $(3)$ & $(4)$ & $(5)$ \\
\hline $\mathrm{R} 40$ & $\begin{array}{c}0.103^{* *} \\
(0.041)\end{array}$ & $\begin{array}{c}0.094^{* *} \\
(0.038)\end{array}$ & $\begin{array}{l}0.059^{*} \\
(0.032)\end{array}$ & $\begin{array}{c}0.049 \\
(0.037)\end{array}$ & $\begin{array}{c}0.037 \\
(0.029)\end{array}$ \\
\hline $\mathrm{R} 48$ & $\begin{array}{c}0.209^{* * *} \\
(0.033)\end{array}$ & $\begin{array}{c}0.191^{* * *} \\
(0.030)\end{array}$ & $\begin{array}{c}0.090^{* * *} \\
(0.029)\end{array}$ & $\begin{array}{c}0.128^{* * *} \\
(0.029)\end{array}$ & $\begin{array}{c}0.065^{* *} \\
(0.025)\end{array}$ \\
\hline Length of Supergame $t-1$ & $\begin{array}{c}0.004^{* * *} \\
(0.001)\end{array}$ & & & & $\begin{array}{c}0.004^{* * *} \\
(0.001)\end{array}$ \\
\hline $\begin{array}{l}\text { Other's inferred coop } \\
\quad \text { in Supergame } t-1\end{array}$ & & $\begin{array}{c}0.095^{* * *} \\
(0.021)\end{array}$ & & & $\begin{array}{c}0.088^{* * *} \\
(0.017)\end{array}$ \\
\hline $\begin{array}{l}\text { Own strategy coop } \\
\text { in Supergame } 1\end{array}$ & & & $\begin{array}{c}0.422^{* * *} \\
(0.034)\end{array}$ & & $\begin{array}{c}0.333^{* * *} \\
(0.036)\end{array}$ \\
\hline $\begin{array}{l}\text { Own optimism } \\
\text { in Supergame } 1\end{array}$ & & & & $\begin{array}{c}0.556^{* * *} \\
(0.048)\end{array}$ & $\begin{array}{c}0.232^{* * *} \\
\quad(0.039)\end{array}$ \\
\hline Mean of dependent variable & 0.467 & 0.467 & 0.467 & 0.467 & 0.467 \\
\hline $\mathrm{N}$ & 9360 & 9360 & 9360 & 9360 & 9360 \\
\hline
\end{tabular}

II: Optimism in Supergame 25

\begin{tabular}{|c|c|c|c|c|c|}
\hline & $(1)$ & $(2)$ & $(3)$ & $(4)$ & $(5)$ \\
\hline $\mathrm{R} 40$ & $\begin{array}{c}0.110^{* *} \\
(0.045)\end{array}$ & $\begin{array}{c}0.011 \\
(0.023)\end{array}$ & $\begin{array}{l}0.086^{*} \\
(0.042)\end{array}$ & $\begin{array}{c}0.062 \\
(0.043)\end{array}$ & $\begin{array}{l}-0.028 \\
(0.023)\end{array}$ \\
\hline $\mathrm{R} 48$ & $\begin{array}{c}0.244^{* * *} \\
(0.043)\end{array}$ & $\begin{array}{c}0.049 \\
(0.033)\end{array}$ & $\begin{array}{c}0.178^{* * *} \\
(0.045)\end{array}$ & $\begin{array}{c}0.171^{* * *} \\
(0.041)\end{array}$ & $\begin{array}{l}-0.014 \\
(0.033)\end{array}$ \\
\hline Length of Supergames 1 to 24 & $\begin{array}{c}0.040 \\
(0.024)\end{array}$ & & & & $\begin{array}{c}0.024^{* *} \\
(0.012)\end{array}$ \\
\hline $\begin{array}{l}\text { Others' inferred coop } \\
\quad \text { in Supergames } 1 \text { to } 24\end{array}$ & & $\begin{array}{c}1.027^{* * *} \\
(0.122)\end{array}$ & & & $\begin{array}{c}0.947^{* * *} \\
(0.110)\end{array}$ \\
\hline $\begin{array}{l}\text { Own strategy coop } \\
\text { in Supergame } 1\end{array}$ & & & $\begin{array}{c}0.232^{* * *} \\
(0.036)\end{array}$ & & $\begin{array}{l}0.061^{*} \\
(0.033)\end{array}$ \\
\hline $\begin{array}{l}\text { Own optimism } \\
\text { in Supergame } 1\end{array}$ & & & & $\begin{array}{c}0.493^{* * *} \\
(0.042)\end{array}$ & $\begin{array}{c}0.419^{* * *} \\
(0.042)\end{array}$ \\
\hline Mean of dependent variable & 0.430 & 0.430 & 0.430 & 0.430 & 0.430 \\
\hline $\mathrm{N}$ & 390 & 390 & 390 & 390 & 390 \\
\hline
\end{tabular}

Table A.9: Effect of experience on behavior and beliefs (robustness)

Notes: The regressions reported in Panel I are the same as those reported in Panel I of Table 6, except that we replace 'Other's strategy coop in Supergame $t-1$ ' with 'Other's inferred coop in Supergame $t-1$ '. The regressions reported in Panel II are the same as those reported in Panel II of Table 6, except that we replace 'Others' strategy coop in Supergames 1 to 24' with 'Others' inferred coop in Supergames 1 to 24'. 'Other's inferred coop in Supergame $t$ ' measures the weighted average of the strategy cooperation of each of the ten strategies, where the weights come from the posterior distribution over the opponent's strategies after Bayesian updating from the realized sequence of play in Supergame $t$; the Bayesian update for Supergame $t$ uses the uniform distribution as the prior, and so the Bayesian update for Supergame $t$ does not use information from sequences of play in prior supergames. See the notes to Table 6 for the definition of strategy cooperation. 'Others' inferred coop in Supergames 1 to 24 ' is the mean of 'Other's inferred coop in Supergame $t$ ' over the first 24 supergames. 


\begin{tabular}{|c|c|c|c|}
\hline & $\begin{array}{c}(1) \\
\text { Strategy cooperation } \\
\text { (Supergames 2-25) }\end{array}$ & $\begin{array}{c}(2) \\
\text { Strategy cooperation } \\
\text { (Supergames 21-25) }\end{array}$ & $\begin{array}{c}(3) \\
\text { Optimism } \\
\text { (Supergame 25) }\end{array}$ \\
\hline Anxiety & $\begin{array}{l}-0.004 \\
(0.009)\end{array}$ & $\begin{array}{c}-0.023^{*} \\
(0.013)\end{array}$ & $\begin{array}{l}-0.005 \\
(0.012)\end{array}$ \\
\hline Cautiousness & $\begin{array}{l}-0.009 \\
(0.011)\end{array}$ & $\begin{array}{l}-0.011 \\
(0.011)\end{array}$ & $\begin{array}{l}-0.003 \\
(0.015)\end{array}$ \\
\hline Kindness & $\begin{array}{l}-0.004 \\
(0.014)\end{array}$ & $\begin{array}{l}-0.010 \\
(0.017)\end{array}$ & $\begin{array}{c}0.009 \\
(0.009)\end{array}$ \\
\hline Manipulativeness & $\begin{array}{l}-0.009 \\
(0.013)\end{array}$ & $\begin{array}{l}-0.005 \\
(0.015)\end{array}$ & $\begin{array}{l}-0.013 \\
(0.013)\end{array}$ \\
\hline Trust & $\begin{array}{l}0.021^{*} \\
(0.010)\end{array}$ & $\begin{array}{c}0.022^{* *} \\
(0.008)\end{array}$ & $\begin{array}{c}0.024^{* *} \\
(0.010)\end{array}$ \\
\hline Mean of dependent variable & 0.467 & 0.461 & 0.430 \\
\hline $\mathrm{N}$ & 9360 & 1950 & 390 \\
\hline Control for beliefs in Sup. 1 & No & No & No \\
\hline Control for behavior in Sup. 1 & No & No & No \\
\hline Controls for experience & No & No & No \\
\hline
\end{tabular}

Table A.10: Effect of personality on behavior and beliefs (robustness)

Notes: The regressions reported here are the same as those reported in Table 9, except that they exclude the controls for experience and for Supergame 1 behavior and beliefs presented in rows three to six of Panel I of Table 6 (in relation to Columns 1 and 2 here) and of Panel II of Table 6 (in relation to Column 3 here); Columns 1 and 2 also exclude the supergame number control (not relevant to Column 3). 


\begin{tabular}{lccc}
\hline \hline & $\begin{array}{c}(1) \\
\text { Strategy cooperation } \\
\text { (Supergame 1) }\end{array}$ & $\begin{array}{c}(2) \\
\text { Strategy cooperation } \\
\text { (Supergame 1) }\end{array}$ & $\begin{array}{c}(3) \\
\text { Optimism } \\
\text { (Supergame 1) }\end{array}$ \\
\hline Anxiety & 0.009 & 0.017 & -0.008 \\
Cautiousness & $(0.019)$ & $(0.016)$ & $(0.011)$ \\
Kindness & -0.002 & 0.000 & -0.002 \\
Manipulativeness & $(0.017)$ & $(0.013)$ & $-0.012)$ \\
Trust & -0.022 & -0.006 & $(0.011)$ \\
& $(0.017)$ & $(0.014)$ & $-0.020^{*}$ \\
Mean of dependent variable & -0.027 & -0.008 & $0.012)$ \\
N & $(0.019)$ & -0.010 & $(0.012)$ \\
Control for beliefs in Sup. 1 & -0.005 & $(0.013)$ & 0.536 \\
Control for behavior in Sup. 1 & $-0.018)$ & 0.478 & 390 \\
Controls for experience & - & 390 & - \\
\hline \hline
\end{tabular}

Table A.11: Effect of personality on behavior and beliefs in Supergame 1

Column 1 (Column 3) reports a linear OLS regression of strategy cooperation (optimism) in Supergame 1 on the five personality factors, controlling for demographic characteristics and standardized cognitive ability (see Section 2.9), and the treatment. The regression reported in Column 2 is the same as the one reported in Column 1, except that it further includes optimism in Supergame 1 as a control. 'Strategy cooperation' is defined in the notes to Table 6 and 'optimism' is defined in the notes to Figure 4. $N=390$ because four subjects did not complete the demographic questionnaire. Heteroskedasticity-robust standard errors are shown in parentheses. ***, ** and * denote significance at the 1 percent, 5 percent and 10 percent levels (two-sided tests). 


\begin{tabular}{lccc}
\hline \hline & $(1)$ & $(2)$ & $(3)$ \\
\hline R40 & 0.039 & 0.039 & 0.039 \\
R48 & $(0.029)$ & $(0.030)$ & $(0.029)$ \\
& $0.068^{* *}$ & $0.060^{* *}$ & $0.060^{* *}$ \\
Length of Supergame $t-1$ & $(0.026)$ & $(0.025)$ & $(0.025)$ \\
& $0.004^{* * *}$ & $0.004^{* * *}$ & $0.004^{* * *}$ \\
Own strategy coop & $(0.001)$ & $(0.001)$ & $(0.001)$ \\
$\quad$ in Supergame 1 & $0.334^{* * *}$ & $0.334^{* * *}$ & $0.334^{* * *}$ \\
Own optimism & $(0.036)$ & $(0.036)$ & $(0.036)$ \\
$\quad$ in Supergame 1 & $0.232^{* * *}$ & $0.231^{* * *}$ & $0.231^{* * *}$ \\
Other's strategy coop & $(0.039)$ & $(0.039)$ & $(0.039)$ \\
$\quad$ in Supergame $t-1$ & $0.066^{* * *}$ & $0.085^{* * *}$ & $0.082^{* * *}$ \\
('Other's strategy coop & $(0.014)$ & $(0.023)$ & $(0.024)$ \\
$\quad$ in Sup. $t-1$ ' $\left.-x_{R}\right)_{+}$ & & -0.037 & -0.035 \\
Trust $\times$ Other's strategy & & $(0.039)$ & $(0.040)$ \\
$\quad$ coop in Supergame $t-1$ & & & $-0.054^{* *}$ \\
Trust $\times$ ('Other's strategy & & & $(0.020)$ \\
$\quad$ coop in Sup. $t-1$ ' $\left.-x_{R}\right)_{+}+$ & & & $0.079^{* *}$ \\
& & & $(0.037)$ \\
\hline Mean of dependent variable & 0.467 & 0.467 & 0.467 \\
$\mathrm{~N} \quad$ & 9360 & 9360 & 9360 \\
\hline \hline
\end{tabular}

Table A.12: Strategy cooperation in Supergame $t$

Notes: The regression reported in Column 1 is exactly the same as the one reported in Column 5 of Panel I of Table 6. The notes to Figure 10 describe how we run a piece-wise linear spline regression by further including $\max \left\{0\right.$, ('Other's strategy coop in Supergame $t-1$ ' $\left.\left.-x_{R}\right)\right\}$, which for conciseness we label here as ('Other's strategy coop in Sup. $t-1$ ' $\left.-x_{R}\right)_{+}$. Column 2 reports coefficients from this spline regression without interactions with trust, while Column 3 reports coefficients with interactions with trust. All regressions control for the five personality factors (including trust), demographic characteristics and standardized cognitive ability (see Section 2.9), and the supergame number, with $R=32$ as the omitted category. $N$ is in multiples of 390 because four subjects did not complete the demographic questionnaire. Heteroskedasticity-robust standard errors with clustering at the session level are shown in parentheses. $* * *, * *$ and $*$ denote significance at the 1 percent, 5 percent and 10 percent levels (two-sided tests). 